\title{
Learning together in mixed-ability elementary classrooms
}

$\infty$

Alieke Mattia van Dijk 


\section{Graduation committee}

Chairman/secretary:

Supervisor:

Co-Supervisor:

Members: prof. dr. T.A.J. Toonen

prof. dr. A.J.M. de Jong

dr. T.H.S. Eysink

prof. dr. C.A.M. van Boxtel

prof. dr. A.W. Lazonder

prof. dr. S.E. McKenney

prof. dr. J.H. Walma van der Molen

dr. P.H.M. Sins

\section{UNIVERSITEIT TWENTE. $\quad \underline{\text { CTIT }}$ ico}

The research and writing of this dissertation was funded by the Dutch Ministry of Education, Culture, and Science in the context of the BE COOL! project (Grant Agreement no. ODB10004) under the OnderwijsBewijs Programme.

ISBN: 978-90-365-4445-0

DOI: $10.3990 / 1.9789036544450$

Printed by Gildeprint

Cover art by Renée van den Kerkhof (Studio Neetje)

(C) 2017, Alieke van Dijk, Enschede, the Netherlands 


\section{LEARNING TOGETHER \\ IN MIXED-ABILITY ELEMENTARY CLASSROOMS}

\section{PROEFSCHRIFT}

ter verkrijging van

de graad van doctor aan de Universiteit Twente,

op gezag van de rector magnificus,

prof. dr. T.T.M. Palstra

volgens besluit van het College voor Promoties

in het openbaar te verdedigen

op vrijdag 22 december 2017 om 14:45 uur

door

Alieke Mattia van Dijk

geboren op 2 juni 1987

te Amersfoort 
Dit proefschrift is goedgekeurd door de promotor: prof. dr. A.J.M. de Jong

en assistent-promotor:

dr. T.H.S. Eysink 


\section{Voor-en dankwoord}

Aan sommige dingen kun je nooit genoeg aandacht besteden. Je kunt niet vaak genoeg opkomen voor jouw idealen. Je kunt niet vaak genoeg juichen om een doelpunt van jouw club. Je kunt niet hard genoeg zingen voor diezelfde club. Je kunt niet genoeg boeken lezen. Non ho potuto investire abbastanza tempo per imparare una nuova lingua. Je kunt niet vaak genoeg dansen door de huiskamer. Je kunt niet vaak genoeg de kleine overwinningen vieren. Je kunt niet genoeg koekjes bakken. Je kunt niet vaak genoeg samenwerken met klasgenoten, collega's en anderen die op je pad komen. En, je kunt nooit genoeg woorden besteden aan de mensen in je omgeving die jou ondersteunen, motiveren en blijdschap brengen.

Dit is mijn kans om aandacht te besteden aan hen die zoveel voor me betekenen of betekend hebben. En de mensen die me goed kennen, weten dat ik dit dan ook vol overgave zal doen. In de rest van dit proefschrift heb ik erg mijn best gedaan om niet te lang van stof te zijn. In dit dankwoord ga ik deze neiging niet langer onderdrukken.

Tijdens de jaren die ik heb mogen besteden aan het schrijven van dit proefschrift, heb ik in veel verschillende kringen samengewerkt. Elke vorm van samenwerking levert nieuwe inzichten op, zorgt voor nieuwe motivatie en laat je anders kijken naar de wereld om je heen. Natuurlijk mogen de BE COOL!'ers niet ontbreken in dit voorwoord. Marga, Mieke, Atteke, Loes en Christa: Tijdens onze samenwerking moesten we vaak creatief zijn, maar gezamenlijk hebben we Lelystad laten zien hoe COOL ons project kon zijn! Jakob, dankjewel voor alle tijd die je hebt gestopt in de ontwikkeling van de BE COOL! leeromgeving. We hebben vele uren besteed aan het finetunen van de kleinste details. Zonder jouw hulp had ik dit project niet af kunnen ronden. Manon, dankjewel dat je altijd met me mee wilde denken als schakel tussen onderzoek en onderwijspraktijk. Bedankt voor jouw bemoedigende mailtjes en de gezellige kopjes koffie in het Lelystadse Wifibolwerk, Mc Donalds ;-). Ik ben blij dat we nu weer opnieuw collega's zijn.

Natuurlijk zijn er twee BE COOL!'ers die een grote bijdrage hebben gehad aan het ontstaan van dit proefschrift. Ton, mijn promotor. Hartelijk dank voor alle tijd die je hebt gestopt in het lezen, herlezen en nogmaals herlezen van de ontelbare versies van dit proefschrift. Jouw ervaring en kritische blik hebben mijn enthousiasme soms op tijd kunnen indammen, 
zodat de studies in dit proefschrift ook daadwerkelijk uitvoerbaar waren. Gelukkig kreeg ik soms ook ruimte om een beetje eigenwijs te blijven. Daardoor voelt dit proefschrift echt als het mijne. Dankjewel voor alles wat je me hebt geleerd. Tessa, als 'chef-BE COOL!' en mijn dagelijks begeleider zijn jouw afgelopen jaren ook ondergedompeld in BE COOL! Hoe kunnen we BE COOL! nog cooler maken? Dat was, vrij vertaald, eigenlijk de vraag die vaak ter sprake kwam. Of het nou ging om potloden met het BE COOL! logo voor de kinderen of de ontwikkeling van de lessenserie, we hebben elk detail binnenstebuiten gekeerd om ervoor te zorgen dat we het onderste uit de kan haalden. Ik wil je vooral bedanken voor al die keren dat je me hebt weten te motiveren, naar mijn eindeloze stroom met ideeën hebt willen luisteren, en tot op het laatst kritisch bleef meelezen om dit proefschrift nog cooler te maken.

En dan zijn er natuurlijk een heleboel mensen die we gerust 'semi-BE COOL'ers' kunnen noemen! Anjo, dankjewel voor het overzichtelijk maken van de grote stapels logfiles. Zonder jouw hulp was ik daar nu nog bezig mee geweest. Sandra, bedankt voor je hulp met invoeren van de grote stapels vragenlijsten en het opmaken van dit proefschrift. Met jouw komst naar IST had ik eindelijk een gelijkgezinde gevonden. Iets met kleurtjes, eenhoorns en gezelligheid. Daphne, ik maakte weleens gekscherend grapjes over het aparte dankwoord-hoofdstuk dat ik voor jou moest gaan schrijven. Je hebt op meerdere vlakken veel voor me betekend. Dankjewel voor al jouw hulp in het halen van deadlines: voorbereiden van honderden leerkrachtmappen, invoeren van opdrachten in de $\mathrm{BE}$ COOL!-leeromgeving en het invoeren van -nogal wat- toetsen. Dankjewel voor jouw mentale ondersteuning van de 'promovenda verstopt tussen de stapels mappen en toetsen'. Maar vooral, bedankt voor je gezelligheid en lieve woorden als ik dat even nodig had. Door jou was het leuker om naar mijn werk te gaan.

Als je zes jaar bezig bent met onderzoeken en schrijven, is het natuurlijk fijn dat je collega's hebt op wie je kunt bouwen, met wie je alles kunt delen en die vertrouwen in je uitspreken. Hannie, je hebt mij enthousiast gemaakt voor het onderzoeken van samenwerkingsprocessen. Deze invloed is duidelijk terug te zien in dit proefschrift. Dankjewel voor alle wijze lessen en lieve aanmoedigingen. Dion, dankjewel voor al jouw hulp met het scoren van de stapels toetsen en het meedenken over de analyses van de samenwerkingsdialogen. Promovendi van IST en Yvonne;-), dank jullie wel voor onze gezellige, en vaak ook leerzame, 'homogene' (of toch heterogene?) 
samenwerkingsbijeenkomsten in de vorm van ProIST! Lieve collega's van Saxion. Dank jullie wel voor het vertrouwen dat jullie in mij hebben uitgesproken en de interesse die jullie altijd toonden voor mijn proefschrift. Ik heb veel van jullie kunnen en mogen leren. Twee jaar is dan toch ineens heel kort, maar de eerste samenwerkingsmogelijkheden hebben we gelukkig alweer weten te creëren. Jullie waren destijds gelijk overtuigd van de overeenkomsten tussen BE COOL! en Dalton, en ik nu dus ook! Ik zal de gezelligheid, koprollen en kopjes koffie op de Daltonkamer niet meer vergeten.

Maar ook buiten je werk kom je in verschillende kringen mensen tegen die zorgen voor de hoognodige afleiding en je op een andere manier laten kijken naar de inhoud van je promotietraject. De grootste gemeenschappelijke noemer is de kleur rood: Red is the color! Lieve vrienden van de PvdA en de JS. Afgelopen jaren waren roerig, maar daarom misschien juist ook wel heel interessant. Dank jullie wel voor de kansen die jullie me gaven om mij te kunnen ontwikkelen op sociaal-maatschappelijk gebied, voor de (soms verhitte) discussies, maar bovenal voor alle gezellige en soms ludieke campagne-activiteiten, congressen en vergaderingen. Jullie hebben ervoor gezorgd dat ik met andere ogen ben gaan kijken naar de maatschappelijke waarde van heel veel dingen, waaronder dit proefschrift.

Een paar mensen wil ik nog even in het bijzonder bedanken. Mijn lieve vriendinnen Ruth, Anne, Karien, Yara, Elin, Quiette en Wietske. Dank jullie wel voor jullie bemoedigende woorden, gezellige uitstapjes, borrelavondjes, koffiedates, etc. etc. Ik heb altijd gezegd dat ik niet wilde dat mijn proefschrift tussen ons in kwam te staan. Ik hoop dat jullie dit ook zo hebben ervaren, en dat we dan de laatste maanden voor het gemak even vergeten. ;-) Jenny, jou wil ik in het bijzonder bedanken. Als iemand mij heeft kunnen motiveren voor het afronden van dit proefschrift, dan ben jij het. Je kent me als geen ander, liet me uitrazen wanneer nodig, maar durfde me ook een spiegel voor te houden. Jouw vriendschap betekent heel veel voor me. En natuurlijk wil ik mijn lieve paranimfen en vriendinnen Judith en Noortje bedanken. Jullie begrijpen als geen ander wat het is om een proefschrift te schrijven. Afgelopen jaren hebben we alle hoogtepunten met elkaar kunnen vieren en elkaar kunnen steunen bij dieptepunten. Mijn persoonlijke hoogtepunt is dat ik aan dit promotietraject dierbare vriendinnen heb overgehouden!

Als je een proefschrift schrijft, leer je vooral jezelf goed kennen. Heel trots ben ik op de eigenschappen die ik van mijn ouders heb meegekregen en die me hebben geholpen om dit 
proefschrift af te ronden. Lieve mama en Anne, lieve papa en Ellen, en natuurlijk Mikael. Jullie hebben me alle vijf op geheel eigen wijze gesteund tijdens het schrijven van dit proefschrift. Dank jullie wel!

En tot slot wil ik heel graag mijn lieve Lars bedanken. We hebben elkaar leren kennen in een drukke periode. Gelukkig vond je het niet erg dat mijn proefschrift soms even voorrang moest krijgen. Sterker nog, jij hebt dit proefschrift mooier gemaakt. Niet alleen door mij te helpen met de afbeeldingen in dit proefschrift, maar je hebt vooral het schrijfproces van dit proefschrift mooier gemaakt door jouw rotsvaste vertrouwen dat ik het af zou maken en jouw lieve, bemoedigende woorden (en ijsjes). Het kan vanaf nu alleen maar mooier worden. Damn'd you are cool! Ik hou van je.

Heel veel dank gaat natuurlijk ook uit naar de leerkrachten en directies van de coole scholen: de 3Sprong, de Albatros, Alfonsus, Al Ishaan, de Boeier, de Brink, , de Driemaster, Driestromenland, de Finnjol, de Fontein, de Grundel, de Horizon, Ichthus, de Kring, Laetare, de Lepelaar, de Lispeltuut, de Meander, de Mozaiek, de Optimist, Paus Joannes, de Regenboog, de Schakel, 't Schrijverke, de Sluis, het Spectrum, de Tjalk, de Tjotter, de Toermalijn, de Triangel, de Vuurtoren, de Warande, de Wildzang, de Windroos, de Windroos en de Wingerd.

Alieke 



\section{Table of contents}

\section{Chapter 1}

General introduction $\quad 1$

Introduction - - 3

BE COOL! project

Jigsaw method - 4

Collaboration and cooperation - 5

Design of the homogeneous expert phase -6

Design of the heterogeneous design phase -7

Problem statement -8

Dissertation outline -___ 9

\section{Chapter 2}

BE COOL! Designing the lesson series and digital learning environment 11

Introduction 13

BE COOL! lesson series - 13

$B E C O O L$ ! learning environment- 18

Design process - _ 24

\section{Chapter 3}

Ability-related differences in performance of an inquiry task 33

Introduction - -36

Method - 40

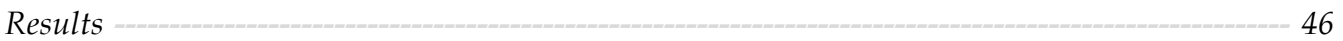

Discussion - 53 


\section{Chapter 4}

Supporting cooperative dialogue in heterogeneous groups 61

Introduction - 64

Method - 69

Results -__ 77

Discussion ___ 81

\section{Chapter 5}

Comparing the ability-adjusted jigsaw method to individual learning 87

Introduction - 90

Method ___ 94

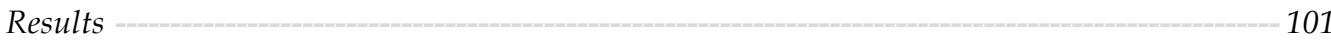

Discussion —__ 106

\section{Chapter 6}

General discussion $\quad 111$

Introduction - 113

BE COOL! lesson series - _ 113

Evaluating the lesson series - 114

Implementation of the lesson series - 118

Conclusion-_- 121

References - 125

English summary -137

Nederlandse samenvatting $\quad 149$ 

Chapter 1

General introduction 



\section{Introduction}

Quality of education is an ongoing topic of debate among parents, teachers, researchers, and policy makers. The debate mostly revolves around two questions: What is the core business of education? and What does effective and efficient teaching look like? In this discussion, the purpose of education can be broadly divided into two major aspects: 'education as preparation for the workplace' and 'education as preparation for participation in society'. When focusing on children's preparation for the workplace, the notion is that education should mostly attend to teaching children the necessary skills and knowledge for them to be able to carry out future professions. To prepare children for their participation in society, the focus in education should be on teaching children the skills and knowledge that contribute to their personal development and their ability to communicate, work, and live with others. Recent views on education, however, have blurred the sharp lines of this division. Our rapidly changing society, guided by technological developments, has created a situation in which we are uncertain what the professions of the future will entail, and what society will look like (e.g., Trilling \& Fadel, 2009). The skills and knowledge that children must acquire to carry out future professions and to be part of a changing society have thus recently become a topic of discussion themselves. To prepare for professions and society of the future, children should be taught what are termed 21st century skills, which include, for example, communicative and cooperative knowledge and skills (Dede, 2010; Geisinger, 2016; OECD, 2004; Onderwijs2032, 2016; Thijs, Fisser, \& van der Hoeven, 2014; Trilling \& Fadel, 2009). The importance of integrating these 'new skills' and 'existing knowledge' into educational practice is not a topic of debate. However, there are all the more questions about how to manage their integration (Thijs et al., 2014).

Zooming in on the Dutch elementary educational context, which is also the context of the research presented in this dissertation, teachers must accommodate these new demands within an already overcrowded time schedule. Teachers are supposed to attend to these 'new' skills as an addition to the existing focus on the basic subjects, such as language skills and mathematical skills. In Dutch society, educational politics seem to operate around a single goal: reaching a set level of cognitive performance in as little time as possible. Schools are urged to let their students graduate without delay and are judged by their cognitive performance scores at the end of each year (e.g., Berends \& Wolthuis, 2014). Within this context, the success of elementary education is generally determined by the rate at which children meet predefined cognitive learning goals (Doolaard \& Oudbier, 2010). Performance higher than the minimal cognitive levels is not necessarily more valued or appreciated (Doolaard \& Oudbier, 2010). As a consequence, teachers have little time and experience little need to give their attention to children who could excel at a higher cognitive level (i.e., differentiation). At the same time, teachers do not feel the need to 
spend time on implementing learning methods that attend to children's social development. The apparent contradiction between the focus on results and the call for differentiation and attending to 21st century skills highlighted the need to gain insight into ways to comply with these demands. The focus of this dissertation is on finding a balanced approach between demands regarding children's cognitive development matching their level of ability and children's development on the social level. In the BE COOL! project an attempt was made to create this balance.

\section{BE COOL! project}

BE COOL! is the Dutch acronym of a project that intended to encourage social interaction between children of different ability level, while improving, or at least maintaining, children' cognitive development. It was set up so that children could learn from and with each other in a context of cooperative and collaborative learning, inquiry learning, and learning by design ${ }^{1}$.

The basis of BE COOL! was a seven-week lesson series, included in a digital learning environment, that was structured according to (an adapted version of) the jigsaw method (Aronson, Blaney, Stephan, Sikes, \& Snapp, 1978). Children were to co-design a house on the moon in heterogeneous design groups of four. To do so, they had to integrate information on four different topics that had been gathered in homogeneous expert groups. These four different topics were interdependent and equally important for completing the shared assignment.

\section{Jigsaw method}

In the jigsaw method, students must work together in order to achieve a shared learning goal (Aronson et al., 1978). To reach this goal, students work together alternately in different cooperative and/or collaborative groups. The main element of the jigsaw method is that the overall assignment is divided into different topics. Students study or gather information on one of the topics, making them experts on their topic. Armed with the information on these topics, the expert groups split up and join mixed-topic cooperative groups in which students share and integrate the information on the different topics in order to complete the main shared assignment.

\footnotetext{
${ }^{1}$ Dutch acronym: Bevorderen van Excellentie door Coöperatief Onderzoekend en Ontwerpend Leren; English translation: Promoting possibilities to Excel by Working Together within the context of Inquiry Learning and Learning by Design.
} 
The jigsaw method and its derivatives are widely acknowledged learning techniques in elementary education (Aronson \& Patnoe, 2011). Its track record of successfully enhancing children's learning results (e.g., Colosi \& Zales, 1998; Karacop \& Doymus, 2013; Walker \& Crogan, 1998) as well as positively influencing children's liking for school and learning has been established before (e.g., Karacop \& Doymus, 2013; Walker \& Crogan, 1998). When looking into the effect of the jigsaw method compared to learning in traditional cooperative groups, learning with the jigsaw method was found not only to be beneficial for learning outcomes, but also to support students' social activities within the group process (Karacop \& Doymus, 2013). Students claimed a more prominent and active role in the group process, sharing their knowledge more actively with their group members. Knowledge-sharing as part of the group process has been identified as an important predictor for students' individual learning outcomes (King, 1998).

In the BE COOL! project, additional efforts were made to adjust the jigsaw method with the intention to reach the project aim.

\section{Collaboration and cooperation}

The type of group work that was used in the BE COOL! lesson series (i.e., collaboration and cooperation) was adjusted to the main purpose of the tasks at hand. As it happens, collaborative and cooperative learning differ greatly as far as learning process and intention (Dillenbourg, 1999). This difference can mainly be attributed to the division of labor within groups. Collaborative learning groups have a horizontal division of labor, meaning that students perform the same task together and each student arrives at their own outcome for that same task. This differs from the vertical division of labor that is characteristic of cooperative learning groups, in which tasks and responsibilities are divided among group members. In cooperative groups, the individual contributions of group members are co-constructive and are eventually merged into one joint outcome.

In this dissertation, collaboration was reflected in the homogeneous expert groups in which children were able to complete tasks together with their group members or individually. Cooperation was the basis of the heterogeneous design groups. In the cooperative groups, a major goal was to create a situation in which children relied on their group mates for information on the to-be-learned subjects. For this to happen, the success of the cooperation should no longer be driven by ability-related differences, but should be guided by the relevance, quality, and content of the contributions from group members. However, this aim is not easily achieved. In most situations in which students of different ability levels work together, status differences based on ability become activated almost immediately (Cohen \& Lotan, 1995). This situation could be improved by making students aware of the 
value of different input and skills in tackling collective tasks and that these different input and skills are represented by the different group members. In this regard, it is important to enhance the status of the different individuals in the group, so that group members consider each other as resources instead of competitors or not potential contributors. In the BE COOL! project, an attempt was made by making the different children in the group responsible for their own part of the task, reflected in their assigned topic. In order to complete the shared assignment, groups had to integrate the information on these different topics to create a shared product.

\section{Design of the homogeneous expert phase}

In order to bring back enough information to later share with each other in the heterogeneous cooperative groups, children must gather information on their assigned topics. The jigsaw method does not necessarily prescribe whether this information should be given to group members or whether students should take charge of their own informationgathering process. When children are responsible themselves for discovering new information and play an active role in the process of discovering and interpreting this new information, deeper learning is evoked (Alfieri, Brooks, Aldrich, \& Tenenbaum, 2011; Mayer, 2003, 2004; Minner, Levy, \& Century, 2010). In inquiry learning, children are expected to actively collect new information, process this information, and construct new knowledge. They are personally responsible for collecting the necessary knowledge that the group can later use to complete the shared assignment; this responsibility should therefore enhance children's engagement in the group process and their feelings of 'expertise'.

However, one must be careful in assuming that all children will be able to collect the needed information by themselves. There are huge differences in children's learning skills, depending on their level of ability (Lou et al., 1996; Wang, Kinzie, McGuire, \& Pan, 2010). In order to make sure that children of different levels of ability are able to learn at a level matching their ability, learning assignments should be adjusted to these different levels (i.e., differentiation; Tomlinson, 2000).

The content of the inquiry learning tasks in the homogeneous design phase was connected to children's level of ability, based on the complexity and depth of the to be learned information. Differentiation with regard to the process for completing the inquiry task needed additional input to create clear guidelines (see Chapter 3). It is widely accepted that inquiry learning should be thoroughly supported in order to lead to a learning process that elicits successful learning outcomes (Alfieri et al., 2011; d'Angelo et al., 2014; Mayer, 2004). In this context, it was relevant to gain insight into the nature of support that could enhance the inquiry learning process for children of different ability levels. Is it indeed true that all 
children need support during their performance of inquiry tasks? It has often been stated in the literature that high-ability children can best be left alone to discover their learning path (Diezmann \& Watters, 1997; VanTassel-Baska, 2003), insofar as supporting them might hinder their natural learning processes (Kalyuga, Ayres, Chandler, \& Sweller, 2003).

\section{Design of the heterogeneous design phase}

Coming together in the heterogeneous design groups, children should now focus on integrating their different knowledge bases into one shared knowledge base so that they can take part in the co-construction of the response to the joint assignment (Aronson et al., 1978). Sharing information is an important condition for a cooperative process to be effective (Webb, 1982a, 1982b, 1984). Providing others with information helps students to clarify their understanding and organize their knowledge base. Receiving information complements students' knowledge base and helps to correct possible misconceptions. However, merely putting children in cooperative groups and telling them to share their knowledge does not guarantee a fruitful cooperative process (Mercer, 1996; Mercer, Wegerif, \& Dawes, 1999). Children often do not know what is expected of them in a cooperative setting and therefore engage in unproductive activities.

Considering that children have different competencies, cooperation in heterogeneous groups might create difficulties during the cooperative process. Differences in pace of learning (Wang et al., 2010), speed with which they are able to grasp new knowledge (Zimmerman, 2007), and ability to express and explain information to others (Webb, Nemer, \& Zuniga, 2002) might lead to a cooperative process in which the group process lacks connectivity. Specific concerns have been expressed for the higher ability children in the group and their opportunities to benefit from heterogeneous cooperative processes (Gillies, 2003; Kulik \& Kulik, 1982). However, even though the success of the cooperative process has often been linked to the composition of the group (Lou, Abrami, \& Spence, 2000; Webb, 1995), there seems to be another, sometimes overruling, characteristic that plays an important role in determining the quality of the group process: participation by the different group members in the group dialogue (Förrer, Kenter, \& Veenman, 2000).

The Social Interdependence Theory of Johnson, Johnson, and Smith (2007) provides guidelines for structuring the cooperative process to be beneficial for all participants. Johnson et al. (2007) identified five conditions that need to be met in order for any cooperative process to be productive: (positive) social interdependence, individual accountability, promotive interaction, evaluation of the group process, and the use of social skills. When these conditions are met, the cooperative process is structured in such a way 
that the focus is on the different expertise of children in the group, predetermined by the different topics that children represented.

Judging from the conditions of the Social Interdependence Theory, support of the heterogeneous cooperative process should first make sure that group members realize that they share a common goal and that this goal can only be reached when all group members participate in the group process (i.e., positive social interdependence). Second, group members should be reminded of their personal responsibility in the group process (i.e., individual accountability). Group members should all be made aware of their need to participate in the group process. This element is in part inherent in the jigsaw method, but could be made more prominent by explicating group members' specific roles (Walker \& Crogan, 1998). Third, group members should be encouraged to engage in promotive interaction during the cooperative process, in that they should stimulate and assist their group members in working to complete their joint task, making sure that all group members feel free to take part in the shared process. Fourth, groups should be encouraged to evaluate the group process. And, fifth, the cooperative process can profit from the appropriate use of social skills in the mutual communication between group members.

In the context of this dissertation, it is important to integrate these necessary conditions in a type of support that strengthens the natural flow of the jigsaw method and complements the ability-adjusted expert phase preceding the heterogeneous cooperative process instead of adding a separate element to the method that might even disturb the positive effects of the jigsaw method in its original form (see Chapter 4).

\section{Problem statement}

Capitalizing on the situation in Dutch elementary education described at the beginning of this chapter, the main focus of this dissertation is to design and investigate a learning method that complies with two demands: high emphasis on cognitive learning outcomes on the one hand and a call for differentiation and the development of 21st century skills on the other hand. The jigsaw method (Aronson et al., 1978) seemed to be a good starting point to address these demands. In this dissertation, the focus of the investigation was whether it is possible to design a lesson series that encourages social interaction between children of different ability levels, while improving - or at least maintaining - cognitive learning outcomes for all children.

Measurements to assess social development were not included in this dissertation, since the jigsaw method in itself is said to provide a stimulating environment for children's social development (Doymus, Karacop, \& Simsek, 2010; Karacop \& Doymus, 2013; Walker 
\& Crogan, 1998). Therefore, cognitive learning outcomes (i.e., knowledge of the topics that were central to the lesson series at hand) were the main objective assessed in this dissertation. In addition to the cognitive learning outcomes, children's knowledge about inquiry and their attitudes towards science and technology were assessed, as the lesson series took place within a context of inquiry learning and addressed a scientific topic. The latter measurement is interesting in the context of children's preparation for future professions, as scientific and technological skills are designated as important prerequisites for children's future participation in society (e.g., Trilling \& Fadel, 2009).

To answer the research question, we developed a lesson series that was embedded in a digital learning environment (see Chapter 2). The research was conducted with a target population of fourth, fifth, and sixth graders (9 - 13 years of age) from 30 different elementary schools from a mid-sized city in the Netherlands. Schools differed in their denomination (e.g., public, Catholic, and Protestant Christian) and didactic style (e.g., regular, Dalton, and Jenaplan).

\section{Dissertation outline}

In Chapter 2, the BE COOL! lesson series and digital learning environment are described. The chapter includes both the design process and a description of the final version of the lesson series that was embedded in the digital learning environment.

The two empirical studies that are described in Chapter 3 and Chapter 4 of this thesis form the basis of the design of the BE COOL! lesson series. These studies were conducted to gain insight into how to provide ability-adjusted inquiry assignments during the homogeneous expert phase (Chapter 3 ) and how to support the heterogeneous cooperative process so that all group members are able to participate equally in this process and have opportunities for learning (Chapter 4). On the basis of these studies, support was fitted into the inquiry assignments that are central to the information-gathering activities in the homogeneous expert phase, and a worksheet was implemented into the lesson series to structure children's information sharing activities in the heterogeneous design groups.

In Chapter 5, a large-scale evaluation study is described that compared the final version of the BE COOL! lesson series to a control version of the lesson series. 

Chapter 2

\section{BE COOL!}

Designing the lesson series and digital learning environment 



\section{Introduction}

The research that is described in this dissertation was conducted in the context of the BE COOL! project. The BE COOL! project was a four-year design project that aimed at developing and evaluating a seven-week lesson series in which children of different ability levels work together in homogeneous and heterogeneous groups. In the context of the jigsaw method (Aronson et al., 1978), children were to co-design a house on the moon that could be inhabited by a family of four (two adults and two children), working in heterogeneous groups of four (one high-ability child, one low-ability child, and two average-ability children). The lesson series was included in a digital learning environment that offered children the possibility of structuring their own learning process. Teachers were able to monitor children's progress and provide feedback by means of the teacher section of the digital learning environment.

In this chapter, the BE COOL! learning environment and its lesson series are introduced, together with underlying theoretical ideas and design decisions that were partly based on the two studies presented in Chapters 3 and 4. The BE COOL! environment as presented in the current chapter was evaluated in a study presented in Chapter 5 .

\section{BE COOL! lesson series}

\section{Learning by design}

In the lesson series, children basically followed the steps of learning by design (Kolodner et al., 2003). In the context of the BE COOL! project, seven different steps guided the children through the design process of their final assignment, designing a moon house: 1) children were confronted with a problem (what is the problem; how are we going to tackle it?), 2) they oriented themselves to what they already knew about the problem (activation of prior knowledge), 3) they gathered information by means of ability-adjusted inquiry assignments, 4) they made their first design, 5) they tested this design to identify further improvements, 6) they created an improved prototype, and 7) reported on their design choices.

These seven steps in our learning by design approach were organized into three learning phases, adapted to the jigsaw method: 1) a heterogeneous prior knowledge phase (i.e., confrontation with the problem and activation of prior knowledge), 2) a homogeneous expert phase (i.e., gathering of information), and 3) a heterogeneous design phase (i.e., creation of an initial design, testing of the design, creating an improved prototype, and reporting on design choices). See Figure 2.1 for an overview of the groups' composition in the three phases. 


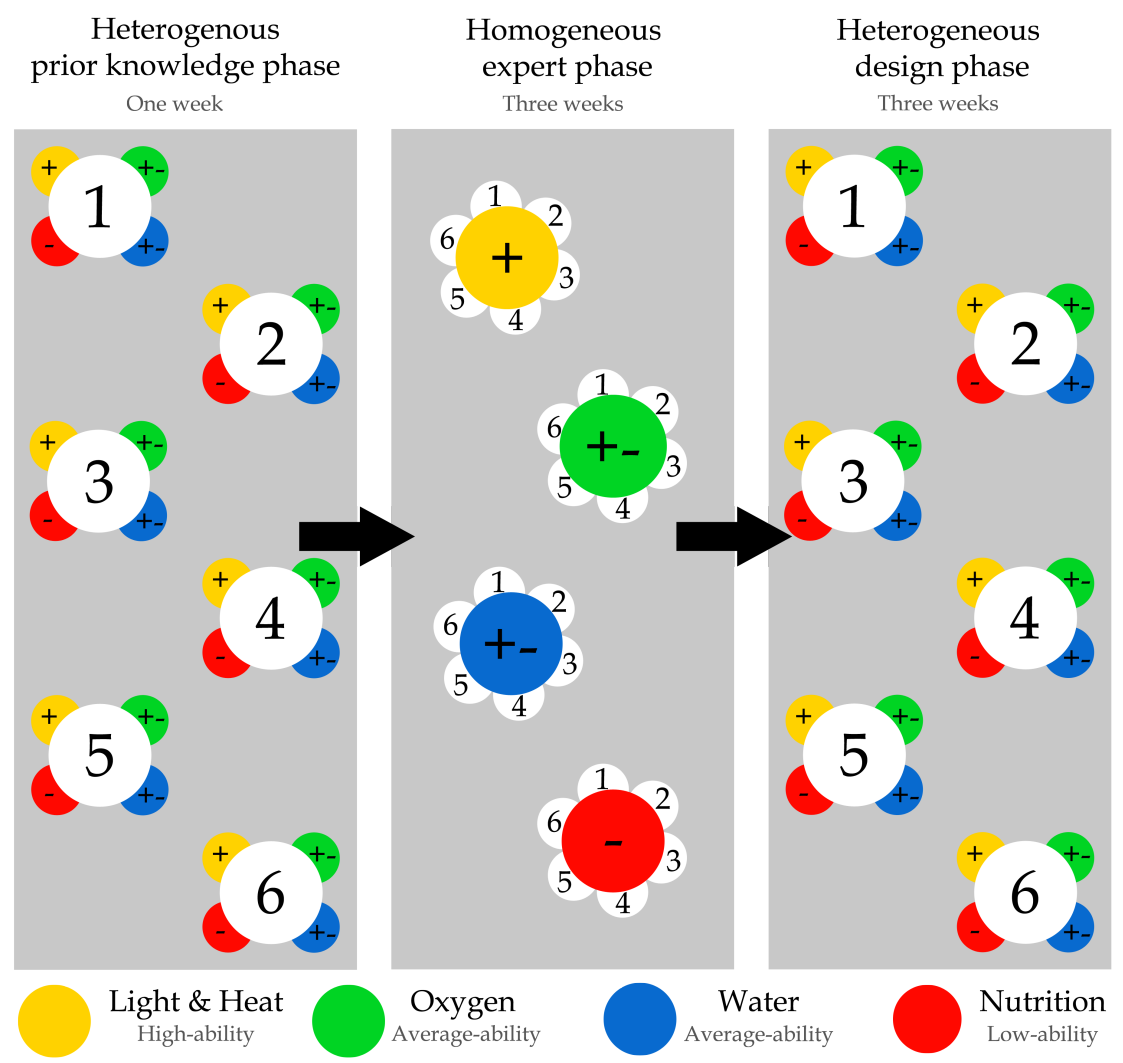

Figure 2.1. Overview of the phases as implemented in the BE COOL! jigsaw lesson series. The four colors represent the four topics assigned to children of different ability levels. The plus signs and minus signs represent the ability levels of the children (i.e., $+=$ high-ability, $+-=$ average-ability, and $-=$ low-ability). The numbers identify the heterogeneous design groups to which the children belong

\section{Heterogeneous prior knowledge phase}

The heterogeneous prior knowledge phase lasted two hours. Children were introduced to the problem, the inquiry method, and their prior knowledge was activated. Children also received information about the two groups that they would be working in and about the digital learning environment. ${ }^{2}$

\footnotetext{
${ }^{2}$ In the large-scale evaluation study, reported in Chapter 5, children could either be part of the experimental BE COOL!-condition or the control condition. Children in the BE COOL!-condition were called 'Astronauts' and children in the control condition were named 'Globetrotters'. These names were communicated to the children so that they were not aware of the condition that they were part of.
} 
At the start of the project, the children received a letter from the 'Research \& Design Department of BE COOL!' that called upon them to design a house on the moon so that a family of four could live there (see Figure 2.2 for the content of this letter).

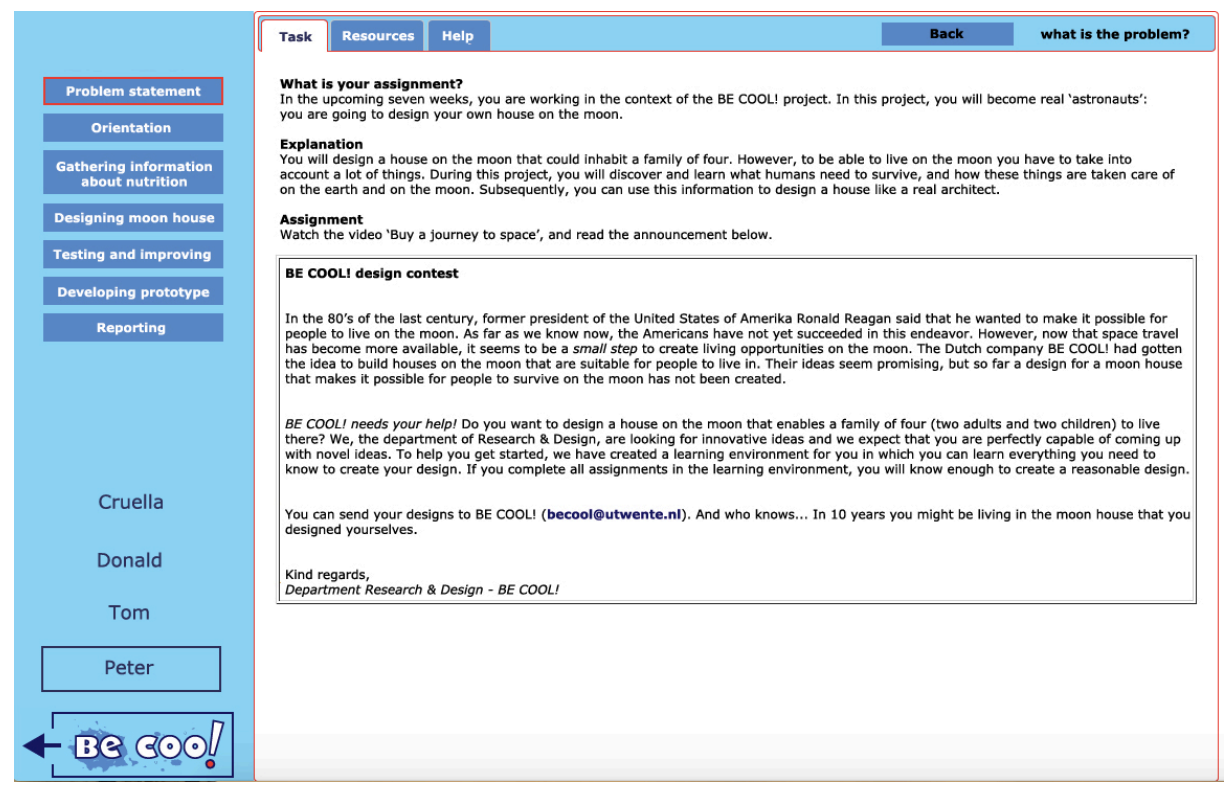

Figure 2.2. Letter from the 'Research \& Design Department of BE COOL!' that called upon the children to design a house on the moon [translated from Dutch]

Children learned about inquiry learning and gained knowledge about gravity and air friction by means of a simulation assignment. This assignment was based on the simulation assignment as described in Chapter 3. In addition to the original inquiry assignment used in the experiment in Chapter 3, there was classroom instruction in which the teacher explicitly named and explained the different steps of the inquiry cycle as used throughout the lesson series at hand: 1) orientation (What do we already know about the topic?), 2) researching (How can we find out the answer to the research question stated in the assignment?), 3) concluding (What did we find and what can we conclude from this?), 4) evaluation (What do the conclusions mean?), and 5 ) broadening (What do the conclusions mean for our upcoming design of the moon house?). This instruction prepared children for the knowledge-gathering, inquiry assignments that they would receive in the homogeneous expert phase (i.e., step 3 of the learning by design cycle).

As a final assignment in the heterogeneous prior knowledge phase, children worked together on an assignment that mapped and triggered their prior knowledge. Children were given an assignment that resembled the cooperative learning method, Placemat. 
Placemat is a cooperative learning method that consists of three steps. First, children are required to individually think about and write down what they already know about a domain. Second, children share what they have written down and check for similarities and differences. Third, they decide together what will be their shared conclusions. In the BE COOL! version of Placemat, the first step was that children individually explored their prior knowledge on 'what they would need to survive on the moon' and write this down on a piece of paper. Subsequently, children were to connect their ideas and knowledge to the four topics (i.e., 'Light \& Heat', 'Oxygen', 'Water', and 'Nutrition'). Together, they would then reflect upon their answers and think about missing pieces of information that needed to be gathered in order to enable themselves as a group to make fully-informed design decisions later on in the lesson series. Finally, children were encouraged to keep in mind the questions that they had developed during the prior knowledge activity, so that they could gather information during the homogeneous expert phase to answer these questions during the heterogeneous design phase.

After this, it was explained to the children that in the upcoming seven weeks, they would be working together in two different groups (i.e., an expert group and a design group) to co-create their house on the moon; they were then introduced to the group members in both groups and were told their assigned topic for the homogeneous expert phase.

\section{Homogeneous expert phase}

In the homogeneous expert phase, children were divided over four different expert groups based on their level of ability (see Chapter 5 for the procedure that was followed to assign children to groups). The four topics that were distinguished in this dissertation were assigned to one of the three ability levels based on their complexity: 'Light \& Heat' for the high-ability children, 'Nutrition' for the low-ability children, and 'Oxygen' or 'Water' for the average-ability children. Over three successive weeks, children would spend two hours per week on different assignments that covered their topic, to be completed either individually or collaboratively, sometimes using on-line material, sometimes performing investigations in the real world. These assignments followed the five steps of the inquiry cycle and included ability-adjusted structure and support. The structure of the assignments and of the support offered was designed on the basis of results of a study that investigated ability-related differences in approaching an inquiry task and in use of support in this learning process (see Chapter 3). 
The homogeneous expert phase ended with a core assignment that assisted the children in summarizing the most important concepts of their topic by answering six questions. These six questions represented the different subtopics that were central to the topics at hand (see Figure 2.3 for an example of the topic 'Oxygen'). This assignment was to be completed simultaneously by the entire homogeneous expert group, so that children would have the opportunity to fill in missing pieces of information with the help of the others in the group. The summary that resulted from answering the questions in the core assignment functioned as a starting point for the upcoming heterogeneous design phase.

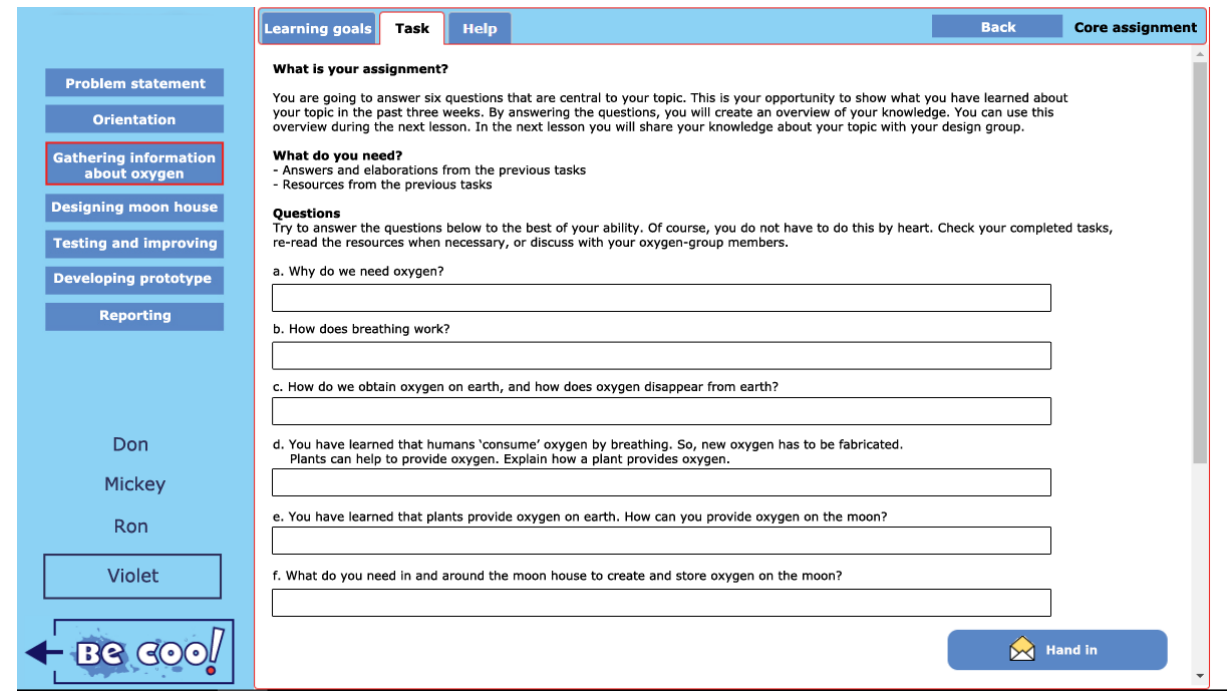

Figure 2.3. Core assignment for the topic 'Oxygen' [translated from Dutch]

\section{Heterogeneous design phase}

In the heterogeneous design phase, children returned to their heterogeneous cooperative groups from the prior knowledge phase. In the upcoming three weeks, children were to share and integrate their knowledge on the different topics so that they could all play a part in making design decisions.

To start the heterogeneous design phase, children were to share the knowledge that they gathered in their homogeneous expert groups. To support the process of knowledge sharing, the first lesson was guided by means of a worksheet. This worksheet was designed based on the results of a study that explicitly focused on supporting the heterogeneous cooperative dialogue in such a way that domain-related differences would be more important than ability- related differences (see Chapter 4). 
The worksheet strengthened the principles of the jigsaw method by explaining children's different, equally important roles as experts in creating the final assignment. Furthermore, it placed emphasis on the content of the four topics by making sure that children shared their knowledge (using the core assignment from the previous phase as input), that the other children in the group were involved with the information that was shared by their group members, and it asked the group members to think concretely by converting the information into design proposals.

After integrating their knowledge, in the second lesson of the heterogeneous design phase groups started their first design by elaborating on the design proposals that had been created with the help of the worksheet. A flowchart prompted groups to test their design to identify further improvements (see Figure 2.4).

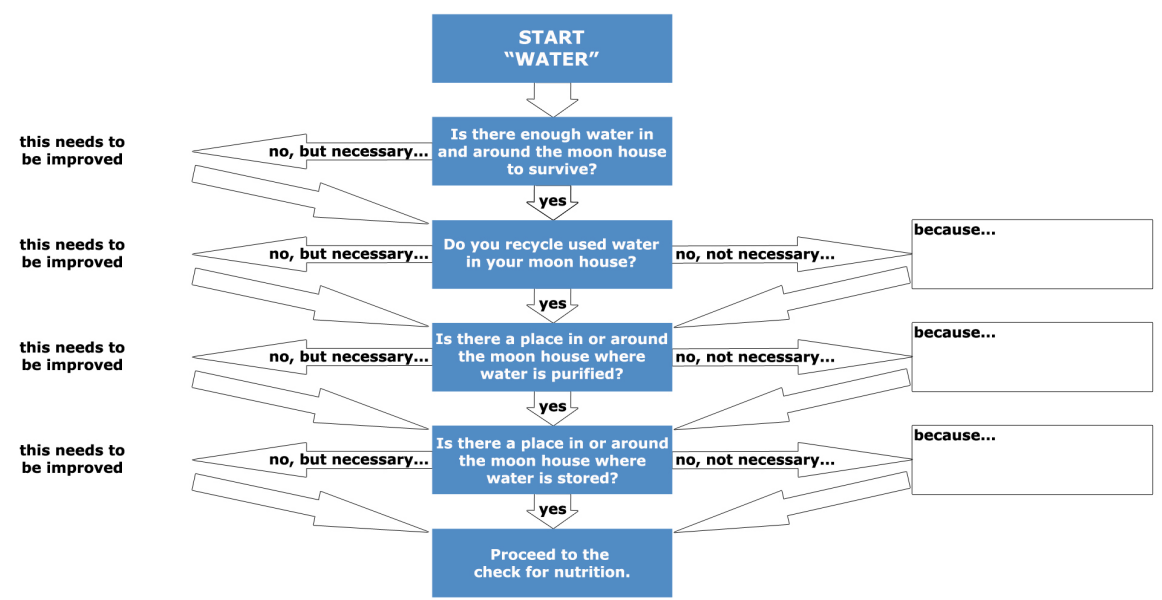

Figure 2.4. Flowchart for the topic 'Water' [translated from Dutch]

There was a separate flowchart for each topic, which specified different elements that could be considered prerequisites for designing a proper house on the moon. The outcomes from the check following the steps of the flowchart were subsequently used in the final lesson of the heterogeneous design phase to create an improved prototype of the house on the moon, which was to be justified in a report on the shared design choices of the group.

\section{BE COOL! learning environment}

The lesson series was implemented in the BE COOL! digital learning environment. The learning environment consisted of two parts: 1) a student section that presented 
children with their assignments, and 2) a teacher section that enabled teachers to organize the lesson series for their children, provided them with an overview of children's progress, and created the opportunity for providing feedback on assignments that were handed in.

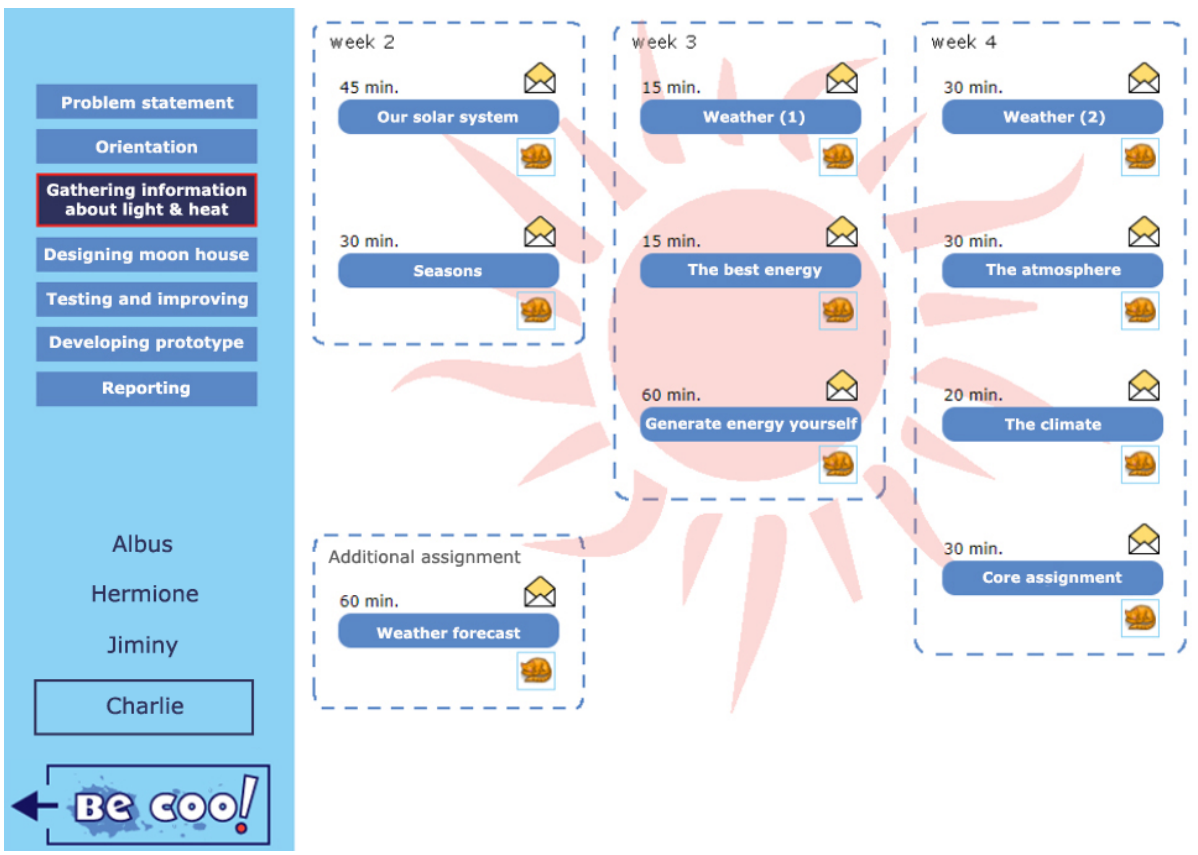

Figure 2.5. Overview of the assignments in the homogeneous expert phase for the high-ability children [translated from Dutch]

\section{Student section}

To enter the BE COOL! learning environment, children received a personal login code. When logging in, children were redirected to their personalized learning environment that corresponded to the topic and groups that they were assigned to. The menu on the left displays the different steps of the learning by design cycle: problem statement, orientation, gathering information about [topic], designing moon house, testing and improving, developing prototype, and reporting. Corresponding buttons house the assignment(s) that define the steps that children need to take to complete the design process. In Figure 2.5, the child named Charlie is in the 'Gathering information step', and an overview of all assignments to be completed in this step are given in the window on the right. 


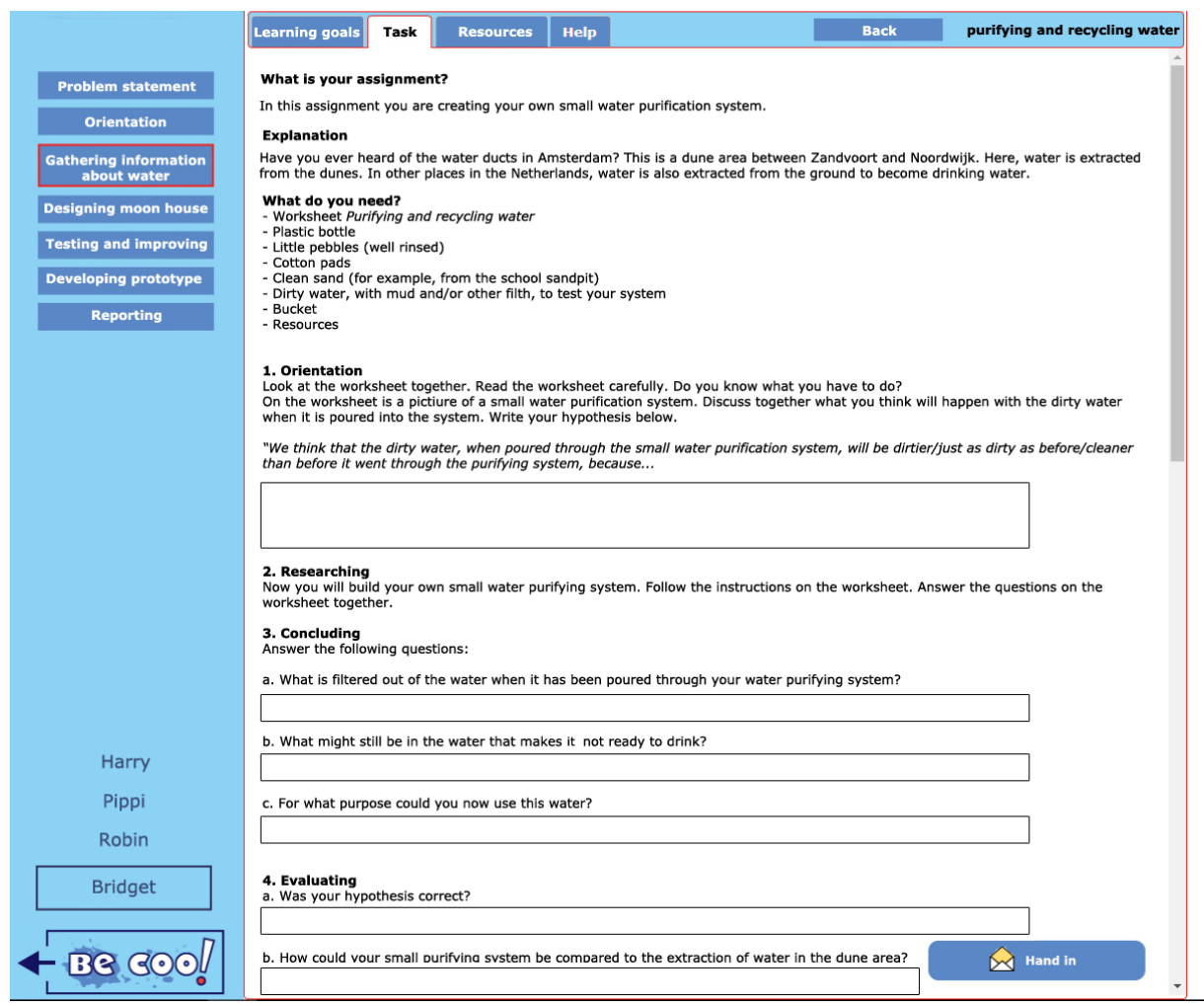

Figure 2.6. Inquiry assignment for the topic 'Water' for the average-ability children, including the first four steps of the inquiry cycle [translated from Dutch]

The assignments in the 'Gathering information step', which is central to the homogeneous expert phase, are structured according to the inquiry cycle (see Figure 2.6 for an example of an inquiry assignment). Children did not receive additional instruction about how to use the inquiry cycle, as this was already given in the prior knowledge phase. By completing the different inquiry assignments, children were expected to implicitly learn about the different steps of the inquiry cycle. To illustrate the inquiry cycle for the children, the steps of the cycle recurred explicitly and recognizably in the different assignments. In Figure 2.6, the child named Bridget opened the assignment 'Purifying and recycling water' as part of the 'Gathering information step' of the topic Water. The window on the right shows four of the different steps that are to be taken in this inquiry assignment: orientation, researching, concluding, and evaluating. Also part of the assignments but not visible in Figure 2.6, is the step 'Broadening'.

When children opened an assignment for the first time, they were presented with learning goals concerning the content of the task at hand. Children had to indicate 
their prior level of skills and knowledge. When handing in the assignment, children had to reflect on what they learned by indicating their level of skills and knowledge once more. To contextualize the inquiry assignment, children received information on what the assignment was about and an overview of the materials needed to complete the assignment. In addition, relevant resources were given and could be requested by clicking the tab at the top of the task window.

Children were offered eight to ten inquiry assignments that covered the content of their topic. Inquiry assignments varied, from investigating and drawing (e.g., drawing the process of photosynthesis as part of the topic 'Oxygen') to building an experimental design (e.g., investigating the optimal conditions for growing tomato plants as part of the topic 'Nutrition'). Similar inquiry assignments were provided for each topic and could be completed either individually or collaboratively with one or more partners from the homogeneous expert group. The BE COOL! learning environment indicated the recommended number of partners that were needed to complete the assignments at hand.

\section{Teacher section}

Teachers were provided with a teacher's manual that contained information on the digital learning environment (i.e., technical information and practical information) and an overview of children's assignments - supplemented with printable worksheets that were part of some assignments. After logging into the BE COOL! learning environment, teachers had access to a teacher section in which they could prepare the learning environment for their class and could monitor and evaluate children's progress. Teachers had also access to the student section to view the assignments that were offered to the children. Below, the features of the teacher section are described.

Registration and grouping. The first step for teachers in the teacher section of the learning environment was to register the participating children by entering both name and ability level of the children (see Figure 2.7 for the Registration page). Teachers entered children's ability level by means of a categorization procedure based on CITO (i.e., a standardized scoring system that defines children's level of ability) and/or the 'Digital Measuring Protocol for Giftedness' (i.e., Digitaal Handelingsprotocol Hoogbegaafdheid; van Gerwen \& Drent, 2011). 


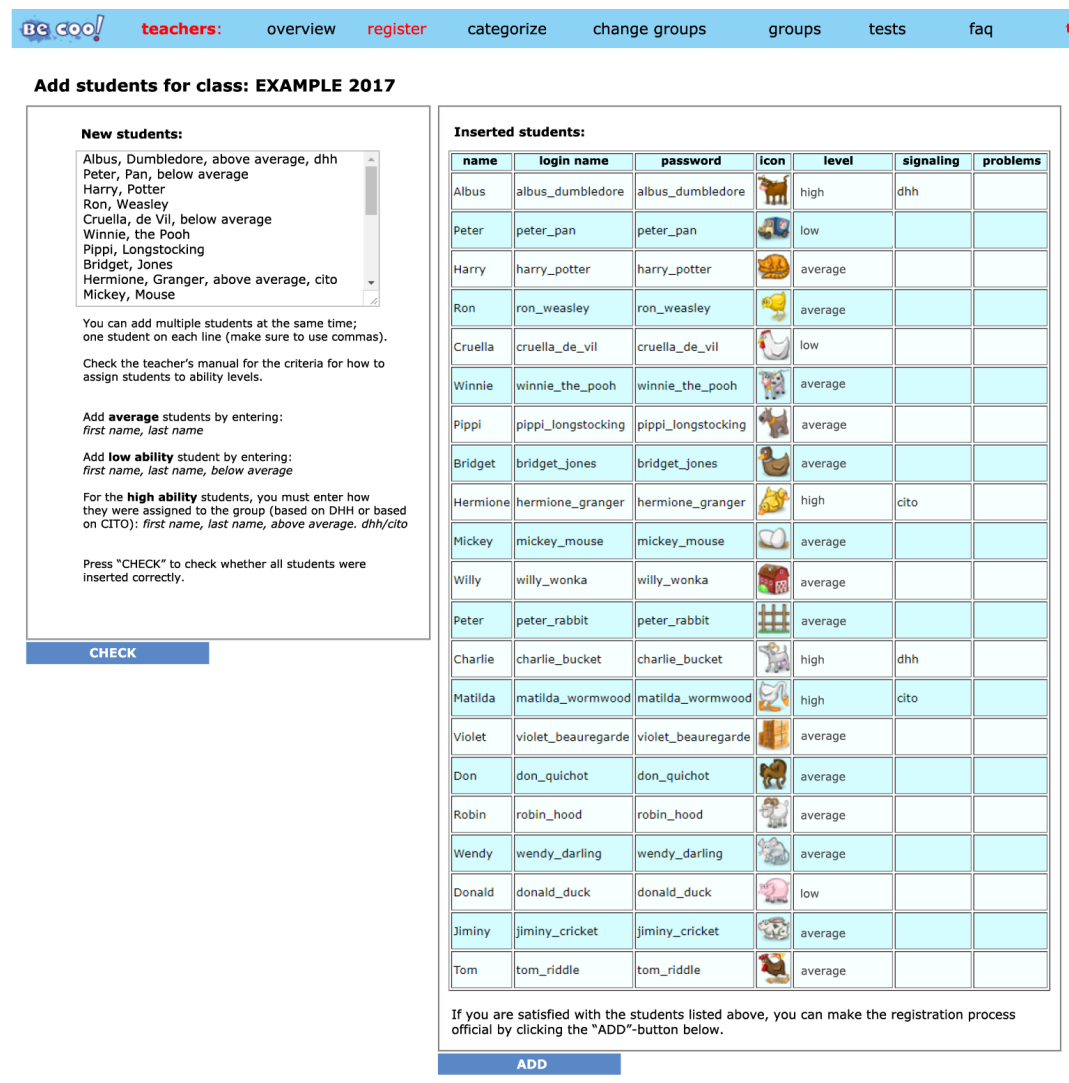

Figure 2.7. Page for teachers to register their students. Left: Registration window. Right: Overview of the children, with an 'Add-button' to complete the registration process. [Names of the children used in this example are fictitious; the content of the figure is translated from Dutch]

Then, the BE COOL! system sorted the children into their heterogeneous design groups and homogeneous expert groups. Teachers only had to give the command to categorize the children. In the next window, they were shown the categorization of the BE COOL! system (see Figure 2.8 for an example).

At this point, teachers were allowed to make alterations to the heterogeneous groups within the assigned conditions. Teachers were told that they could make these alterations when an average-ability child was used to fill up the low-ability homogeneous group or the high-ability homogeneous group, but their level of ability was either too high or too low to fit the profile of these groups. 


BS $3 \circ \circ]$ teachers: overview register categorize change groups groups tests faq teacher | log out

Current division of students

\begin{tabular}{|c|c|c|c|}
\hline naam & loginnaam & icon & niveau \\
\hline Albus & albus_dumbledore & in & high \\
\hline Bridget & bridget_jones & $y$ & average \\
\hline Charlie & charlie_bucket & (3⿻) & high \\
\hline Cruella & cruella_de_vil & $y$ & low \\
\hline Don & don_quichot & ins & average \\
\hline Donald & donald_duck & 3 & low \\
\hline Harry & harry_potter & 90 & average \\
\hline Hermione & hermione_granger & 63 & high \\
\hline Jiminy & jiminy_cricket & isc & average \\
\hline Mickey & mickey_mouse & 0 & average \\
\hline Peter & peter_rabbit & $\#$ & average \\
\hline Pippi & pippi_longstocking & 6 & average \\
\hline Robin & robin_hood & 30 & average \\
\hline Ron & ron_weasley & 용 & average \\
\hline Tom & tom_riddle & 21 & average \\
\hline Violet & violet_beauregarde & 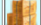 & average \\
\hline
\end{tabular}

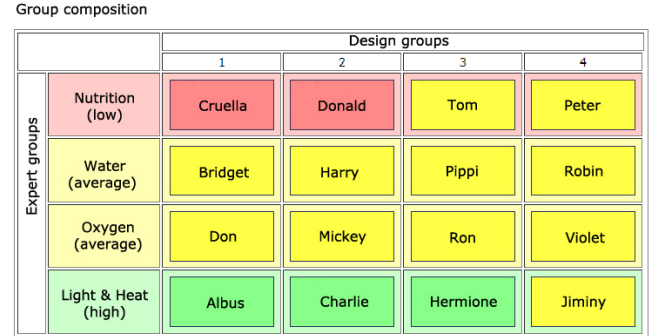

Figure 2.8. Window showing the categorization of children. [Names of the children used in this example are fictitious; the content of the figure is translated from Dutch]

Monitoring and evaluating. In the teacher section of the BE COOL! digital learning environment, teachers could also monitor and evaluate children's progress. Entering the teacher section, teachers could request an overview of their children's progress by entering school name and class. Due to privacy reasons, teachers could only view data from their own class. Teachers received an overview of the assignments per topic. Children's progress was displayed by five different symbols (see Figure 2.9): 1) an opened envelope showed that children had opened the assignment and were working on it, 2) a closed envelope showed that children had finished and handed in the assignment, 3) a red cross showed that teachers provided the assignment with feedback and that children were to improve the assignment, 4) a green exclamation point showed that teachers approved the assignment but added feedback that was important for children to read before continuing with the other assignments, or 5) a green curled ribbon showed that teachers approved the assignment.

The assignments that were 'handed-in' by the children, identified in the teachers' overview by the symbol of the closed envelope, could be provided with feedback. Teachers were forwarded to the feedback page by clicking on the envelope for that particular assignment. The feedback page consisted of different parts: 1) information on 


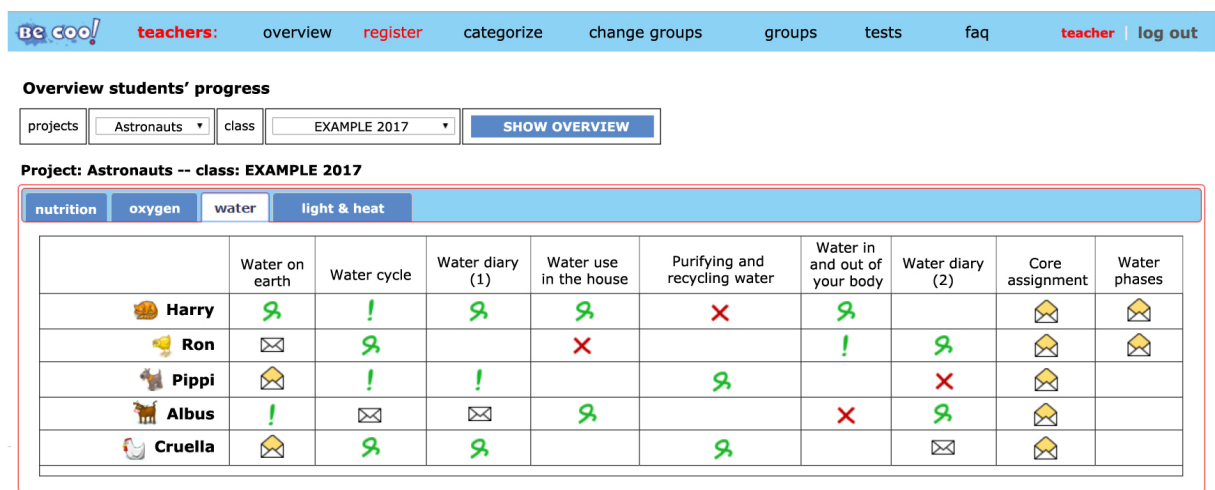

Figure 2.9. Teacher's overview of the progress of their children in the 'Water' group [Names of the children used in this example are fictitious; translated from Dutch]

the children who were involved with the assignment (depending on whether the assignment had to be completed individually or collaboratively), 2) an answer key that teachers could use to check children's answers, 3) the assignments with children's answers, 4) a feedback section in which teachers could write their feedback and provide the assignment with a rating (i.e., red cross, green exclamation point, or green curled ribbon), and 5) an overview of any previously given feedback. See Figure 2.10 for an example of a feedback page.

After teachers provided an assignment with feedback, the status of the assignment in the overview changed, displaying the symbol that showed the rating. Children received a notification of the feedback and rating of their assignments when logging into the digital learning environment.

\section{Design process}

The BE COOL! lesson series and corresponding learning environment (as described in the previous sections of this chapter) were developed as part of a four-year design project. Research and development alternated with each other to shape the BE COOL! lesson series and its implementation in the learning environment (see Figure 2.11 for a timeline of the research and development phases). Results from different (pilot) studies were used to prepare materials before the start of the studies (described in Chapters 4 and 5) in which these materials were used. The studies described in Chapter 4 and 5 both tested the complete set of materials that had been designed (and re-designed) so far, to make sure that the final version of the BE COOL! lesson series would be the optimal version. 


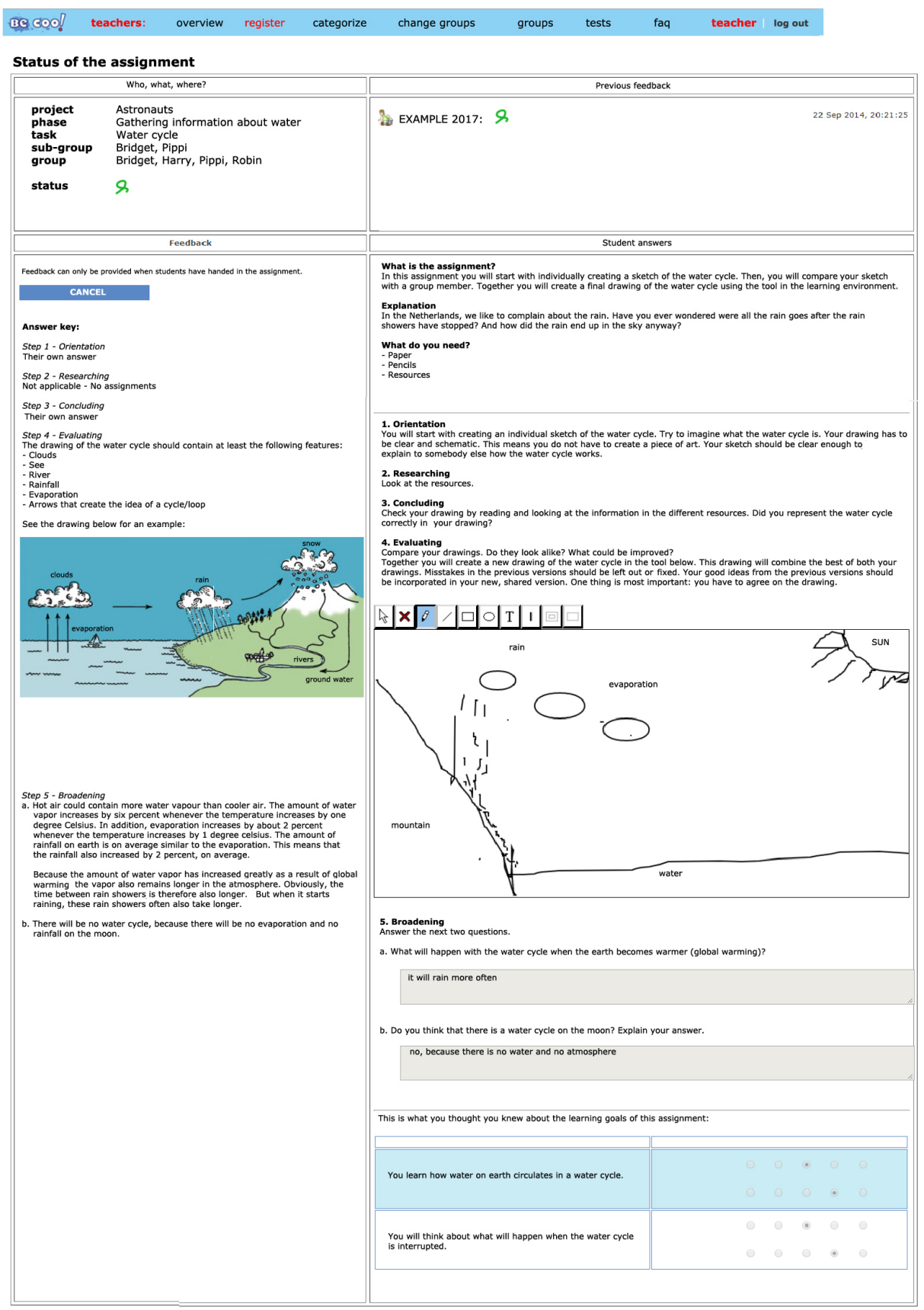

Figure 2.10. Example of feedback page for the assignment 'Water cycle' from the topic 'Water' [translated from Dutch] 
Research

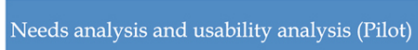

Differentiation in the homogeneous expert phase (Chapter 3)

First check of the BE COOL! lesson series (Pilot)

Support for the heterogeneous design phase (Chapter 4)

\section{Development}
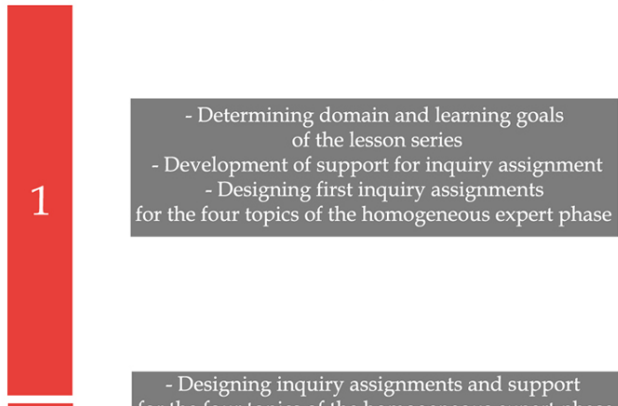

- Designing inquiry assignments and suppor

for the four topics of the homogeneous expert phase

- Designing assignments and support

for the heterogeneous design phase

- Designing assignments

for the heterogeneous prior knowledge phase

- Implementing assignments

in digital learning environment

- Developing parallel domain knowledge tests

Adjusting inquiry assignments

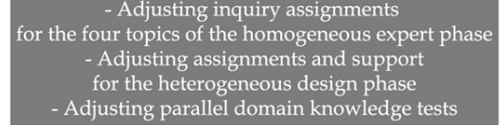

3

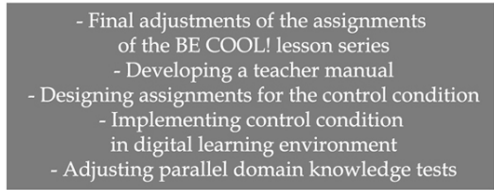

- Adjusting parallel domain knowledge tests

Providing workshops for

implementation of the lesson series

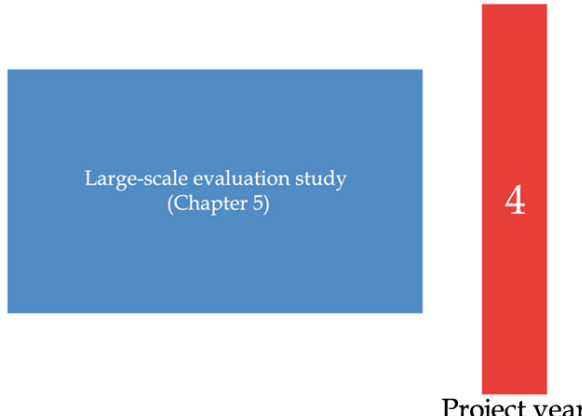

\section{Project year}

Figure 2.11: Timeline of the research and development phases in the context of the BE COOL! lesson series 


\section{Pilot study: Needs analysis and usability analysis}

In the first year of the BE COOL! project, a study was conducted to serve as input for the inquiry assignments in the homogeneous expert phase of the lesson series. The study consisted of two parts: 1) a needs analysis to explicate the teacher's needs and expectations of a digital learning environment that embeds differentiated assignments, homogeneous collaboration, and heterogeneous cooperation, and 2) a usability study to gain insight into elementary school children's experience with inquiry assignments and a digital learning environment.

In the needs analysis, 14 teachers were interviewed to gain insight into their needs and expectations concerning the lesson series and the accompanying learning environment. As described in Chapter 1, the BE COOL! project aimed to assist teachers to cope with the demands of cognitive development on the one hand and a renewed focus on differentiation and 21st century skills on the other hand, within a limited time frame. By means of the interviews, teachers' visions about these issues and how BE COOL! could contribute were gathered. The main issues that emerged from the interviews were: a) the domain of the lesson series should be easy to integrate into the curriculum, b) topics should be challenging and/or feasible for children with different ability levels, c) the learning environment should include information and links to resources so that children can be self-sufficient, d) the heterogeneous cooperation should be supported (the different roles of the children should be structured), and e) the learning environment should enable teachers to monitor children's progress and to provide completed assignments with feedback. These issues were accounted for in the design of the BE COOL! lesson series and learning environment.

In the usability study, 37 fourth, fifth, and sixth graders of three different ability levels completed five different inquiry assignments in a digital learning environment (e.g., developing a concept map, working with a simulation, configuring data from the simulation into charts). Children were asked to think aloud while performing their activities in the learning environment. The researcher recorded their actions and choices by means of a predetermined checklist. The results showed that all children, regardless of their level of ability, needed contextualizing information about what was expected in the assignments at hand (i.e., what was the goal of the assignment and how could they use the tools and information resources provided). The ease with which they could then work with the inquiry assignments differed between ability levels, and did not differ for the different ages. High-ability children needed less support than the lower-ability children. When high-ability children did request support, they were satisfied with more abstract prompts than the lower-ability 
children, who preferred and needed more concrete instructions to be able to handle the inquiry assignments at hand.

\section{Differentiation in homogeneous expert phase (Chapter 3)}

The results of the usability study were used to shape the support that was offered in the study that is reported in Chapter 3. A digital inquiry assignment (i.e., a simulation) was provided with support by means of prompts that children could access when they needed them to answer the different research questions. The prompts were constructed in ascending order with respect to their level of concreteness: from abstract prompts that provided children with information that should trigger their prior knowledge, recognition, and understanding of the relevant topic area to concrete suggestions of simulation runs that children could perform to find the answers to the research questions. The buildup in the prompts was created intentionally, so as to avoid demotivation of the high-ability children by over-structuring the assignment and to avoid demotivation of the lower-ability children by challenging them too much. The results showed that using the prompts affected all children's inquiry process. However, mainly high-ability children used the prompts. These results gave insight into how to support high-ability children, and made clear that the average-ability and low-ability children would need more explicit instruction. A more detailed description of this study is reported in Chapter 3.

\section{Using findings to design assignments}

Findings from the previous studies were used to design an initial set of assignments for the homogeneous expert phase. The domain of the lesson series, designing a moon house, led to four topics: 'Light \& Heat', 'Oxygen', 'Water', and 'Nutrition'. These four topics were considered equally important in the survival chances of people on the moon. The assignments and the accompanying structure and support within the topics were matched to ability level by means of the information collected thus far. These results led to a different structure of the assignments for the different ability levels. High-ability children showed that they would profit from start-up information and were then able to shape their inquiry process themselves, whereas average- and lowability children needed more guidance in following the inquiry steps. This resulted in inquiry assignments for the high-ability children in which they were given the needed resources but were to study these resources themselves. Average-ability and lowability children were provided with more information on the different steps, how to complete the steps, and the connection between the steps. Low-ability children were given more extensive information than the average-ability children. 
At the same time, the assignments for the heterogeneous prior knowledge phase were developed. Special attention was also paid to the learning situation in the first lesson of the heterogeneous design phase: children were to share the (most important) information on their topics with their group members. Both the literature and the needs analysis made clear that this process needs to be thoroughly supported. Support, in the form of a worksheet, was designed to structure this first lesson. The worksheet focused on two elements: 1) strengthening the role division that had already been outlined by the jigsaw method, and 2) creating a focus on domain-related interaction within the cooperation.

\section{Pilot study: First check of the BE COOL! lesson series}

A large-scale pilot study with 155 fourth, fifth, and sixth graders from six different schools in the Netherlands was conducted. The pilot tried out the assignments for the heterogeneous prior knowledge phase and the homogeneous expert phase, tested an initial version of the assignment and support designed for the first lesson of the heterogeneous design phase, and tested the concrete design lessons that followed in the heterogeneous cooperative design phase. The assignments were investigated at three levels: 1) observations and evaluations by the researcher, 2) evaluations by teachers, and 3) evaluations by children.

The observations and evaluations by teachers and children showed that children did not have enough time to finish all assignments of the homogeneous expert phase within the set time of three two-hour lessons. This seemed to be because of a lack of planning skills and the high number of assignments in this phase. Teachers reported that the average-ability and low-ability children needed more structure in the assignments, especially concerning when and how to use the resources.

These results led to a number of changes in the lesson series. The number of assignments in the homogeneous expert phase was reduced. In addition, a change was made in the presentation of the assignments: in the previous version, children decided the order of completing the assignments themselves, while in the new version assignments were presented as sets of assignments for the three different weeks (see Figure 2.5 for an example of the assignments from 'Light \& Heat' for the high-ability children). Furthermore, the assignments for the average-ability and low-ability children (i.e., 'Oxygen', 'Water', and 'Nutrition') were provided with more structure. This was reflected in more explanation about what the next step in the procedure would be. Assignments were divided into different, explicit parts by means of the inquiry cycle so that children were guided through the assignments. For the low- 
ability children, each step was provided with separate and concrete sub-assignments that allowed them to complete the assignment 'one step at a time', without the necessity to think ahead several steps. To make sure that these children completed the different sub-assignments in the overall context of the inquiry cycle, short texts were added that explained the purpose of each step for completing the entire inquiry assignment.

The worksheet that structured the information sharing as start of the heterogeneous design phase seemed to achieve its goal: children were able to work with the different steps on the worksheet, and an initial comparison with groups that did not use the worksheet showed that there was a more equal distribution of the contributions to the cooperative process in the worksheet groups. However, the second step of the worksheet was not self-evident. It was not always clear to the children what the step involved, leading to a situation in which children did not always follow the predefined path. Therefore, an updated version of the worksheet was integrated into the BE COOL! lesson series, which included new and more extensive explanation of the second step. The improved version of the worksheet was tested in the study described in Chapter 4.

Children also completed a pretest and posttest on their knowledge of their topic and the topics of the others in their group. The concepts that represented the content of the topics were derived from the concepts that were central to the core assignments of the topics. Children's answers on the tests were scored to check that the tests were able to measure a possible gain in knowledge. Some questions were pointed out by the children as 'difficult' mainly as a result of the language used in the questions. These questions were adjusted so that difficult terms and sentences better matched children's level of understanding.

\section{Support for the heterogeneous design phase (Chapter 4)}

This study was conducted in the context of the entire BE COOL! lesson series. This gave the opportunity to gain insight into the suitability of the assignments in the homogeneous expert phase. The changes that were made in response to the results of the previous pilot study seemed to have paid off: children were able to finish the set of assignments that were part of their assigned topic, and were better able to work with the structure of the assignments.

The main aim of this study was to gain insight into the effect of the worksheet on the first lesson of the heterogeneous design phase (i.e., the information-sharing lesson). A 
comparison was made between groups that worked with the worksheet and groups that worked without the worksheet, so that the added value of the worksheet as a measure of support could be determined. Results showed that the group dialogues benefited from working with the worksheet: domain-related participation by the group members was more equally distributed, supported groups spent more of their dialogue on discussing domain-related information, and a larger proportion of their dialogue was task-oriented in comparison to the dialogue in groups that worked without the worksheet. A more detailed description of this study is provided in Chapter 4 .

The results of this study yielded new, but minor, issues to which attention should be paid, in both the lesson series and the learning environment. These issues mainly concerned minor ambiguities in the purpose of the assignments, formulation of assignments, bugs in the learning environment, or language difficulties in the domain knowledge tests. Before starting the final and large-scale evaluation study (Chapter 5), time was spent on addressing these issues.

\section{Large-scale evaluation study (Chapter 5)}

The main aim of this final study was to investigate whether the final version of the BE COOL! lesson series, that encouraged social interaction between children of different ability levels, would improve, or at least maintain, children's cognitive development. A comparison was made to a condition in which children worked on the same learning goals by means of more traditional, individual assignments. Results showed that working with the BE COOL! lesson series showed equal cognitive benefits as more traditional, individual learning. 



\section{Chapter 3}

\section{Ability-related differences in performance of an inquiry task ${ }^{*}$}

* This chapter is based on:

van Dijk, A.M., Eysink, T.H.S, \& de Jong, T. (2016). Ability-related differences in performance of an inquiry task: The added value of prompts. Learning and Individual Differences, 47, 145-155. doi:10.1016/j.lindif.2016.01.008 



\begin{abstract}
This study investigated how children of different ability levels approached inquiry tasks, whether prompting improved their inquiry process and influenced children's levels of motivation, and whether children's inquiry process led to domain knowledge gain. Fifth and sixth graders $(n=478)$ of three different ability levels worked individually with a simulation, either with or without included prompts. Prompts appeared to affect children's inquiry process at all three ability levels. This inquiry process, in turn, was related to their learning outcomes. High-ability children, who engaged in more active and effective inquiry than children of lower ability, used the prompts frequently. Average-ability and low-ability children rarely used the prompts. High and average-ability children gained knowledge from pretest to posttest but not from posttest to retention test; low-ability children only gained knowledge from posttest to retention test. Contrary to what might have been expected, prompts did not affect the level of motivation of children.
\end{abstract}




\section{Introduction}

In modern-day elementary education emphasis is increasingly placed on teaching 21st century skills. In the context of the upcoming knowledge society, children should no longer be educated to become passive knowledge-consumers but should actively discover and integrate new knowledge. A well-known instructional approach that enables children to actively gather and process new knowledge is the inquiry method (Alfieri, Brooks, Aldrich, $\&$ Tenenbaum, 2011). Even though research has been done to sketch an optimal inquiry process, little is known about differences in inquiry approaches and the effects of inquiryspecific support for children of different ability levels. Optimizing the inquiry learning method for children of different ability levels requires more insight into these differences. The aim of this study was to explore the inquiry approaches of children of different ability levels, whether and how children integrated support that was offered to them into their learning process, and whether children's inquiry approaches affected their learning outcomes and motivation.

\section{Inquiry learning}

Recent studies have shown that inquiry learning, if well-designed, can lead to better results than learning by more direct forms of instruction (see, for example, Eysink \& de Jong, 2012; Furtak, Seidel, Iverson, \& Briggs, 2012; Smetana \& Bell, 2012). This applies to a variety of domains, but inquiry is especially effective for learning in science domains (Arnold, Kremer, \& Mayer, 2014). These benefits can mainly be attributed to the fact that in inquiry learning students are expected to actively collect information, process information, and construct knowledge (Alfieri et al., 2011; Mayer, 2003, 2004; Minner, Levy, \& Century, 2010). This active engagement in the learning process enhances students' development of knowledge and skills (Manlove, Lazonder, \& de Jong, 2006).

When engaging in inquiry, students are expected to learn actively by completing a set of different activities (de Jong, 2006; de Jong \& van Joolingen, 1998). The inquiry process often starts with orientation to the domain, which leads to generation of hypotheses concerning the domain. To test the hypotheses, experiments are designed and conducted, after which conclusions are drawn from the experimental outcomes. As a wrap-up activity, the inquiry outcomes and procedure are evaluated (Pedaste et al., 2015). Students are often given considerable freedom in working through these different activities (Mayer, 2004), allowing them to determine their own learning process and learning pace (Minner et al., 2010). The downside of this freedom is that students then experience difficulties with inquiry learning (Mayer, 2004). This is why it has repeatedly been stated that inquiry learning is only effective when it is adequately guided (Alfieri et al., 2011; d'Angelo et al., 2014; Mayer, 2004). 
Difficulties students experience with carrying out the different inquiry activities and how to support them in these activities have been addressed in a considerable body of research (e.g., Alfieri et al., 2011; de Jong, 2006; de Jong \& van Joolingen, 1998; Rutten, van Joolingen, \& van der Veen, 2012). Students are often unsuccessful in generating hypotheses (Gijlers \& de Jong, 2009; Njoo \& de Jong, 1993), experience difficulties with conducting experiments that go beyond their initial understanding of the variables within a domain (Klahr \& Dunbar, 1993), and find it difficult to draw the right conclusions from the collected data (Klahr \& Dunbar, 1988). For younger children, problems with inquiry learning activities are often attributable to difficulties they experience with identifying relevant variables within an inquiry task (Zimmerman, 2007). Identification of these variables is a prerequisite for conducting the right set of experiments to answer a research question, or even for formulating an appropriate research question in the first place.

\section{Differences between ability levels}

Children of different ability levels are expected to differ in how they approach an inquiry task, because they vary in how skillful they are at relating new information to their existing knowledge and determining its relevance and meaning (Wang, Kinzie, McGuire, \& Pan, 2010). More specifically, within the context of inquiry learning children are expected to vary in skillfulness at drawing accurate conclusions from experimentation and integrating this knowledge into their existing knowledge schemas (Zimmerman, 2007).

In general, it is assumed that high-ability students are skilled at independently figuring out how to solve a problem or complete a task (Diezmann \& Watters, 1997; vanTassel-Baska, 2003). They prefer a challenging learning process (Phillips \& Lindsay, 2006; Reis \& Renzulli, 2010), and favor learning tasks that involve complexity and the possibility of engaging in open-ended discovery (Diezmann \& Watters, 1997; vanTassel-Baska, 2003). Challenging and complex tasks align with high-ability students' advanced knowledge schemas (Kalyuga, Ayres, Chandler, \& Sweller, 2003). In fact, providing high-ability students with tasks and support that are too explicit could even be counterproductive. In contrast, low-ability students tend to experience more difficulties with navigating through learning tasks than high-ability students (Alexander \& Schwanenflugel, 1996; Margolis \& McCabe, 2003), and most studies conclude that low-ability students need more structured tasks to engage in successful learning (e.g., Lou et al., 1996; Wang et al., 2010). Therefore, positive effects of instruction and support seen for children with lower levels of ability might disappear for children with higher levels of ability, as the level of redundancy of the instructional materials might be too high (cf., expertise reversal effect; Kalyuga, 2007; Kalyuga et al., 2003). 
Advocates of differentiated instruction maintain that instruction and support should match children's ability level and their specific learning needs (e.g., Tomlinson, 2000; Vygotsky, 1986; Weinert \& Helmke, 1998). This should then lead to an efficient learning process with effective learning outcomes (i.e., aptitude-treatment interaction; Cronbach \& Snow, 1977), and lead to high motivational levels when working on learning tasks (Lens \& Rand, 2000; Margolis \& McCabe, 2003). Within the context of inquiry learning, this means that averageability and low-ability students, in particular, need support to engage in effective inquiry learning (Lou et al., 1996; Wang et al., 2010). When they are challenged too much and have to face the learning task and its difficulties on their own, they can become discouraged, demotivated, and even become frustrated (Margolis \& McCabe, 2003). High-ability students, however, might be able to carry out successful inquiry without much or any additional support, as they prefer challenging, complex, and open-ended learning tasks (Diezmann \& Watters, 1997; vanTassel-Baska, 2003). Challenging and complex tasks are an important motivator for high-ability (Lens \& Rand, 2000). Providing these students with too much support might decrease their levels of motivation when working on these tasks. Recent research has shown that these children could also benefit from support (Eysink, Gersen, \& Gijlers, 2015), but that additional studies should be done to look into the type of support that fits the needs of these children best.

\section{Differentiated support}

A suitable type of support that capitalizes on differences between children could be prompts. First, prompting is a form of support that incorporates autonomous learning (Davis \& Linn, 2000). When available upon request, prompts function merely as stepping stones and do not necessarily intrude upon children's inquiry process. Consequently, highability children should profit from prompts, which still leave them enough freedom to determine their own learning process (Diezmann \& Watters, 1997; vanTassel-Baska, 2003). For the same reason, high-ability children's motivation should not be negatively affected by offering prompts during their inquiry process (Lens \& Rand, 2000). Lower ability children would also benefit from prompts, as the prompts provide them with direct assistance when needed (Margolis \& McCabe, 2003) and guide them through difficulties they often experience with their inquiry process. Consequently, the guidance offered by prompts should positively influence lower ability children's level of motivation (Margolis \& McCabe, 2003).

Second, prompts have proven to be effective in explaining scientific domains and underlying principles (Davis \& Linn, 2000), and can provide students with proper guidance during formulation and conducting of experiments (Zacharia et al., 2015). As 
stated above, most difficulties that younger children experience with inquiry learning are related to their inability to identify relevant variables within a domain (Zimmerman, 2007).

\section{This study}

The literature indicated that children's learning processes and their need for support in general are ability dependent. However, specific differences between children of different ability levels in their learning approach have not yet been investigated in the context of inquiry learning. Studies on inquiry learning show that support is needed for inquiry learning processes to be effective, without making a distinction between children of different ability levels (Alfieri et al., 2011; d'Angelo et al., 2014; Mayer, 2004). This discrepancy gives us reason to further explore differences in children's inquiry processes and the role of support for different ability levels. Consequently, we explored high, average, and low-ability children's inquiry approaches in conditions with and without support to structure their inquiry process.

With regard to children's inquiry learning process, two main issues were central to this study. First, the abovementioned literature provides clear indications that children of different ability levels differ on how they address problem-solving tasks. This gave us reason to believe that these differences would also manifest themselves in children's inquiry approaches. The current study was designed to give more insight into how these differences express themselves in the experimental activities children of different ability levels undertake, such as performance of unique experiments, and the correctness of their conclusions.

Second, literature related to children's use of support during their learning process is more ambiguous. Even less information is available on children's tendency to use support in the context of inquiry learning. On the assumption that problems young children experience with inquiry are mainly attributable to identification of relevant variables (Zimmerman, 2007), prompts were offered to help children identify the relevant variables within the domain. A major issue we wanted to explore was high-ability children's inclination to use the prompts during their inquiry approach. High-ability children might, on the one hand, consider the prompts redundant and disruptive to their learning process (cf., expertise reversal effect; Kalyuga, 2007); they might therefore be inclined not to use the prompts during the inquiry tasks. On the other hand, as all children need to be supported for their inquiry process to be effective (Mayer, 2004), and prompts are considered a way of support that allows children to act autonomously (Davis \& Linn, 2000), high-ability children might feel they could benefit from the prompts and therefore use them to structure their inquiry process. High-ability children's level of motivation is likely to coincide with this. In the 
event they consider the prompts as beneficial, this might enhance their level of motivation. When the prompts are considered disruptive to their learning process, level of motivation might be reduced. Another issue we wanted to gain insight into was average-ability and low-ability children's use of prompts. We tried to gain insight into the suitability of prompts to support these children's inquiry process. To check for prompts as a suitable type of support in the context of inquiry learning, children's use of the prompts, whether their use of the prompts positively influenced their inquiry approach, and their level of motivation were explored.

In order to see the effect of inquiry approach on learning, we additionally explored children's gain in domain knowledge. For inquiry learning to be effective, children should be able to conduct the different inquiry activities correctly (de Jong, 2006; Mayer, 2004). Assuming differences in inquiry approaches between children of different ability levels, differences in domain knowledge between these children might occur. As we had reason to believe that the prompts would positively influence children's inquiry approaches, we investigated differences in domain knowledge between children who received the prompts and children who did not receive the prompts. To gain more insight into coherence between children's inquiry approach and their outcomes, relations between children's inquiry activities and their domain knowledge gain were also examined.

\section{Method}

\section{Participants}

The sample consisted of 478 fifth and sixth graders (222 boys, 256 girls; $M_{\text {age }}=11.3$ years, $S D=.72$, ranging from 9 to 13 years) attending seven different elementary schools located in a mid-sized city in the Netherlands. Children participated in this study as an extracurricular activity during school hours. They were categorized according to their ability level (high-ability, average-ability, and low-ability). Categorization was based on scores from the Dutch student monitoring system (CITO, 2012), a standardized scoring system that defines children's level of ability. CITO takes into account both earlier performance by the individual child and the child's position relative to his or her age group. On the basis of these data, CITO generates a learning profile for every student indicating their learning abilities. The scoring system presents scores as Roman numerals on a continuum, varying from ' $\mathrm{I}$ ' (highest scoring children) to ' $\mathrm{V}$ ' (lowest scoring children). For the present study, four subjects were selected that best define children's general learning skills: mathematical skills, spelling skills, reading skills, and reading comprehension. Children were categorized as high-ability when they scored ' $\mathrm{I}$ ' on at least three out of the four subjects $(n=95 ; 20 \%)$ and as low-ability when they scored ' $\mathrm{V}$ ' on at least two out of the four subjects $(n=69 ; 14 \%)$. The remaining children were categorized as 
average-ability children $(n=315 ; 66 \%)$. A team of elementary school teachers were asked to check the categorization method prior to the grouping procedure, so that grouping was in line with teacher's intuitive ability-grouping.

Originally, 533 children were to participate in the study. Two children were excluded beforehand, as their parents did not give active consent for their child to participate in the experiment. Children were randomly assigned to the prompted and unprompted conditions. However, 53 children were later excluded from the sample as they did not complete the pretest, simulation tasks, or the posttest, or due to technical difficulties while working with the simulation. The prompted condition consisted of 249 children (high: 23 boys, 29 girls, $M_{\text {age }}=11.3$ years; average: 77 boys, 85 girls, $M_{\text {age }}=11.3$ years; low: 18 boys, 17

girls, $M_{\text {age }}=11.5$ years), and the unprompted condition included 229 children (high: 19 boys, 24 girls, $M_{\text {age }}=11.3$ years; average: 60 boys, 92 girls, $M_{\text {age }}=11.2$ years; low: 25 boys, 9 girls, $M_{\text {age }}=11.5$ years).

\section{Materials}

The goal of the learning task was to study the effects of gravity and air resistance on how fast objects fall. Children had to comprehend the relations of gravity and air resistance for falling objects. More far-reaching information, such as underlying formulas, was not considered. A simulation was developed that allowed children to drop different items of different weights and shapes (familiar objects, such as an apple, a hammer, a feather, and a piece of paper) in environments with different gravities, that is, on the earth and on the moon (see Figure 3.1). Children could drag the objects to the characters on the earth and the moon. To investigate further the effect of air resistance, children could also vary the presence of an atmosphere (on the earth as well as on the moon). Children could investigate the effects by watching the objects fall, and comparing the time in seconds shown on an indicator that ran while the object was falling (time remained visible till the next simulation).

In order to identify the effects, children could infer patterns by interacting with the simulation. Three tasks were distinguished, covering the following subtopics: 1) the effect of gravity on the speed with which objects fall, 2) the effect of air resistance on the speed with which objects fall (related to the presence of an atmosphere), and 3) the effect of an object's shape on the speed with which it falls (combining the main effects). For each task, children had to answer two research questions, for which they could develop an answer by working with the simulation (see Figure 3.1 for an example of an assignment and the two associated research questions). The simulation was identical in all three tasks. Answers to the questions could be typed in a textbox that was integrated into the learning environment. 


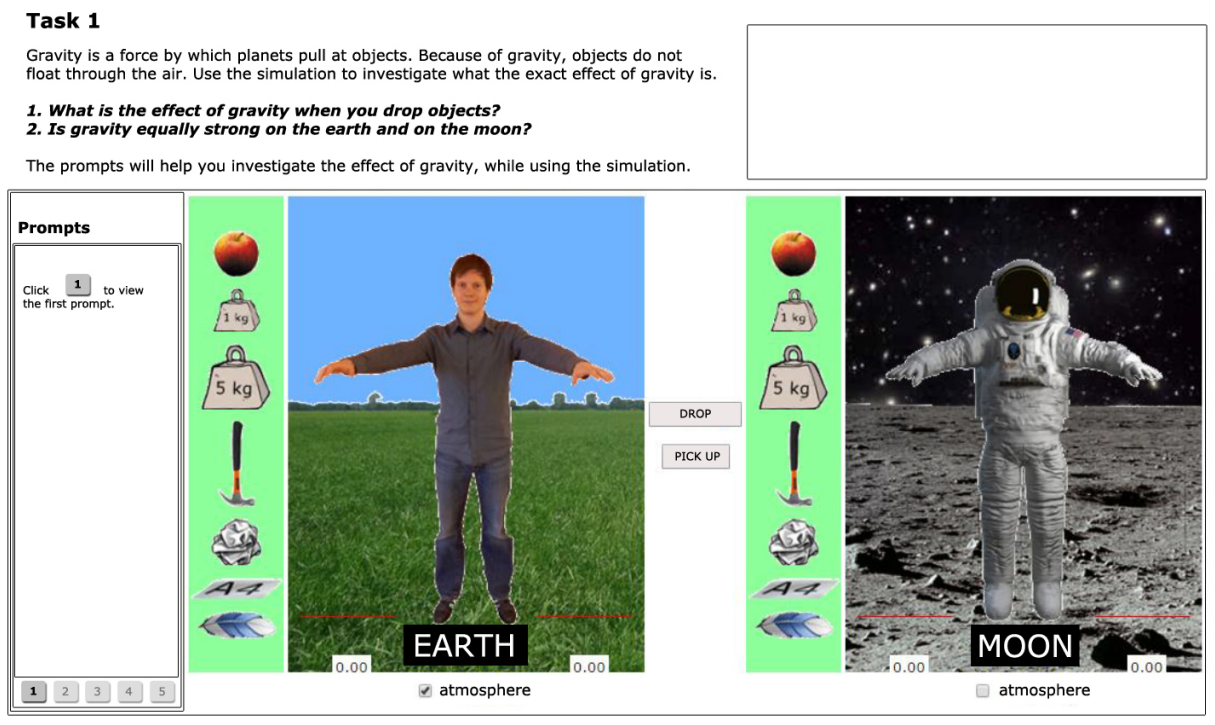

Figure 3.1. First simulation task for the prompted condition [translated from Dutch]

Together with the questions concerning the effect of gravity, air resistance, and shape of objects on the speed of falling objects, children in the prompted condition received a set of five prompts per task to help them infer the requested information from the simulation. These prompts were intended to steer children in the right direction regarding identifying the variables they should include in their experiments. The support given in the prompts progressed from merely trying to activate prior knowledge and promote recognition and understanding of the relevant topic area (e.g., 'An ice skater wears a really tight suit to skate as fast as possible.') to suggesting informative simulation runs to answer the questions under investigation (e.g., 'What differences do you see when you drop a paper ball and a piece of paper on the earth and on the moon?'). In order to proceed to the next task, children had to click on all prompts. Children in the unprompted condition did not receive these prompts.

A pilot study was conducted to test whether the children could work with the inquiry tasks and the prompts, and whether consulting the prompts resulted in useful experiments. Think-aloud protocols and observations indicated that the children could work with the set of five prompts per task. A number of linguistic changes were made to better match the language level to the age group.

\section{Measures}

Domain knowledge. A domain knowledge test was developed containing 16 questions (nine essay questions and seven multiple choice questions with three alternatives each) 
measuring children's knowledge of the effects of gravity, air resistance, and shape of objects when objects fall. The test was designed as a representative test that consisted of four conceptual knowledge questions (de Jong \& Ferguson-Hessler, 1996; two essay, two multiple choice), and twelve questions that covered near and far transfer knowledge (Reed, 1999; seven essay, five multiple choice). The conceptual knowledge questions requested children to name and describe the main concepts of the domain (e.g., 'What causes objects that are thrown in the air to come back to the earth eventually?'). Near transfer questions tested children's knowledge in a context comparable to the simulation (e.g., 'There is a glass tube. The air is removed from the tube. Drop a wooden ball and a feather in the airfree tube. Which object hits the bottom first? Explain your answer.'), and far transfer knowledge was measured in a context different from the simulation (e.g., 'The earth and the moon pull on one another. How is the gravitational force of the moon visible on earth?').

The final version of the domain knowledge test was tested in a pilot study which indicated that the questions were suitable for the target group. Pretest, posttest, and retention test were identical. The domain knowledge test had adequate reliabilities at the pretest, posttest, and retention test, reaching Cronbach's alpha's of $\alpha=.72, \alpha=.71$, and $\alpha=.74$, respectively.

Motivation. Children's motivation was assessed by means of a short questionnaire, consisting of three statements. Motivation was measured as expectation of success and positive valence ('I like the tasks.', 'I will do a good job finishing the tasks.', and 'I know how to do the tasks.'), derived from earlier work by Vollmeyer and Rheinberg (2000). Children could indicate their opinion using a five point Likert scale, ranging from 'I totally disagree' to 'I totally agree'.

The motivation questionnaire was administered three times, in two different versions. A version in future tense was used after they received explanation of the tasks at hand but before starting on the simulation tasks, and after they completed the first simulation task. The version administered after all three simulation tasks had been completed was written in past tense. The motivation questionnaire reached adequate reliabilities for all three testing time points. Cronbach's alpha was $\alpha=.64, \alpha=.73$ and $\alpha=.81$, respectively.

\section{Procedure}

Children began by completing the pretest of domain knowledge. They were given 30 minutes to complete the test. One to four days after they completed the pretest, children took part in the experiment; this session lasted 90 minutes. Children worked individually 
with the simulation. They were given an introduction prior to the simulation by means of a screen recording of the simulation, demonstrating the different features of the simulation. Children were told that they were to follow in the footsteps of Galileo and Neil Armstrong, and perform similar experiments themselves with the simulation. Then, the children filled out the first motivation questionnaire. After this, children worked on the inquiry tasks, for which they were given 45 minutes. Children were instructed to answer all questions, which was checked by the researcher before closing the simulation. After completing the first of the three simulation tasks, children filled out the second motivation questionnaire. Directly after they finished the simulation tasks, children completed the posttest, and filled out the final motivation questionnaire. Children were again given 30 minutes to complete the domain knowledge test. After approximately three or four weeks (18-29 days), the retention test on domain knowledge was administered. They were again given 30 minutes to complete the test.

\section{Data analysis}

Log files. To capture children's activities, their actions in the simulation were logged. The following measures were extracted from the log files to examine children's experimental approach: the number of (unique) simulation runs (i.e., 'unique simulation runs'), and whether or not children conducted experiments with the most informative variables (i.e., 'most informative runs'). In order to extract the latter measure, for every question a unique run or configuration of runs was identified that was most informative for obtaining the information needed to answer the question being addressed (e.g., the question 'Is the gravity equally strong on the earth and the moon?' could be answered by dropping the same object both on the earth and on the moon). For every 'most informative' simulation run or set of runs conducted for the given question, children received 1 point. Accordingly, children could receive a score varying between 0 to 6 points.

For children in the prompted condition, two measures were extracted to examine children's use of support. First, it was determined whether or not children viewed the prompts before answering the questions (i.e., 'viewing prompts'). Children's views score was set at the point when they typed their final answer to the questions in the simulation. The number of prompts viewed by that point was counted for each of the three tasks, and summed accordingly; views score could thus vary from 0 to 15 . Second, it was determined whether or not children conducted the simulation runs suggested in a number of the prompts (i.e., 'using prompts'). Suggestions were given in the third, fourth, and fifth prompts in all three simulation tasks. Children's use score could thus vary from 0 to 9. 
The effectiveness of children's inquiry process was determined by extracting the answers to the questions presented in the three simulation tasks from the log files. These answers were scored to gain insight into the children's understanding of the subtopics covered in the simulation tasks. The answer to each of the six questions was determined to be either correct ( 1 point) or incorrect ( 0 points), on the basis of a previously developed coding scheme. The maximum possible score was 6 points. A second coder scored $10 \%$ of the answers to the questions. Neither coder was aware of condition and ability level of the children when scoring the answers. The inter-rater reliability coefficient reached .74 (Cohen's kappa).

Domain knowledge tests. The essay questions on the domain knowledge test were scored following a coding scheme. Answers to essay questions were rated on presence of essential concept(s), and/or explanations of essential process(es). An overview of the concepts and/or processes that were to be described or explained, and how many points should be granted to these concepts and processes, was drafted for each question. An answer including all concepts and mechanisms received a score of 4 points, and scores per question could vary from 0 to 4 points. A second coder scored the answers on the essay questions for $10 \%$ of the domain knowledge tests. Neither coder was aware of condition and ability level of the children when scoring the answers. The inter-rater reliability coefficient reached .92 (Cohen's kappa).

The multiple-choice questions were treated similarly to the essay questions, since they had similar levels of difficulty, with 4 points given when the answer was correct; an incorrect answer was granted zero points. The maximum score on the test was, therefore, 64 points (16 points for the four conceptual knowledge questions, and 24 points each for the six near transfer knowledge and six far transfer knowledge questions). To account for possible differences in prior knowledge as shown on the pretest, normalized domain knowledge gain scores were calculated. To calculate these scores, children's absolute learning gain (i.e., posttest score minus pretest score, or retention test score minus posttest score) was divided by children's possibility for learning gain (i.e., maximum score minus the score on the pretest or the posttest, respectively).

Motivation. The motivation questionnaire was administered three times: before the simulation tasks, after the first task, and directly following completion of the three tasks. To create an overview of children's motivational state while working with the simulation tasks, these three measures were combined into one overarching score. Each questionnaire consisted of three items that could be answered using a 5-point Likert scale, ranging from 
low motivation to high motivation. Consequently, children's motivation could be represented as the sum of scores on the three measures, varying between 9 and 45 points.

\section{Results}

The main focus of this study was to gain insight into children's inquiry approaches and their use of prompts during inquiry. We first discuss differences in children's learning processes. Thereafter, to explore whether inquiry approach influenced children's learning outcomes, differences in domain knowledge gain were analyzed. These analyses are followed by correlational measures to determine coherence between children's inquiry approach and their knowledge gain. Finally, differences in level of motivation are discussed to find out whether being prompted affected children's motivation.

\section{Learning process}

To gain insight into children's approach to the inquiry task when working with the simulation, their engagement in different activities was analyzed. Thereafter, children's use of the prompts was examined. First, differences between ability levels were analyzed to indicate whether and how high, average, and low-ability children's inquiry approaches differed with regard to both their inquiry activities and their use of prompts. Second, differences between conditions were assessed for each ability level separately. Children's inquiry approaches were explored in a context in which they were offered prompts to guide their inquiry and a context in which they had to complete the inquiry tasks without prompts. Table 3.1 shows children's mean scores on the measures concerning their viewing and use of the prompts, simulation runs, and scores on the questions for the simulation tasks.

Differences between ability levels - Inquiry activities. Three univariate analyses of variance (ANOVAs) assessed differences between high, average, and low-ability children concerning the total number of unique runs performed, number of 'most informative' runs performed, and their score on the answers to the simulation task questions. The analyses indicated significant differences between ability levels on the mean number of unique simulation runs $\left(F(2,473)=6.27, p=.002, \eta_{\mathrm{p}}{ }^{2}=.03\right)$, the mean number of 'most informative' simulation runs $\left(F(2,473)=9.14, p<.001, \eta_{\mathrm{p}}{ }^{2}=.04\right)$, and the mean score on the answers on the questions of the simulation tasks $\left(F(2,458)=32.87, p<.001, \eta_{\mathrm{p}}{ }^{2}=.13\right)$. Pairwise comparisons using Bonferroni corrections revealed that high-ability children conducted more unique simulation runs in total than average-ability children $(p=.023)$ and lowability children $(p<.001)$, conducted more 'most informative' simulation runs than average-ability children $(p=.003)$ and low-ability children $(p<.001)$, and showed higher scores on the answers for the simulation tasks than average-ability $(p<.001)$ and low- 
ability $(p<.001)$ children. Average-ability children, in turn, demonstrated higher mean scores on the answers for the simulation tasks than low-ability children $(p<.001)$.

Table 3.1

Mean scores for abilities and conditions on measures of approach to the inquiry task

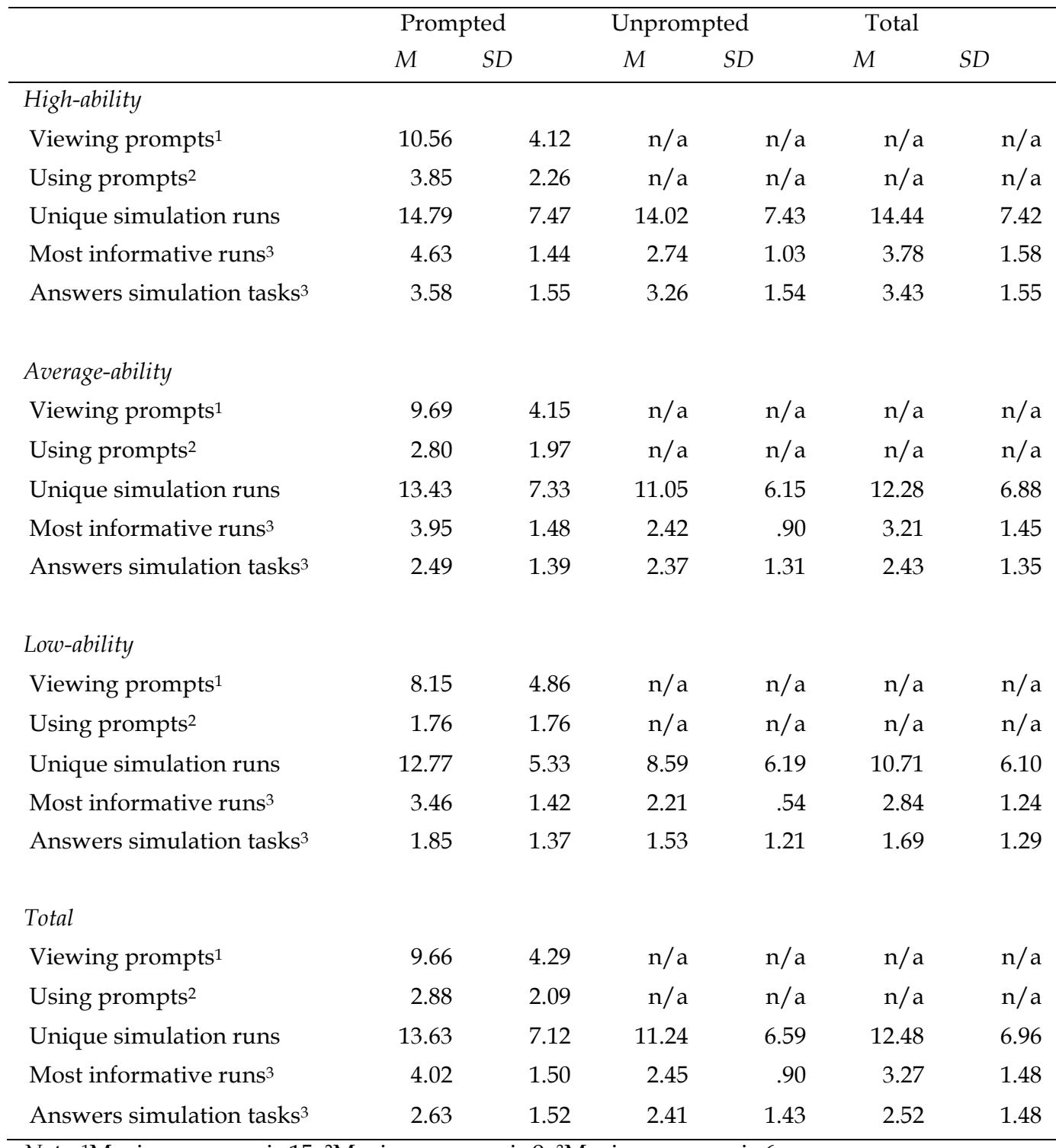

Note. ${ }^{1}$ Maximum score is $15 ;{ }^{2}$ Maximum score is $9 ;{ }^{3}$ Maximum score is 6.

Differences between ability levels - Prompts. Children's viewing of prompts before answering the questions and whether they conducted the simulation runs suggested in the prompts were assessed. Two ANOVAs indicated differences between 
high, average, and low-ability children within the prompted condition. The analyses revealed significant differences between ability levels on the number of prompts children looked at before answering the questions for the three tasks $(F(2,231)=3.21, p$ $\left.=.042, \eta_{\mathrm{p}}^{2}=.03\right)$ and the number of simulation runs children conducted that followed the suggestions in the prompts $\left(F(2,244)=11.43, p<.001, \eta_{\mathrm{p}}^{2}=.09\right)$. Pairwise comparisons using Bonferroni corrections indicated that high-ability children looked at more prompts before answering the questions of the simulation tasks than low-ability children $(p=.036)$, and conducted more of the simulation runs suggested in the prompts than average-ability children $(p=.004)$ and low-ability children $(p<.001)$. Average-ability children, in turn, followed the suggestions in the prompts more often than did the low-ability children $(p=.020)$.

Differences between conditions. Differences between conditions were analyzed by means of multivariate analyses of variance (MANOVAs) within ability levels and involved the total number of unique runs performed, number of 'most informative' runs performed, and score on the answers to the simulation task questions. Using Wilks' statistic, the MANOVA for high-ability children revealed a significant difference between conditions $(\Lambda=.61, F(3,89)=$ 19.36, $\left.p<.001, \eta_{\mathrm{p}}^{2}=.40\right)$. Subsequent ANOVAs indicated that high-ability children who received prompts conducted more 'most informative' simulation runs, on average, than the unprompted high-ability children $\left(F(1,91)=48.89, p<.001, \eta_{\mathrm{p}}{ }^{2}=.35\right)$.

A second MANOVA revealed significant differences between conditions for the averageability children $\left(\Lambda=.71, F(3,297)=40.13, p<.001, \eta_{\mathrm{p}}^{2}=.29\right)$. Subsequent ANOVAs showed that average-ability children who received prompts outperformed the unprompted average-ability children on the mean total number of unique simulation runs conducted $\left(F(1,299)=9.49, p<.001, \eta_{\mathrm{p}}{ }^{2}=.03\right)$ and on mean number of 'most informative' simulation runs $\left(F(1,299)=114.57, p<.001, \eta_{\mathrm{p}}^{2}=.28\right)$.

A third MANOVA indicated significant differences between conditions for the low-ability children $\left(\Lambda=.69, F(3,63)=9.26, p<.001, \eta_{\mathrm{p}}^{2}=.31\right)$. Subsequent ANOVAs revealed that lowability children who received prompts conducted more unique simulation runs in total $\left(F(1,65)=8.28, p=.005, \eta_{\mathrm{p}}{ }^{2}=.11\right)$ and conducted more 'most informative' runs $(F(1,65)=$ $\left.24.62, p<.001, \eta_{\mathrm{p}}{ }^{2}=.28\right)$, on average, than the unprompted low-ability children.

\section{Knowledge gain}

To explore children's domain knowledge gain, ability-related and condition-related differences were assessed. First, differences in normalized domain knowledge gain between ability levels were examined to gain insight into children's potential for growth 
when working with the inquiry tasks at hand, which could be informative regarding learning by children of different ability levels when working with an inquiry task. Second, differences in absolute domain knowledge gain between children who were offered prompts and children who did not receive prompts (i.e., by condition) were assessed for each ability level separately by means of repeated measures analyses. The latter analyses explore the learning outcomes with or without prompts for children at each ability level, taken separately. Table 3.2 shows high-ability, average-ability, and low-ability children's mean domain knowledge test scores on the pretest, posttest, and retention test, and provides an overview of children's normalized domain knowledge gain scores, which were used only for comparisons across ability levels.

Table 3.2

Mean domain knowledge test scores and normalized domain knowledge gain scores

\begin{tabular}{|c|c|c|c|c|c|c|}
\hline & \multicolumn{2}{|c|}{ High-ability } & \multicolumn{2}{|c|}{ Average-ability } & \multicolumn{2}{|c|}{ Low-ability } \\
\hline & $M$ & $S D$ & $M$ & $S D$ & $M$ & $S D$ \\
\hline \multicolumn{7}{|c|}{ Absolute test scores ${ }^{1}$} \\
\hline \multicolumn{7}{|l|}{ Pretest } \\
\hline Prompted & 37.47 & 9.26 & 28.78 & 9.18 & 23.94 & 8.06 \\
\hline Unprompted & 36.63 & 9.35 & 28.46 & 9.25 & 24.57 & 8.82 \\
\hline Total & 37.10 & 9.26 & 28.63 & 9.20 & 24.24 & 8.37 \\
\hline \multicolumn{7}{|l|}{ Posttest } \\
\hline Prompted & 39.51 & 9.88 & 30.44 & 9.05 & 24.75 & 8.65 \\
\hline Unprompted & 38.77 & 10.20 & 30.71 & 8.64 & 25.50 & 8.45 \\
\hline Total & 38.19 & 9.98 & 30.57 & 8.84 & 25.11 & 8.49 \\
\hline \multicolumn{7}{|l|}{ Retention test } \\
\hline Prompted & 40.94 & 9.89 & 31.09 & 9.08 & 25.72 & 8.40 \\
\hline Unprompted & 39.42 & 9.28 & 30.90 & 9.63 & 27.90 & 8.29 \\
\hline Total & 40.27 & 9.61 & 31.00 & 9.34 & 26.77 & 8.35 \\
\hline \multicolumn{7}{|c|}{ Normalized domain knowledge gain } \\
\hline Pre - Post & .18 & .34 & .15 & .32 & .09 & .37 \\
\hline Post - Retention & .09 & .28 & .03 & .32 & .08 & .34 \\
\hline
\end{tabular}

Note. ${ }^{1}$ Maximum score $=64$.

Differences between ability levels. To assess possible differences in prior knowledge, an ANOVA was conducted. This ANOVA showed that children of different ability levels indeed differed in domain knowledge on the pretest $\left(F(2,475)=43.07, p<.001, \eta_{\mathrm{p}}^{2}=.15\right)$. Pairwise comparisons using Bonferroni corrections indicated that high-ability children showed higher prior domain knowledge than average-ability $(p<.001)$ and low-ability 
children $(p<.001)$. Average-ability children, in turn, had a higher prior domain knowledge than low-ability children $(p<.001)$. Differences between conditions and the interaction (Ability level $x$ Condition) were not significant. To take into account these differences in prior knowledge, normalized domain knowledge gain scores were calculated (i.e., absolute learning gain (posttest score minus pretest score, or retention test score minus posttest score) was divided by children's possibility for learning gain (i.e., maximum score minus the score on the pretest or the posttest, respectively)). To determine whether high-ability, averageability, and low-ability children showed comparable normalized domain knowledge gains from pretest to posttest, an ANOVA was conducted. This ANOVA indicated significant differences between children of different ability levels $\left(F(2,475)=5.26, p=.005, \eta_{\mathrm{p}}{ }^{2}=.02\right)$. Subsequent pairwise comparisons using Bonferroni corrections revealed that high-ability children showed a higher mean normalized learning gain from pretest to posttest than average-ability $(p=.045)$ and low-ability children $(p=.005)$. Mean normalized learning gain did not differ significantly between average-ability and low-ability children $(p=.334)$.

A comparable ANOVA was conducted to determine children's relative learning gain from posttest to retention test. The analysis revealed significant differences between ability levels $\left(F(2,450)=3.30, p=.038, \eta_{\mathrm{p}}{ }^{2}=.01\right)$. Subsequent pairwise comparisons using Bonferroni corrections revealed that high-ability children showed a higher mean normalized learning gain from posttest to retention test than average-ability children $(p=.032)$. Other comparisons were not significant.

Differences between conditions. High-ability children's domain knowledge gain and possible differences between conditions were investigated for the absolute scores on the pretest (Time 1) and the posttest (Time 2) with repeated measures analysis. A significant main effect for the within-subject factor Time $\left(\Lambda=.89, F(1,93)=11.24, p=.001, \eta_{\mathrm{p}}^{2}=.11\right)$ was found, indicating an increase in domain knowledge from pretest to posttest. There was no interaction (Time $\times$ Condition; $\Lambda=1.00, F(1,93)=.00, p=.980, \eta_{\mathrm{p}}^{2}=.00$ ). A similar analysis was conducted to analyze high-ability children's knowledge at posttest (Time 2) and retention test (Time 3). There was no significant effect for the within-subject factor Time $\left(\Lambda=.97, F(1,89)=2.70, p=.104, \eta_{\mathrm{p}}^{2}=.03\right)$, nor was there a significant interaction (Time $\times$ Condition; $\Lambda=.99, F(1,89)=.38, p=.539, \eta_{\mathrm{p}}^{2}=.00$ ).

Average-ability children's domain knowledge at pretest (Time 1) and posttest (Time 2) and possible differences between conditions were similarly analyzed with repeated measures analysis. There was a significant main effect for the within-subject factor Time $(\Lambda=.93, F(1,312)$ $\left.=23.55, p<.001, \eta_{\mathrm{p}}{ }^{2}=.07\right)$, indicating an increase in domain knowledge from pretest to posttest. There was no interaction (Time $x$ Condition; $\Lambda=.99, F(1,312)=.38, p=.537, \eta_{\mathrm{p}}{ }^{2}=.00$ ). Analysis 
of average-ability children's knowledge at posttest (Time 2) and retention test (Time 3) showed no significant main effect for Time $\left(\Lambda=.99, F(1,298)=1.06, p=.305, \eta_{p}{ }^{2}=.00\right)$, nor was there a significant interaction (Time $\times$ Condition; $\Lambda=.99, F(1,298)=.32, p=.573, \eta_{\mathrm{p}}{ }^{2}=.00$ ).

Low-ability children's domain knowledge gain and possible differences between conditions were also investigated with repeated measures analysis. From pretest (Time 1) to posttest (Time 2), the main effect for the within-subject factor Time was not significant $(\Lambda=.97, F(1$, $67)=1.85, p=.178, \eta_{\mathrm{p}}^{2}=.03$ ). There was no interaction (Time $\mathrm{x}$ Condition; $\Lambda=1.00, F(1,67)$ $\left.=.00, p=.998, \eta_{\mathrm{p}}^{2}=.00\right)$. Low-ability children showed a significant increase in domain knowledge from posttest (Time 2) to retention test (Time 3), indicated by a main effect for the within-subject factor Time $\left(\Lambda=.91, F(1,60)=5.68, p=.020, \eta_{\mathrm{p}}{ }^{2}=.09\right)$. There was no interaction (Time $x$ Condition; $\Lambda=.98, F(1,60)=1.03, p=.315, \eta_{\mathrm{p}}{ }^{2}=.02$ ).

\section{Relations between process and knowledge gain measures}

To indicate whether the different inquiry activities, as part of children's inquiry approach, were related to effective completion of the inquiry tasks and children's domain knowledge gain, correlational analyses were performed. Separate correlational analyses were conducted for the three ability levels to reveal the relations between viewing and use of the prompts, the total number of unique runs performed, number of 'most informative' runs performed, score on the answers to the simulation task questions, domain knowledge gain from pretest to posttest, and domain knowledge gain from posttest to retention test (see Table 3.3).

High-ability children's capacity to conduct the most informative runs, which was largely related to their viewing and use of the prompts, was positively associated with successful completion of the inquiry tasks. Being able to effectively answer the research questions of the inquiry tasks was positively related to high-ability children's knowledge gain from the pretest to the posttest.

For average-ability children, their level of activity in the inquiry tasks (i.e., the number of simulation runs and of the most informative runs) was positively associated with the effectiveness of the inquiry tasks (i.e., higher scores on the answers to the tasks). Their inquiry process, in turn, was positively influenced by their inspection and use of the prompts. The score that average-ability children obtained on their answers to the research questions for the inquiry tasks was positively related to their knowledge gain from the pretest to the posttest. 
Low-ability children's success on the inquiry tasks (i.e., their score on the answers) was positively related to the total number of simulation runs, and the number of most informative runs performed. However, inspection and use of the prompts were not associated with their ability to answer the research questions of the inquiry tasks correctly. In addition, success on the inquiry tasks did not relate to low-ability children's knowledge gain.

\section{Table 3.3}

Correlations between experimental activities and use of prompts by ability level

\begin{tabular}{|c|c|c|c|c|c|c|c|}
\hline & 1 & 2 & 3 & 4 & 5 & 6 & 7 \\
\hline \multicolumn{8}{|l|}{ High-ability } \\
\hline 1. Unique simulation runs & - & & & & & & \\
\hline 2. Most informative runs & $.306^{* *}$ & - & & & & & \\
\hline 3. Viewing prompts 1 & .196 & $.511 * * *$ & - & & & & \\
\hline 4. Using prompts ${ }^{1}$ & .180 & $.704^{* * *}$ & $.459^{* *}$ & - & & & \\
\hline 5. Answers simulation tasks & .132 & $.345^{* *}$ & $.290^{*}$ & .002 & - & & \\
\hline 6. Knowledge gain pre to post & .075 & .097 & $.319^{*}$ & .153 & $.258^{*}$ & - & \\
\hline 7. Knowledge gain post to retention & .060 & .149 & .129 & .236 & -.112 & $-.481^{* * *}$ & - \\
\hline \multicolumn{8}{|l|}{ Average-ability } \\
\hline 1. Unique simulation runs & - & & & & & & \\
\hline 2. Most informative runs & $.319^{* * *}$ & - & & & & & \\
\hline 3. Viewing prompts ${ }^{1}$ & $.262^{* *}$ & $.363^{* * *}$ & - & & & & \\
\hline 4. Using prompts ${ }^{1}$ & $.260^{* *}$ & $.722^{* * *}$ & $.380^{* * *}$ & - & & & \\
\hline 5. Answers simulation tasks & $.177^{* *}$ & $.282^{* * *}$ & .102 & $.297^{* * *}$ & - & & \\
\hline 6. Knowledge gain pre to post & .093 & .081 & .115 & .063 & $.159 * *$ & - & \\
\hline 7. Knowledge gain post to retention & -.043 & -.036 & -.106 & .012 & -.078 & $-.410^{* * *}$ & - \\
\hline \multicolumn{8}{|l|}{ Low-ability } \\
\hline 1. Unique simulation runs & - & & & & & & \\
\hline 2. Most informative runs & $.304^{*}$ & - & & & & & \\
\hline 3. Viewing prompts ${ }^{1}$ & .205 & $.400^{*}$ & - & & & & \\
\hline 4. Using prompts ${ }^{1}$ & -.013 & $.591^{* * *}$ & .259 & - & & & \\
\hline 5. Answers simulation tasks & $.279^{*}$ & $.259^{*}$ & .050 & .158 & - & & \\
\hline 6. Knowledge gain pre to post & .028 & .127 & .233 & .160 & .001 & - & \\
\hline 7. Knowledge gain post to retention & .093 & -.171 & -.083 & -.040 & .009 & $-.267^{*}$ & - \\
\hline
\end{tabular}

Note. ${ }^{*} p<.05,{ }^{* *} p<.01,{ }^{* * *} p<.001 .{ }^{1}$ Prompted condition only.

\section{Motivation}

Motivational differences between ability levels were assessed to gain insight in the effect of inquiry tasks on high, average, and low-ability children's motivation. To explore whether being prompted affected high, average, and low-ability children's level of motivation during working with the inquiry tasks, differences between conditions were investigated 
for each ability level separately. Table 3.4 shows high-ability, average-ability, and lowability children's motivation scores.

Table 3.4

Mean motivation scores by ability level

\begin{tabular}{lllllll}
\hline & \multicolumn{2}{c}{ Prompted } & \multicolumn{2}{c}{ Unprompted } & \multicolumn{2}{c}{ Total } \\
\cline { 2 - 7 } & $M$ & $S D$ & $M$ & $S D$ & $M$ & $S D$ \\
\hline High-ability & 36.84 & 6.01 & 37.09 & 6.01 & 36.96 & 5.98 \\
Average-ability & 34.23 & 6.96 & 35.13 & 5.91 & 34.67 & 6.48 \\
Low-ability & 35.40 & 6.31 & 35.26 & 6.20 & 35.33 & 6.21 \\
\hline
\end{tabular}

Note. Maximum score $=45$.

Differences between ability levels. An ANOVA was conducted to identify differences between children of different ability levels regarding their motivation while working with the inquiry tasks. Differences between ability levels were significant $(F(2,468)=4.71, p=$ $\left..009, \eta_{\mathrm{p}}^{2}=.02\right)$. Subsequent pairwise comparisons using Bonferroni corrections showed that high-ability children were more highly motivated than average-ability children $(p=.007)$. Other comparisons were not significant.

Differences between conditions. Motivation was assessed for every ability level separately by means of three ANOVAs. The analyses showed no significant difference between conditions for high-ability children $\left(F(1,92)=.04, p=.841, \eta_{\mathrm{p}}^{2}=.00\right)$, average-ability children $\left(F(1,306)=1.51, p=.221, \eta_{\mathrm{p}}^{2}=.01\right)$, and low-ability children $(F(1,67)=.01, p=.929$, $\left.\eta_{\mathrm{p}}^{2}=.00\right)$.

\section{Discussion}

Ability level is generally considered to play a crucial role in children's potential to learn. This study explored whether and how children of different ability levels varied in the way they approached an inquiry task, whether and how support played an additional role in their inquiry process, whether this affected learning outcomes, and if children's motivation was influenced by the presence of prompts.

\section{Learning process}

Based on the literature on general differences in children's learning skills and preferences, high-ability, average-ability, and low-ability children were expected to show different inquiry approaches. High-ability children should know their way around the inquiry tasks at hand as their learning skills seem to match the required skills to engage in inquiry 
learning best (e.g., Diezmann \& Watters, 1997; vanTassel-Baska, 2003). Average-ability and low-ability children should experience more difficulties navigating through the inquiry tasks and need more support to complete the inquiry activities (Alexander \& Schwanenflugel, 1996; Margolis \& McCabe, 2003). Results of the present study suggest that high-ability children indeed showed a more effective learning process than did the average-ability and low-ability children. Even though knowledge gains were small, highability children showed a more effective inquiry process, as they outperformed the others on responding correctly to the research questions accompanying the simulation tasks, and learned relatively more than the average-ability and low-ability children, as shown on the knowledge tests. With regard to the efficiency of their inquiry process, results are more ambiguous as high-ability children performed more simulation runs than the other children. One might have expected that these children would need fewer simulation runs to solve the problems, as these children's problem-solving skills would have made it easier for them to navigate through the tasks at hand (Diezmann \& Watters, 1997; vanTasselBaska, 2003). However, this result might also be due to differences in prior knowledge between the different ability levels. High-ability children's prior knowledge was indeed higher than that of the average-ability and low-ability children. Lazonder, Wilhelm, and Hagemans (2008) showed that prior knowledge affects strategy use in the experimentation phase, such that children who start an inquiry task with some domain knowledge are more likely to adopt a theory-driven approach than children with lower levels of prior knowledge. This theory-driven approach comes with a high number of predictions or conjectures, which are then tested by conducting a relatively low number of carefully planned experiments. The present results point to interpretations within this line of reasoning. For example, it could be that high-ability children had far more ideas to investigate than average-ability and low-ability children, and hence conducted more experiments. It could have increased their ability to 'search the experiment space for a combination of experiments' to answer the research question (as described in the SDDS model; Klahr \& Dunbar, 1988). High-ability children's motivational level, which showed to be higher than that of the average-ability children, might corroborate this line of reasoning. On the one hand, a higher level of motivation might have resulted in a higher task orientation, and, hence, in more simulation runs to complete the task successfully. On the other hand, being able to navigate through the tasks without experiencing difficulty might have positively affected children's level of motivation. However, the correlational analysis showed no relation between the number of experiments performed and the score on the answers on the questions of the inquiry tasks for the high-ability children. Future research could be done to gain more insight into the role of prior knowledge in children's experimentation activities. 
Considering high-ability children's preference for open and challenging learning tasks that are minimally supported (Diezmann \& Watters, 1997; Phillips \& Lindsay, 2006; Reis \& Renzulli, 2010; vanTassel-Baska, 2003) and lower ability children's explicit need for support during challenging tasks (Lou et al., 1996; Wang et al., 2010), one could have expected to see a difference in the use of prompts during the inquiry tasks. High-ability children inspected and used the prompts more often during their learning process than the averageability and low-ability children. On the one hand, this result might be surprising as children who need support most used the prompts the least. On the other hand, this result might indicate that the prompts that presented children with further assistance during the experimental phase might have been a better addition to high-ability children's existing knowledge of the domain than they were for the average-ability and low-ability children. High-ability children were consequently perhaps better able to grasp the content of the prompts, which allowed them to follow the line of reasoning presented.

High-ability children's motivational levels were not affected by offering prompts during the inquiry tasks. This result, together with the finding that high-ability children viewed and used the prompts more during their inquiry process than the other children, suggests that these children did not feel hindered by the support offered during the simulation tasks. In fact, their experimental activity became more efficient when using the prompts; they conducted 'most informative' simulation runs more often in the prompted condition than in the unprompted condition. Since high-ability children seem to have benefited from prompts during their inquiry process, it might be interesting to look into the effects on their inquiry process when offered other forms of support, and how much support needs to be given in order to reach the optimal learning process (see also Tomlinson, 2000).

A different pattern emerged for the other ability groups. Both average-ability and lowability children were expected to need support to engage in effective inquiry (Lou et al., 1996; Wang et al., 2010) and prompts are often recommended as a good way to offer support during inquiry learning (Arnold et al., 2014; Zacharia et al., 2015). However, the average-ability and low-ability children made minimal use of the prompts. An interesting issue here is to gain insight into why the results show that these children responded oppositely to what might have been expected. First, average-ability and low-ability children's relatively low level of experimental activity (i.e., viewing and use of prompts, and number of simulation runs) might have been a result of their low prior knowledge. This might have influenced their ability to identify and conduct appropriate experiments during the inquiry tasks (Lazonder et al., 2008). A recent study by Roll, Briseno, Yee, and Welsh (2014) revealed that scaffolding online simulation tasks was beneficial for children with high prior knowledge, and did not benefit children with lower levels of prior knowledge. 
Second, the content and implementation of the prompts might have influenced children's capacity and inclination to use the prompts during their inquiry process. The prompts were offered in progressive levels of concreteness, meaning that the first prompts that focused on activating children's prior knowledge and understanding of the domain might have been too abstract for them to convert the information into experimental activities. When the lower ability children were confronted with these first prompts, they might have been discouraged from consulting the other prompts, since they did not feel that these prompts could help them with completing the inquiry tasks.

An alternative, third explanation could be that the lower ability children might not have been aware of their poor ability to answer the simulation task questions, and therefore did not seek the assistance of the prompts in order to do so. Research shows that the discrepancy between children's (prior) domain knowledge and confidence as to how they will perform on certain tasks tends to be very large (de Bruin \& van Gog, 2012), which might lead these children to fail to realize that they are not able to complete the task without support and, therefore, not to seek assistance (Ferguson-Hessler \& de Jong, 1990). These findings might also explain the result that average-ability and low-ability children's motivation, similar to the high-ability children, did not differ between conditions.

Prompted children showed a more active and effective inquiry process than their unprompted counterparts. When the children incorporated the prompts in their inquiry process, they generally showed a more effective inquiry process, although an effect of prompting on low-ability children's inquiry process was not found. Since working with the inquiry tasks seemed to have lacked effectiveness for the low-ability children, even when prompted during these tasks, further investigation is called for regarding how these children should be supported so that they could benefit from inquiry learning activities. In this study, the prompts could be considered an additional challenge for the average-ability and low-ability children and might therefore have failed to achieve their objectives. Prompts should perhaps be more prominent and mandatory, or should be offered according to the 'just-in-time' principle (Berry \& Broadbent, 1987; Hulshof \& de Jong, 2006). To make sure that support becomes actually supportive instead of an additional challenge for these children, future studies should look into other forms of support that are better suited in terms of concreteness of the information offered, and into the implementation of these forms of support.

\section{Domain knowledge}

With differences in children's approach to the inquiry tasks in mind, it could be expected that high-ability children would also show the largest domain knowledge gain. The results confirmed this expectation, showing that, even though differences were quite small, high- 
ability children indeed showed a higher normalized learning gain than average-ability and low-ability children. The size of high-ability children's learning gain did not differ between conditions. However, at the same time the results showed that high-ability children's experimental activities became more efficient when consulting the prompts, leading to more effective performance on the inquiry tasks.

Average-ability children showed a small but significant knowledge gain from pretest to posttest as well. Contrary to what might have been expected, whether they received support did not make a difference. Low-ability children did not seem to profit in the short term from working with the simulation, as they did not show a significant knowledge gain from pretest to posttest in either the prompted or the unprompted condition. Overall, even though the analyses showed that prompted children had a more active and effective inquiry process than their unprompted counterparts, this did not lead to higher knowledge gain for the children in the prompted condition.

The low-ability children were the only ones whose scores increased significantly from the posttest to the retention test, although this gain did not exceed high and average-ability children's score on the retention test. This finding is rather peculiar, since the children were not exposed to the learning material in the weeks between posttest and retention test. A possible, highly speculative explanation could be that these children required more time than the other children to grasp the meaning of the different concepts of the domain. When confronted with the same concepts for the third time, responding to the retention test, they might have been better able to integrate their new knowledge into their answers on the questions. Research into the incubation effect might corroborate this assumption. An incubation period might enhance children's ability to solve problems, as a break from the task might distract them from false and fixed assumptions (i.e., fixation; Segal, 2004; Wiley, 1998). A study into the effects of domain knowledge differences on the incubation effect showed that the effect was observed for children with lower knowledge of the domain (Wiley, 1998). However, although results supporting the incubation effect have increased, discussion continues about the mechanisms that cause the effect (Sio \& Ormerod, 2015). Future research should therefore be done to corroborate a possible incubation effect for low-ability children in the context of inquiry learning.

\section{Conclusions}

The results of this study showed that there were prominent differences in approach to inquiry tasks between children of different ability levels. High-ability children, as expected, showed a more active and effective learning process than average-ability and low-ability children. However, there were surprising findings regarding the role that could be 
attributed to the prompts within children's learning process. Although it is often assumed that high-ability children do not need and may not welcome additional support to engage in an effective and efficient learning process, offering prompts improved their inquiry process. The absence of this effect for average-ability and low-ability children suggests that further research into differentiated support and the suitability of inquiry learning for children of different ability levels is needed. Consequently, in educational practice, teachers should match support to children's ability level when engaging in inquiry learning activities. Special attention should be paid to the fit between the support offered and the children it is intended for, with particular attention to both the type of support that is offered and how it is implemented in the inquiry tasks. 


Chapter 4

Supporting cooperative dialogue in heterogeneous groups 



\begin{abstract}
Learning in heterogeneous cooperative groups is generally seen as a way of learning that is not always without problems. Support should be offered to structure the heterogeneous cooperative process, but research is inconclusive on what this support should look like. In the current study, the effects of a worksheet to structure the heterogeneous cooperative process were investigated. In the worksheet, the elements of Social Interdependence Theory (i.e., individual accountability, social interdependence, promotive interaction, and group evaluation; Johnson, Johnson, \& Smith, 2007) were addressed. Fourth to sixth graders $(n=136)$ worked cooperatively in heterogeneous groups of four $(n=34)$ in the context of the jigsaw method (Aronson et al., 1978), either with or without the worksheet to structure the cooperative process. Results showed that heterogeneous cooperation benefited from support by the worksheet. Group members participated more equally in the domain-related dialogue, a larger proportion of the dialogue was task-oriented, and supported groups spent more of their dialogue on exchanging domain-related explanations in comparison to groups who performed the same task without the worksheet. Overall, children did not show a learning gain on their assigned topic; only low-ability children increased their knowledge level. Future research should explore the possibilities to further structure the cooperative process so that children's learning outcomes could benefit more from the improved heterogeneous group dialogue.
\end{abstract}




\section{Introduction}

Cooperative learning is a popular instructional approach in elementary education (Slavin, 2015). In cooperative learning, children work together to learn from and with each other, being responsible for their own learning process as well as that of their group members (Förrer, Kenter, \& Veenman, 2000; Slavin, 1990). However, children working together in elementary school often fall into unproductive patterns of cooperative interaction, and do not engage in productive activities (Mercer, Wegerif, \& Dawes, 1999). For cooperative learning to be effective, children should focus on the task and on sharing explanations (Baker \& Lund, 1997), and they should build upon each other's reasoning (i.e., transactivity; Teasley, 1997). If this occurs, then cooperative learning has been shown to have positive effects on children's achievement (Slavin, 2015). However, children are often unaware of what is expected from them in a cooperative setting, leading to uncooperative, competitive dialogue that does not involve sharing information and building upon each other's knowledge (Mercer, 1996). In elementary education, the common practice is that children with a broad spectrum of needs, abilities, and interests are often seated together in one classroom (Bosker \& Doolaard, 2009; Lou et al., 1996). Cooperation in these mixedability classrooms might present additional difficulties due to differences in the level and pace of learning (Lou et al., 1996; Wang, Kinzie, McGuire, \& Pan, 2010). Children, therefore, need support for cooperation (e.g., Mercer, Dawes, Wegerif, \& Sams, 2004), but research into heterogeneous cooperation is inconclusive about what is needed to support the group process and individual learning of group members (Lou et al., 1996; Slavin, 2015). This study looks into a possible way to support heterogeneous cooperation.

\section{Heterogeneous cooperation}

The effect of cooperation is often assumed to be associated with group composition (Webb, 1995 ) but there is no consensus on what is the best composition for groups (Webb, Nemer, \& Zuniga, 2002). Research into heterogeneous cooperation has generally concluded that high-ability children do not benefit from learning in heterogeneous groups (e.g., Gillies, 2003; Kulik \& Kulik, 1982) and seem to benefit more from 'special honours programs' designed for talented and gifted children than from heterogeneous cooperation (Kulik \& Kulik, 1982). For low-ability and average-ability children, working in a heterogeneous setting with at least one high-ability student is generally considered to affect their performance positively (Webb, Nemer, Chizhik, \& Sugrue, 1998). However, lower ability children might consider their high-ability classmates to be superior to them, and they might therefore be inclined to accept the higher ability children's contribution to the dialogue without critically reflecting on it (Webb, Nemer, Chizhik, \& Sugrue, 1998). 
In their review, Lou et al. (1996) state that they could not specify one form of grouping that best promoted all students' achievement. When homogeneous and heterogeneous cooperative learning groups are compared, the quality of the cooperative process seems to coincide with the atmosphere in the group rather than with group composition (Gillies, 2003). Webb et al. (2002) showed that high-ability children performed better in groups in which children demonstrated help-giving behaviour. Which group member demonstrated this help-giving behaviour made no difference to children's performance. In fact, Förrer et al. (2000) stated that heterogeneity could even be constructive when differences between children are used positively within the learning process. Children should then be able to learn from and with each other.

\section{Structuring heterogeneous cooperation}

In their Social Interdependence theory, Johnson et al. (2007) distinguished five conditions that should be fulfilled in order to ensure a fruitful cooperative learning process. First, group members who share common goals should realize that working together could benefit both their individual and collective learning goals (i.e., positive social interdependence; Johnson et al., 2007). A precondition for positive social interdependence to occur is that group members leave room for each other to participate in the group process. However, dominance of some group members over others might prevent some children from fully contributing to the cooperative process, or might cause other group members not to receive needed help and feedback on their contributions to the group process (Cohen, 1994; Cohen \& Lotan, 1995). High-ability children tend to dominate the cooperative process by solving problems individually while ignoring suggestions from their lower ability partners (Mugny \& Doise, 1978), although a study by Webb et al. (2002) showed that children taking the lead in a cooperative process often do not have the intention of suppressing their group members. When positive social interdependence exists, group members work together to optimize the learning process by sharing their resources and providing each other with support. The meta-analysis by Lou et al. (1996) strengthened this position by stating that groups appear to learn more during cooperative learning when the group members felt interdependent in the group's learning process.

A second important element of cooperative learning is 'individual accountability' (Johnson et al., 2007). This means that every group member is responsible for their own work as well as the group's accomplishments. However, a recurring issue in cooperative groups is that some group members do not feel the need to participate, and contribute less than they would when working individually (i.e., diffusion of responsibility; Slavin, 1990). This is often caused by low motivation to contribute that results from the idea that contributing has little value for the group product (Shepperd, 1993). Individual accountability will be 
most prominent in a group in which each member has his or her own task or role to fulfil. One method that promotes individual accountability is the jigsaw method (Aronson et al., 1978). In this method, each group member possesses a unique piece of information necessary for the group to complete the group task successfully (Walker \& Crogan, 1998). A study by Karacop and Doymus (2013) demonstrated that the jigsaw method is more successful than learning in traditional cooperative groups, leading to higher academic achievement. Students actively take part in the group process by sharing their knowledge with their group members and discussing the content in differently composed groups; students work in one group to develop their expertise and in another group to share the different pieces of expertise they have developed. This fits in with the work of Damon and Phelps (1989), who stated that a prerequisite for the cooperative process to be cognitively beneficial is that group members build upon each other's knowledge. This process is most effective when group members do not have too much knowledge about the topics of their group members prior to the cooperation, so that each partner shares new information with the group (Wood, Bruner, \& Ross, 1976). Combining this information should help the group to tackle a problem that they would normally not be able to tackle alone.

Third, the cooperative learning process benefits from students encouraging and assisting their group members to achieve the group's goals (i.e., promotive interaction; Johnson et al., 2007). There is quite a clear connection between the group members' positive social interdependence and their engagement in promotive interaction. The way interdependence is structured defines whether the group members interact with each other and how their interaction pattern shapes the group process. Since learning when in groups benefits from the processes of giving and receiving explanations (Webb, 1982a, 1982b, 1984), it seems important to create an atmosphere that promotes information-sharing between group members. Giving explanations clarifies and organizes students' learning, and receiving explanations helps the learner to correct possible misconceptions and gain new knowledge. It is generally assumed that lower ability students benefit from explanations they receive from their higher ability peers during a heterogeneous cooperation process (Gillies, 2003; Lou et al., 1996) and higher ability students benefit from giving those explanations (Lou et al., 1996). However, student learning shows benefits from giving and receiving explanations in general (Webb, 1982a, 1982b, 1984). Therefore, for the cooperative process to be cognitively beneficial, children should be able to engage in both of these activities.

Fourth, evaluation of the group process enacted by the group itself plays an important role in the productiveness of the cooperative process (Johnson et al., 2007). Process evaluation consists of reflecting on the achievement of group goals and group members' contribution to this achievement, and making decisions on whether or not to change elements of the 
group process. For process evaluation to occur, groups should be provided with time and opportunities to reflect on their group process.

As a fifth essential element, Johnson et al. (2007) mention that appropriate use of social skills during the cooperative process is essential for the success of the cooperative process. Social skills, such as decision making and conflict-managing skills, are considered to be complex and require extensive training. Research into children's social skills during cooperative processes has indicated that younger children especially need training in these skills (Gijlers, Weinberger, van Dijk, Bollen, \& van Joolingen, 2013; van Dijk, Gijlers, \& Weinberger, 2014), and that this training should occur outside of the cooperative process itself (cf., Saab, van Joolingen, \& van Hout-Wolters, 2007).

It seems important to structure the heterogeneous cooperative process in such a way that it comes to terms with the principles of the Social Interdependence Theory (Johnson et al., 2007). The occurrence of these principles should be beneficial for children's learning possibilities in the heterogeneous cooperative groups.

\section{This study}

In the current study, children worked in the context of the jigsaw method. In addition to that, the principles from Johnson et al. (2007) were applied to the design of a worksheet to further support sharing of information in the jigsaw context. In the jigsaw method, children prepare to be experts on a specific topic and then come together to use their different expertise in design groups. Basically, this learning method should create a cooperative learning situation in which children treat each other as resources and need each other to reach a shared learning goal (Aronson et al., 1978). However, when grouped heterogeneously, the cooperative learning process has to deal with issues that are attributable to differences between group members in level and pace of learning (Lou et al., 1996; Wang, Kinzie, McGuire, \& Pan, 2010). In this context, a worksheet was designed to increase (positive) social interdependence, individual accountability, promotive interaction, and evaluation of the group process (Johnson et al., 2007). The fifth element specified by Johnson et al. (2007), appropriate use of social skills, was not integrated in the worksheet, as research has shown that training children in social skills should be done prior to the cooperative process (cf., Saab et al., 2007). Such training was not part of the support offered in this study, as it would require more extensive preparation of teacher's lessons, and would therefore not apply as a support tool that could be offered 'just-in-time'. In the current study, the focus was on developing this worksheet so that it could be applied by teachers 'just-in-time', when heterogeneous groups are sharing information in the context of the jigsaw method. 
A pretest-posttest design compared an experimental condition in which heterogeneous groups were supported by means of the worksheet to a control condition in which heterogeneous groups were not supported by the worksheet (supported vs. unsupported condition, respectively). The jigsaw process entailed that prior to the lesson involving heterogeneous cooperation, every child became an expert on a subtopic that was essential for completion of the shared goal assignment. Dialogue analyses and analyses of knowledge tests were used to indicate whether or not working with the worksheet would result in a better cooperative process and would lead to higher domain knowledge than working without the worksheet.

The worksheet intended to explain children's individual responsibilities to share knowledge in the group. Two expectations could be derived from this. First, the worksheet was expected to elicit equivalence concerning participation of different group members in the group dialogue. This means that groups that worked with the worksheet were expected to show a higher equality of group members' contribution than groups that did not work with the worksheet. Both children's general participation in the group dialogue and their participation in sharing domain-related information were expected to be more equally distributed as a result of working with the worksheet. Second, groups that worked with the worksheet were expected to spend more of their dialogue on exchanging task-oriented information and on providing domain-related explanations than groups that did not work with the worksheet. The latter should become clear at both the group level and the individual level (i.e., individual contributions to group dialogue).

Another element that was central to the worksheet was that children were made aware of their individual role in the group process and group members' mutual interdependence on each other in this process. It, therefore, was expected that working with the worksheet would elicit relatively more theoretical explanations, compared to working without the worksheet.

As sharing information is considered to be an important prerequisite for individual learning during cooperative processes (Webb, 1982a, 1982b, 1984), the worksheet was also expected to enhance children's development of domain knowledge. Children working in groups with the worksheet were, therefore, expected to show a higher level of domain knowledge gain than children who worked in groups without the support of the worksheet. 


\section{Method}

\section{Context of the research}

Data were collected in the context of a seven-week lesson series (see Chapter 2 for a detailed description of the lesson series). The overarching assignment for the children was to design a house on the moon that could be inhabited by a family of four (two adults, two children), and that contained all necessities for living on the moon. In the seven weeks of the course, children worked according to the jigsaw method (Aronson et al., 1978). In the homogeneous expert phase, children worked in homogeneous groups to gather information on one of four different topics that served as later input for the moon house design that they would create in the following design phase, when they worked in heterogeneous design groups. Allocation of topics was ability-related, based on the complexity of the topics: high-ability children studied Light $\mathcal{E}$ Heat, average-ability children examined the topic of either Oxygen or Water, and low-ability children were concerned with Nutrition. Tasks provided in the homogeneous expert phase were further differentiated to children's ability level with regard to their structure and degree of support. The homogeneous expert phase concluded with an overarching, core assignment that asked children to list the most relevant conclusions about their assigned topic. Following the homogeneous expert phase, children were grouped into heterogeneous groups for the heterogeneous design phase, in which they shared the information they had gathered on their assigned topics. During this heterogeneous design phase, groups were instructed to combine information on the topics from all group members and successively integrate this information into an overarching learning product: the design of their moon house.

\section{Participants}

Originally, 347 fourth, fifth, and sixth graders from six different elementary schools located in a mid-sized city in the Netherlands participated in the lesson series. Children were categorized as low-ability, average-ability, or high-ability by means of the Dutch students monitoring system (CITO, 2012). This standardized scoring system is used in Dutch elementary education to determine children's relative position on various subjects within their age group. Scores on each subject vary from ' $\mathrm{I}$ ' (children scoring in the top 20\%) to ' $\mathrm{V}$ ' (children scoring in the bottom $20 \%$ ). For this study, four subjects were selected to define children's learning skills: technical reading skills, mathematics, spelling, and reading comprehension. Children were categorized as low-ability when they scored ' $\mathrm{V}$ ' on two out of the four subjects $(n=51 ; 15 \%)$. The group of high-ability children $(n=53 ; 15 \%)$ included children who scored ' $\mathrm{I}$ ' on three out of the four subjects as well as children who were identified on the basis of the Dutch 'Digital Measuring Protocol for Giftedness' (i.e., Digitaal Handelingsprotocol Hoogbegaafdheid; van Gerwen \& Drent, 2011). The latter protocol combines teacher's and parents' impression of the children's abilities, as well as 
data on children's cognitive performance, to include underachieving children within the high-ability group. The remaining children who were not categorized as either low-ability or high-ability were categorized as average-ability children $(n=243,70 \%)$.

Heterogeneous cooperative groups of four were assembled that consisted of one highability child, two average-ability children, and one low-ability child. Children within the different ability levels were randomly assigned to a group. Considering that the majority of the children in the original sample were categorized as 'average-ability children' (i.e., 70\%), it was not possible to assign all children to a heterogeneous group that also included a high-ability and a low-ability classmate. Data of 211 children who were part of a group that did not fit the grouping criteria for the heterogeneous grouping during the design phase (one high-ability child, two average-ability children, and one low-ability child) were excluded from the final sample.

Consequently, the final sample consisted of 136 children (60 boys, 76 girls; $M_{\text {age }}=10.95$ years, $\mathrm{SD}=0.86$, ranging from 8 to 12 years). After the grouping procedure, groups were randomly assigned to the supported or unsupported condition. The supported condition consisted of 19 groups (33 boys, 43 girls, $M_{\text {age }}=10.95$ years), and the unsupported condition included 15 groups (27 boys, 33 girls, $M_{\text {age }}=10.96$ years). Furthermore, due to recording equipment failure, data collection (i.e., video recordings) for eight groups (i.e., 32 children) was of poor quality (i.e., inaudible). Process data for these groups were left out of the analyses. Data derived from the knowledge tests were included in the analyses.

Prior to the study, children's parents were informed about their child's participation in the study that included video recordings of the cooperative process, and they gave active consent for their child's participation.

\section{Materials}

Worksheet. The worksheet that structured the heterogeneous design phase (see Figure 4.1) presented four steps that guided the group members through the cooperative process of information-sharing based on the conditions for successful cooperation specified by Johnson et al. (2007). The main aim was to make sure that all children shared the information on their topic and that all group members were actively and equally participating in the cooperative process. First, children were to inform their group members about their assigned topic one-by-one. This first step should contribute to children's feelings of responsibility for the group's accomplishments by sharing the information on their topic (i.e., individual accountability). Children were given the hint to 


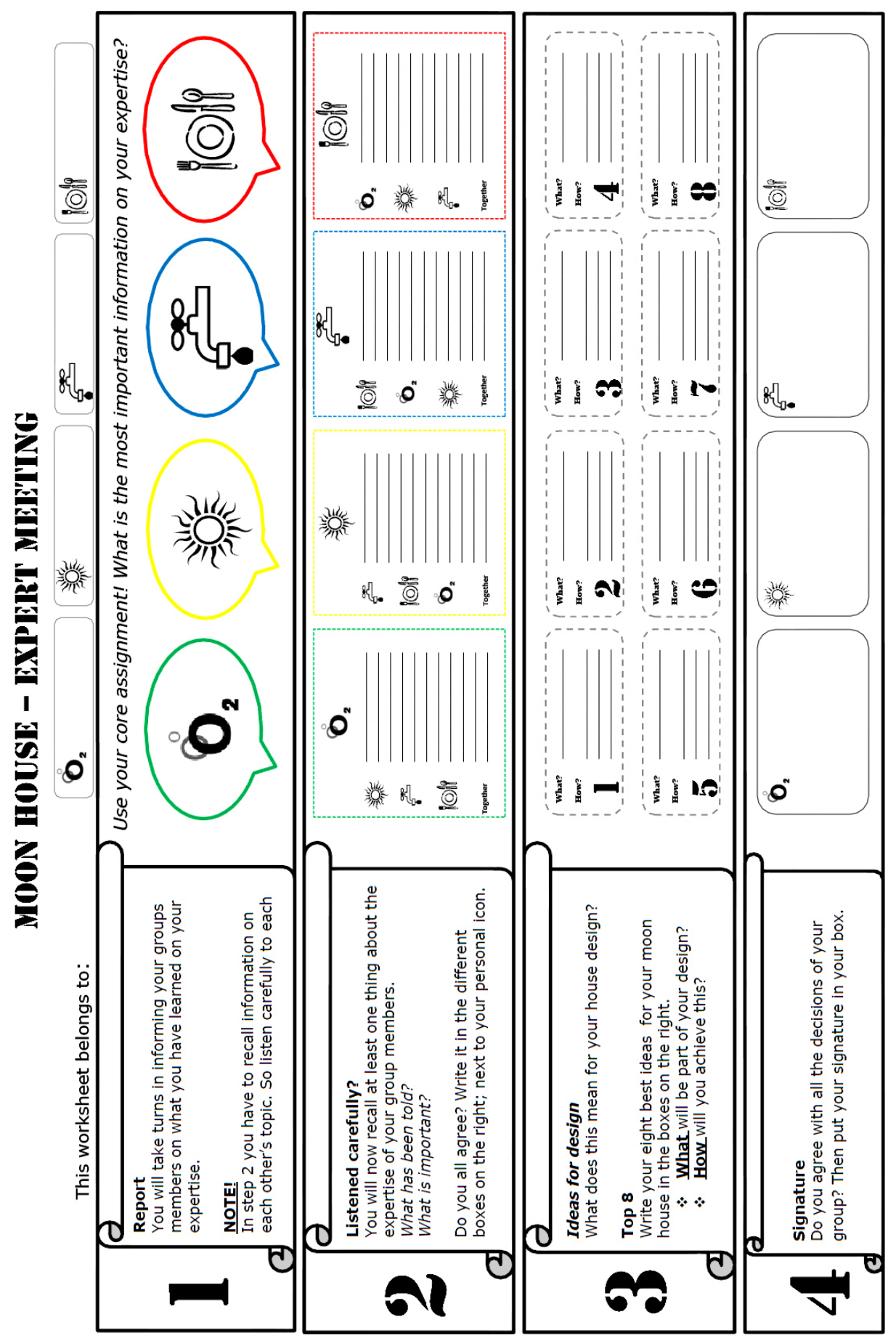

Figure 4.1. Worksheet that supported information-sharing in the heterogeneous design phase [translated from Dutch] 
use the core assignment from the homogeneous expert phase as a guideline to share the basic elements about their topic.

In the second step, children had to write down two concepts per topic that their group members just informed them about. To make sure that every group member listened to their fellow group members during the first step, they were told in the explanation of the first step that they had to be able to recall concepts of their group members' topics during the following activity. At the end of the second step, if the group felt an important concept had not been mentioned, additional concepts could be added under the heading 'Together'. This second step should contribute to children's notion of the benefits of working together and what they could learn from one another (i.e., positive social interdependence). By challenging children to name the most important elements of each other's topics, the importance of group members' information was made more explicit.

In the third step, group members were asked to cooperatively construct a top eight list of elements that should definitely be considered in their moon house design. For every element, they had to write down how they would achieve the inclusion of this element in their design.

In the fourth and final step, every group member had to evaluate the cooperative process by determining whether or not he or she agreed with the decisions made by the group, and whether their topic was sufficiently taken into account in the process (i.e., evaluating the group process). By signing the worksheet, children stated that they agreed with the content discussed during the cooperative process and written on the worksheet. This final step was explicitly added to the worksheet to make children aware of their role in the group process and to reflect on this role.

All in all, the worksheet intended to strengthen the division of roles that comes forward in the jigsaw method. Children were to share the information on their topic with their group members and were stimulated to integrate and process the information of each other's topics. The clear references in the worksheet to the different topics, by using corresponding symbols and colors, intended to make children aware of the content that had to be discussed. This facilitated 'promotive interaction' between group members as children could easily refer to the information of the topics that still had to be shared and discussed (and thus call upon the group member that represented this topic to share the information).

Domain knowledge assigned topic test. Eight knowledge tests were developed; a parallel pretest and posttest for each topic (i.e., Light \& Heat, Oxygen, Water, and 
Nutrition) to assess what children gained from working cooperatively in the heterogeneous design groups. Each test contained eight open-ended questions measuring children's knowledge of their assigned topic. For each topic, four main subtopics were selected that children learned about in the context of their assigned topic. Per subtopic, two questions were asked: 1) a question that tested children's ability to name and describe a main concept of their area of expertise (e.g., "What do plants need to create oxygen?"), and 2) a question that tested children's skills to apply their knowledge (e.g., "Explain what role plants play in decreasing the amount of carbon oxide and increasing the amount of oxygen in the air."). The domain knowledge assigned topic tests, administered separately for each topic, had varying reliabilities (Cronbach's alphas between .18 and .70). Considering that the tests assessed children's knowledge on varying subdomains, it could not always be expected that children achieved equal knowledge acquisition in these different subdomains. The relatively low reliability scores on some of these tests are, therefore, not considered alarming.

Open recall other topics test. To assess children's conceptual knowledge of the three topics from the three homogeneous expert groups that they had not been involved in, an open recall test was administered. Children were instructed to write down everything they knew about these topics in single words or short sentences, without a set minimum or maximum. In the pretest, children were asked to write down everything they knew about the topics (i.e., prior knowledge), and in the posttest children were instructed to write down what they had learned (additionally) about the topics during the cooperative dialogue.

Video recordings. To gain insight into the group's cooperative dialogues, the informationsharing lesson of the heterogeneous design phase was videotaped. Each group was taped by an individual video camera with a Bluetooth-connected microphone to record the audio. Video recordings started after groups received an explanation of the cooperative task. To determine the exact start of the cooperative dialogue, group members were instructed to say their names into the microphone. Video recordings ended when all four group members confirmed to the researcher that they had completed the cooperative assignment.

\section{Procedure}

Children's participation in the project spanned seven lessons. In the first lesson, children were assigned to their topic and started the project in the heterogeneous design groups with whom they would also later cooperate during the heterogeneous design phase. In these groups, they completed an assignment that had them write down everything they already knew related to all four of the topics (i.e., activating prior knowledge). In the three 
following weeks, children were given three lessons of two hours each to complete a set of assignments covering various sub-areas of their assigned topic. Children worked in homogeneous expert groups on these assignments, which were provided in the digital learning environment (see Chapter 2). To conclude the homogeneous expert phase, groups completed an overarching core assignment, putting together all information they had gathered about their assigned topic during these lessons.

At the next lesson, children individually completed the domain knowledge assigned topic pretest on the topic they had studied in the previous weeks, and the open recall other topics pretest on their knowledge related to the other three topics. They were given 30 minutes to complete the tests. Children then returned to their heterogeneous design groups and started the heterogeneous design phase in a face-to-face cooperative setting with the main purpose of sharing their knowledge about the different topics. Groups were told that they had to inform their group members on the information about their assigned topic so that every group member could participate in making design decisions in the upcoming lessons. They could use their core assignment for content input. Groups in the experimental condition received the worksheet to support this process and were given additional instructions on how to complete the four steps in the worksheet. Groups in the control condition did not receive the worksheet to support their cooperative process. This lesson at the beginning of the heterogeneous design phase was the core focus of the data collection of this study; groups' cooperative processes were video-recorded.

At the end of the lesson, children were told that in the upcoming two lessons they were to visualize their design by creating an annotated drawing. The main requirement for their design was that every group member must agree on the design decisions. In the week following the final design lesson, children individually completed the domain knowledge assigned topic posttest and the open recall other topics posttest. They were given 30 minutes to complete the tests.

\section{Data analysis}

Domain knowledge assigned topic test. A coding scheme was developed to analyze children's answers for each of the eight domain knowledge assigned topic tests. The answers were scored for the presence of required concepts and the explanations of required process(es). Depending on the presence of required concepts and processes, answers were awarded zero to three points. Each test had eight questions, so the maximum score per test was 24 points. A second coder scored $20 \%$ of the domain knowledge assigned topic tests. Coders scored the answers blind to children's condition. The inter-rater reliability coefficient (i.e., Cohen's kappa) was calculated separately for each pretest and posttest. Cohen's kappas showed good inter-rater reliabilities, varying between .73 to .84 . 
Open recall other topics test. For each topic, eight key concepts were selected, based on the content of the assignments that were central in the homogeneous expert phase of the lesson series. These concepts were the basis of a coding scheme that was used to score the open recall other topics tests. Considering that the instruction that accompanied the pretest and the posttest differed (i.e., in the pretest, children had to write down everything they knew about the topics, and in the posttest children had to write down what they had learned about the topics during the cooperative dialogue), normalized learning gain was calculated. First, the number of correct key concepts given on the pretest was assessed using the coding scheme. Every concept was awarded one point, with a maximum score of 24; eight concepts for the three topics that were represented by their group members. Second, the presence of new key concepts in the posttest as compared to the pretest was assessed. Every new key concept was awarded one point. Third, normalized learning gain was calculated by dividing the number of new concepts by children's possibility for learning gain (i.e., maximum score minus score on the pretest). A second coder scored 27 combinations of tests (i.e., 20\%). Inter-rater reliability was calculated for scoring the key concepts on the tests, and identifying the new key concepts in the posttest as compared to the pretest. Cohen's kappa showed acceptable inter-rater reliabilities, reaching .87 and .69, respectively.

Video files. The video files were coded by means of ELAN software ("ELAN Multimedia Annotation Tool," 2013; Sloetjes \& Wittenburg, 2008). To distinguish the individual contributions of the group members, segments were created by pulling out the different speaking turns of the four children in the group. A speaking turn started when a child began to speak and ended when another group member started his/her contribution to the dialogue, when the speaker was interrupted by a third party (e.g., researcher, teacher, or a student from another cooperation group), or a silence occurred for more than two seconds. Segments were given two codes. The content of the segment (i.e., Light \& Heat, Oxygen, Water, Nutrition, or Other) and the conversational mode were determined. When children spoke about more than one topic during a segment, multiple codes were assigned to the segment leading to 'sub-segments'. Different topics were distinguished by means of the list of key concepts per assigned topic, based on the content of the assignments in the homogeneous expert phase.

For the conversational mode, a distinction was made between on-task and off-task input (see Table 4.1 for an overview of the conversational mode codes). Within the on-task coding category, three different codes were distinguished. The first code referred to children's domain-related input regarding the four topics in the context of the moon house (i.e., Light \& Heat, Oxygen, Water, and Nutrition). Two sub-codes were distinguished to 
Table 4.1

Description and examples of the different conversational modes

\begin{tabular}{|c|c|c|}
\hline Code & Description & Example \\
\hline \multicolumn{3}{|l|}{ On-task } \\
\hline Domain-related & $\begin{array}{l}\text { Input regarding one of the four } \\
\text { topics. }\end{array}$ & \\
\hline $\begin{array}{l}\text { Theoretical } \\
\text { explanations }\end{array}$ & $\begin{array}{l}\text { Explanation in the context of one } \\
\text { of the topics. }\end{array}$ & $\begin{array}{l}\text { "The moon has no } \\
\text { atmosphere." }\end{array}$ \\
\hline $\begin{array}{l}\text { Concrete design } \\
\text { ideas }\end{array}$ & $\begin{array}{l}\text { Concrete design idea for the moon } \\
\text { house in the context of one of the } \\
\text { topics. }\end{array}$ & "We need solar panels." \\
\hline Coordination & Coordination of the task. & $\begin{array}{l}\text { "It is your turn to tell us about } \\
\text { your topic." }\end{array}$ \\
\hline Other & $\begin{array}{l}\text { Other task-oriented talk without } \\
\text { referring to one of the topics. }\end{array}$ & $\begin{array}{l}\text { "There is little gravity on the } \\
\text { moon." } \\
\text { "We should add pink roof tiles } \\
\text { to our house to make it } \\
\text { prettier." }\end{array}$ \\
\hline Off-task & Off-task talk. & $\begin{array}{l}\text { "I have soccer practice after } \\
\text { school." }\end{array}$ \\
\hline
\end{tabular}

gain more insight into the type of information children provided when discussing the content of the four topics: theoretical explanations of concepts within these topics and concrete design ideas within the context of one of these topics. A segment that contained both a concrete application for the house design and a theoretical explanation as to why this should be present in the moon house, was coded as theoretical explanation. Second, two codes were distinguished to indicate children's contributions that were related to the task, but were not about one of the four major topics: talk concerning the coordination of the task, and other task-oriented talk that did not refer to one of the four topics (e.g., concrete design ideas beyond the four topics, and talk referring to gravity). A final code was used to indicate children's contributions that dealt with off-task topics. A second coder coded $21 \%$ of the video recordings (i.e., 1521 segments). The inter-rater reliability coefficient (i.e., Cohen's kappa) was calculated for content and conversational mode separately. Cohen's kappa showed good reliabilities of .74 and .72 , respectively.

Dialogues were analysed at the level of both the group and the individual. For each code, the total number of segments was calculated. To account for differences in the length of a dialogue, measured by means of the total number of segments in the dialogue, sum scores for the different codes were divided by the total number of segments of the group or the 
individual group member, respectively. These proportional scores were used in the analyses. Based on the segmentation and coding procedure described earlier, three measures were derived from the coding process that would give more insight into the worksheet's effect on the group dialogues. Dialogues were assessed by looking at the ratio of children's contributions within the group (i.e., 'inequality scores'), the content of children's contributions (i.e., 'domain-related', 'coordination', 'other', or 'off-task'), and the type of domain-related contributions (i.e., 'theoretical explanation' or 'concrete design ideas').

\section{Results}

\section{Cooperative process}

The cooperative dialogue in the heterogeneous groups was examined from both a group and an individual perspective. In total, 7141 segments were produced during the cooperative assignment $\left(M_{\text {supported }}=348.14, S D_{\text {supported }}=119.65 ; M_{\text {unsupported }}=188.92\right.$, $S D_{\text {unsupported }}=119.59$ ). To account for the differences in number of segments between the two conditions, proportional scores were calculated that were used in the analyses.

Group dialogues. First of all, the cooperative dialogues were examined from a group perspective. In order to gain insight into the equality of group members' participation in the group dialogue, two characteristics of the group dialogues were investigated: 1) the ratio of children's contributions to the domain-related content of the group's dialogue (i.e., 'inequality domain-related'), and 2) the ratio of children's contributions to the groups' total dialogue (i.e., 'inequality total'). Table 4.2 shows inequality scores for the group dialogues, by condition. These scores were calculated based on children's proportional contribution to the dialogue, in which a perfect distribution would mean a distribution of $25 \%$ for each of the group members. Basically, the inequality score represents the sum of the deviation from this $25 \%$ of each of the four group members (i.e., inequality score $=\sqrt{ }\left(\left(25-x_{1}\right)^{2}+\left(25-x_{2}\right)^{2}+(25-\right.$ $\left.\left.\left.\mathrm{x}_{3}\right)^{2+}\left(25-\mathrm{x}_{4}\right)^{2}\right)\right)$, so that a 'perfect score' is zero.

Table 4.2

Inequality scores for the group dialogues

\begin{tabular}{lcccrrr}
\hline & \multicolumn{2}{c}{ Supported } & \multicolumn{2}{c}{ Unsupported } & \multicolumn{2}{c}{ Total } \\
\cline { 2 - 7 } & $M$ & $S D$ & $M$ & \multicolumn{1}{c}{$S D$} & \multicolumn{1}{c}{ M } \\
\hline Inequality domain-related & 19.38 & 8.36 & 36.87 & 17.81 & 27.45 & 15.97 \\
Inequality total & 21.72 & 8.09 & 27.40 & 9.90 & 24.34 & 9.25 \\
\hline
\end{tabular}

Two ANOVAs were conducted to identify differences between conditions, with the groups' inequality scores (i.e., 'Inequality domain-related' and 'Inequality total') as dependent variables. The ANOVAs revealed that groups working with the worksheet had 
a more even distribution of domain-related talk than groups working without the worksheet $\left(F(1,24)=10.79, p=.003, \eta_{\mathrm{p}}^{2}=.31\right)$. However, there were no significant differences between conditions concerning the distribution of contributions to the dialogue in total $\left(F(1,24)=2.60, p=.120, \eta_{\mathrm{p}}^{2}=.10\right)$.

Second, to gain insight in the content of the group dialogues, the proportion of contributions to the dialogue concerning the domain, coordination, other task-oriented talk (all three being on-task activities), and off-task talk were analyzed. ANOVAs were conducted to investigate possible differences between conditions. Table 4.3 shows the mean proportional scores for these four codes.

Table 4.3

Mean proportional contributions (\%) to the group dialogues

\begin{tabular}{lrrrrrr}
\hline & \multicolumn{2}{c}{ Supported } & \multicolumn{2}{c}{ Unsupported } & \multicolumn{2}{c}{ Total } \\
\cline { 2 - 7 } & \multicolumn{1}{c}{ M } & SD & \multicolumn{1}{c}{ M } & SD & M & SD \\
\hline On-task & & & & & & \\
$\quad$ Domain-related & 47.64 & 9.88 & 28.74 & 12.51 & 38.92 & 14.56 \\
$\quad$ Theoretical explanations & 31.14 & 8.10 & 8.53 & 4.44 & 20.70 & 13.23 \\
$\quad$ Concrete design ideas & 16.50 & 6.45 & 20.22 & 10.18 & 18.22 & 8.78 \\
Coordination & 26.88 & 4.55 & 20.63 & 9.79 & 24.00 & 7.94 \\
$\quad$ Other & 5.80 & 5.20 & 16.90 & 12.49 & 10.92 & 10.70 \\
Off-task & 19.68 & 6.89 & 33.73 & 19.01 & 26.16 & 15.31 \\
\hline
\end{tabular}

The ANOVAs revealed that groups supported by the worksheet spent more of their dialogue on discussing the content of the four topics $\left(F(1,24)=18.51, p<.001, \eta_{\mathrm{p}}^{2}=.44\right)$ and spent more of their dialogue engaging in coordination of the task $(F(1,24)=4.58, p=$ $\left..043, \eta_{\mathrm{p}}{ }^{2}=.16\right)$ than the unsupported groups. The unsupported groups, in turn, spent a larger proportion of their dialogue on sharing other task-oriented information $(F(1,24)=$ $9.25, p=.006, \eta_{\mathrm{p}}^{2}=.28$ ) and spent a larger proportion of their dialogue engaging in off-task talk $\left(F(1,24)=6.66, p=.016, \eta_{\mathrm{p}}^{2}=.22\right)$ than the supported groups.

Third, within the group's domain-related contributions (i.e., concerning the four topics that were central to the domain), a distinction was made between theoretical explanations of the topics and providing concrete design ideas for the moon house (see also Table 4.3). To analyze differences between conditions in how the groups discussed the domain-related content, ANOVAs were conducted with proportion of theoretical explanations and concrete design ideas as dependent variables. The analyses indicated that groups that were supported by the worksheet spent more of their dialogue on exchanging theoretical explanations $(F(1$, 
$\left.24)=74.24, p<.001, \eta_{\mathrm{p}}{ }^{2}=.76\right)$ than the unsupported groups. The difference in providing concrete design ideas was not significant $\left(F(1,24)=1.18, p=.289, \eta_{\mathrm{p}}^{2}=.05\right)$.

Individual contributions to the dialogues. Subsequently, dialogues were studied on an individual level to gain insight into children's individual contributions within their heterogeneous group. We examined two things: 1) children's engagement in discussing their assigned topic as well as the topics of their fellow group members (i.e., other topics) and 2) the mode of conversation (i.e., either focusing on theoretical issues or suggesting concrete design ideas) that children used to contribute to the dialogue. Table 4.4 shows the mean proportional scores for the measures concerning children's individual, domainrelated contributions as compared to their total contributions.

First, two ANOVAs indicated that the discussion of children's assigned topic did not differ significantly between conditions $\left(F(1,102)=3.08, p=.082, \eta_{\mathrm{p}}{ }^{2}=.03\right)$ whereas children in the supported groups spent more of their dialogue on discussing their group members' topics than children in the unsupported cooperative setting $\left(F(1,102)=69.64, p<.001, \eta_{\mathrm{p}}{ }^{2}=.41\right)$.

Table 4.4

Mean proportional contributions (\%)to domain-related dialogue by individual children

\begin{tabular}{lrrrrrr}
\hline & \multicolumn{2}{c}{ Supported } & \multicolumn{2}{c}{ Unsupported } & \multicolumn{2}{c}{ Total } \\
\cline { 2 - 7 } & \multicolumn{1}{c}{$M$} & \multicolumn{1}{c}{$S D$} & \multicolumn{1}{c}{$M$} & \multicolumn{1}{c}{$S D$} & \multicolumn{1}{c}{$M$} & \multicolumn{1}{c}{$S D$} \\
\hline Own assigned topic & 18.94 & 7.65 & 15.42 & 12.58 & 17.31 & 10.33 \\
Theoretical explanations & 13.93 & 6.35 & 5.49 & 6.86 & 10.03 & 7.80 \\
Concrete design ideas & 5.02 & 4.25 & 9.93 & 9.71 & 7.28 & 7.66 \\
Other topics & 29.55 & 8.89 & 13.91 & 10.22 & 22.33 & 12.29 \\
Theoretical explanations & 17.97 & 6.83 & 2.76 & 3.11 & 10.95 & 9.35 \\
Concrete design ideas & 11.58 & 5.91 & 11.15 & 9.07 & 11.38 & 7.50 \\
\hline
\end{tabular}

Second, four ANOVAs examined differences between conditions concerning the type of contribution (i.e., theoretical explanations or concrete design ideas) children used to discuss their assigned topic and the topics of their group members. The analyses showed that children in the supported groups spent more of their dialogue on providing theoretical explanations on their assigned topic $\left(F(1,102)=42.38, p<.001, \eta_{\mathrm{p}}{ }^{2}=.29\right)$ and on the topics of their group members $\left(F(1,102)=201.90, p<.001, \eta_{p}{ }^{2}=.66\right)$ than the children in the unsupported groups. Children in the unsupported groups spent a larger proportion of their dialogue on providing concrete design ideas for the design of the moon house in the context of their assigned topic $\left(F(1,102)=11.70, p=.001, \eta_{\mathrm{p}}{ }^{2}=.41\right)$ than the children in the supported groups. Providing design ideas for the topics of fellow group members did not differ between conditions $\left(F(1,102)=.08, p=.773, \eta_{\mathrm{p}}^{2}=.00\right)$. 


\section{Knowledge tests}

Table 4.5 shows children's scores on the domain knowledge assigned topic tests (i.e., pretest and posttest) and their normalized learning gain on the open recall other topics tests (i.e., number of new concepts mentioned in the posttest as compared to the pretest).

Table 4.5

Mean scores on domain knowledge assigned topic test (max $=24)$ and normalized gain on open recall other topics tests (in \%)

\begin{tabular}{lrrrrrr}
\hline & \multicolumn{2}{c}{ Supported } & \multicolumn{2}{c}{ Unsupported } & \multicolumn{2}{c}{ Total } \\
\cline { 2 - 7 } & \multicolumn{1}{c}{$\mathrm{M}$} & \multicolumn{1}{c}{ SD } & \multicolumn{1}{c}{$\mathrm{M}$} & $\mathrm{SD}$ & $\mathrm{M}$ & SD \\
\hline Total & 9.28 & 3.93 & 9.89 & 4.42 & 9.54 & 4.14 \\
Assigned topic pretest & 10.16 & 4.00 & 9.20 & 4.40 & 9.74 & 4.19 \\
Assigned topic posttest & 13.56 & 9.16 & 10.85 & 8.06 & 12.36 & 8.76 \\
Other topics & & & & & & \\
& & & & & & \\
High-ability & 9.24 & 4.68 & 10.43 & 4.36 & 9.77 & 4.51 \\
Assigned topic pretest & 9.59 & 3.08 & 9.00 & 3.92 & 9.32 & 3.44 \\
Assigned topic posttest & 13.06 & 11.07 & 10.97 & 10.76 & 12.12 & 10.80 \\
Other topics & & & & & & \\
& & & & & & \\
Average-ability & 9.57 & 3.77 & 10.14 & 4.93 & 9.83 & 4.29 \\
Assigned topic pretest & 10.17 & 4.48 & 9.07 & 4.97 & 9.68 & 4.69 \\
Assigned topic posttest & 13.84 & 8.57 & 10.18 & 6.99 & 12.18 & 8.04 \\
Other topics & & & & & & \\
& & & & & & \\
Low-ability & 8.71 & 3.58 & 8.67 & 3.14 & 8.69 & 3.35 \\
Assigned topic pretest & 10.71 & 3.90 & 9.75 & 3.77 & 10.31 & 3.90 \\
Assigned topic posttest & 13.46 & 8.80 & 12.35 & 7.37 & 13.00 & 8.11 \\
Other topics & & & & & & \\
\hline
\end{tabular}

Domain knowledge assigned topic test. Differences between conditions in knowledge gain on children's assigned topic from pretest to posttest were assessed with repeated measures analyses. Using Wilks' statistic, the main effect for the within-subject factor Time was not significant $\left(\Lambda=.99, F(1,121)=.09, p=.766, \eta_{\mathrm{p}}{ }^{2}=.00\right)$. The interaction (Time*Condition) showed a significant result $\left(\Lambda=.96, F(1,121)=5.56, p=.020, \eta_{\mathrm{p}}{ }^{2}=.04\right)$.

Children of the different ability levels completed a domain knowledge assigned topic test on the topic they were assigned to on the basis of their ability level. Therefore, no direct comparison between ability levels were made. To gain insight into domain knowledge on their assigned topics by the children of different ability levels, and to determine whether the effect of condition could be attributed to a specific ability level, the same analysis was 
conducted for the high-ability, average-ability, and low-ability children separately. Using Wilks' statistic, only the low-ability children showed a significant knowledge gain from pretest to posttest on their assigned topic $\left(\Lambda=.83, F(1,27)=5.56, p=.026, \eta_{\mathrm{p}}^{2}=.17\right)$. The Time*Condition interaction for the low-ability children was not significant $(\Lambda=.98, F(1,27)$ $\left.=.49, p=.489, \eta_{\mathrm{p}}^{2}=.02\right)$. High-ability children showed no significant knowledge gain from pretest to posttest on their assigned topic $\left(\Lambda=.98, F(1,29)=.71, p=.408, \eta_{\mathrm{p}}^{2}=.02\right)$; neither was there a Time*Condition interaction $\left(\Lambda=.94, F(1,29)=1.93, p=.175, \eta_{\mathrm{p}}^{2}=.06\right)$. For average-ability children the analysis indicated no significant knowledge gain from pretest to posttest on their assigned topic $\left(\Lambda=.99, F(1,61)=.25, p=.621, \eta_{\mathrm{p}}^{2}=.00\right)$, nor was there a significant Time*Condition interaction $\left(\Lambda=.95, F(1,61)=3.10, p=.084, \eta_{p}{ }^{2}=.05\right)$.

Open recall other topics test. Possible differences in normalized learning gain between conditions were examined with an ANOVA. Differences between conditions were not significant $\left(F(1,122)=2.96, p=.088, \eta_{\mathrm{p}}^{2}=.02\right)$. Conducting the same analysis for children of the different ability levels separately showed no significant differences between conditions for the high-ability $\left(F(1,29)=.28, p=.600, \eta_{\mathrm{p}}^{2}=.01\right)$, average-ability $(F(1,62)=3.41, p=$ $\left..069, \eta_{\mathrm{p}}{ }^{2}=.05\right)$, and low-ability children $\left(F(1,27)=.13, p=.723, \eta_{\mathrm{p}}{ }^{2}=.00\right)$.

\section{Discussion}

Heterogeneous cooperation is omnipresent in elementary education, because elementary classrooms house children with divergent ability levels (Bosker \& Doolaard, 2009; Lou et al., 1996). However, opinions differ as to whether working in heterogeneous groups is beneficial for learning, in particular for the higher ability children in the group (e.g., Gillies, 2003; Kulik \& Kulik, 1982). Research shows that the success rate of heterogeneous cooperation coincides with the group's functioning (Gillies, 2003; Webb et al., 2002), that learning depends on the sharing of information by group members (Webb, 1982a, 1982b, 1984), and that group dialogues should be mainly concerned with domain-related explanations (Baker \& Lund, 1997). In the current study, children worked according the jigsaw method in which all (four) group members had to first develop expertise on an assigned topic within a homogeneous ability group, and then had to share information about this topic by cooperating in a heterogeneous group. This created a situation in which children were mutually dependent on each other to complete the shared assignment. A worksheet was designed that was intended to strengthen the effects of the jigsaw method by addressing four essential elements for successful cooperation as raised by Johnson et al. (2007). In the worksheet, attention was paid to children's individual accountability, social interdependence, promotive interaction, and evaluation of the group process with a specific focus on providing and receiving domain-related explanations. 


\section{Learning process}

Looking at equality of the dialogue in total (i.e., on-task and off-task talk), children in both conditions took part in their group's dialogue in an equal manner. Concerning this aspect, the worksheet did not seem to have an additional value on top of the jigsaw method. In this method, children are encouraged to participate in the group process, as they are responsible for their own piece of the puzzle (Aronson et al., 1978; Walker \& Crogan, 1998). Presumably, the context of the jigsaw method led to a group process that included all group members. However, there was a difference between conditions concerning the domain-related talk. Children of all ability levels who worked with the worksheet participated more equally in domain-related dialogue. This result could be considered promising, as it could be considered an important prerequisite for an effective cooperative process that children have the opportunity to both provide and receive explanations about the domain (Webb, 1982a, 1982b, 1984).

In addition to more equal participation within the domain-related dialogue, results also showed that groups that received the worksheet spent more of their dialogue on discussing the content of the four topics that were central to the assignment than the children in the groups without the worksheet. Children also spent a larger proportion of their dialogue on providing theoretical explanations about the domain than the unsupported groups. For heterogeneous cooperative processes to be beneficial for children's learning, explanation of domain-related content should be prominent in the cooperative dialogue (Baker \& Lund, 1997). The worksheet thus yielded the desired effect in this regard. The dialogues of the unsupported groups, in turn, were characterized by a greater focus on discussing other aspects of the house design that were not related to the four main topics (e.g., aesthetic features of their house) and the unsupported groups spent a larger proportion of their dialogue on engaging in off-task talk, as compared to the dialogues of the supported groups. By providing each other with theoretical explanations, children have the opportunity to learn from each other (Teasley, 1997; Webb, 1982a, 1982b, 1984). Merely exchanging concrete ideas for the design might lead to a high-quality product, but these exchanges do not enable group members to grasp the underlying reasoning.

Children in the groups that worked with the worksheet spent more of their dialogue on coordinating the task than groups without the worksheet. This result seems to coincide with the differences found with regard to the equality of the domain-related talk, since they seemed to have paid more attention to coordinating the course of the dialogue monitoring whether all topics were discussed. The proportion of coordinative talk could be considered to be a treatment check of the worksheet, since the worksheet clearly laid out the individual accountability of the four group members on the basis of their topic. The 
children working with the worksheet paid attention to navigating through the assignment and communicated with each other about the group's course of action.

\section{Domain knowledge}

Based on the results concerning the dialogue it could be assumed that children's knowledge gains would also benefit from working with the worksheet. However, the results of this study did not indicate a significant knowledge gain on children's assigned topic, neither for the children who worked with the worksheet nor for children who were not supported by the worksheet. The results indicated, however, an interaction effect between children's knowledge gain on their assigned topic and whether or not they worked with the worksheet. This interaction effect might be partly due to the uncommon result that the unsupported group showed a (slight) decrease in knowledge at the posttest. When analyzing these results for the different ability groups, only the low-ability children showed a significant learning gain, but here the difference between the two experimental conditions was not significant. Besides this, the results showed no significant effect of the worksheet on children's knowledge about the group members' topics. This is unexpected considering that children in the groups supported by the worksheet spent a larger proportion of their dialogue on discussing the topics of their fellow group members than children in the unsupported groups. The results on the knowledge measures in this study are a bit puzzling. There is no evident relation between first-order effects of our intervention (on the learning process) and second-order effects (on the learning outcomes). In this line of reasoning, Lazonder \& Harmsen (2016) stated in their meta-analysis concerning guidance in inquiry learning that guidance that is specifically focused on the inquiry process did also not necessarily induce knowledge. These results invite to think about ways to further improve learning possibilities in the cooperative learning setting and to further investigate whether the heterogeneous cooperation that profited from the structure offered in the worksheet is equally beneficial for children of different ability levels.

One particular method of investigating the lack of results concerning children's domain knowledge is to look into the transactivity of the dialogue (Berkowitz, 1980a, 1980b; Teasley, 1997). Transactive dialogue requires children to reflect and act upon each other's reasoning to grasp and process the information. However, research has shown that younger children often experience difficulties with engaging in transactive dialogue and need extensive training to gain these skills (Gijlers et al., 2013; van Dijk et al., 2014). Future research could be done to investigate information processing in heterogeneous cooperative groups, and how training in transactive communication skills could enhance the quality of the group dialogues to further include domain knowledge. 
Another issue that might be considered is that the amount and level of knowledge discussed in the different groups was highly dependent on the children responsible for distributing this knowledge. Slavin (2015) corroborates this notion, stating that research on the jigsaw method not always leads to positive learning effects, as children have limited exposure to the topics of their group members. Children's learning outcomes might be improved when children are provided with guidance about what information to share with their group members. Younger children, in particular, experience difficulties with integrating new knowledge and selecting the most important elements from their information base to share with others (Zimmerman, 2007). Making these children rely on their own abilities to gather and select knowledge to share could create a dialogue with less information to be shared and learned than might be possible.

\section{Conclusions}

Cooperating according to the jigsaw method created a learning situation in which all group members participated in the dialogue. The support offered in the worksheet enhanced the quality of the dialogue, as the supported groups spent a larger proportion of their dialogue on discussing domain-related content and participation in the domain-related dialogue was distributed more equally among group members. Teachers who wish to implement heterogeneous cooperation assignments in their classroom should offer support that addresses children's individual responsibilities to share knowledge, and should make children aware of their individual role in the group's process and group members' mutual interdependence on one another. Since, overall, children did not develop their domain knowledge during the cooperative processes, the effect of the improved dialogue on knowledge acquisition should be further investigated. 


Chapter 5

Comparing the ability-adjusted jigsaw method to individual learning 



\begin{abstract}
Teachers often struggle with balancing children's cognitive and social development. In this study, the original jigsaw method of Aronson et al. (1978) was adjusted to fit the needs of children with different ability levels. A comparison was made between the ability-adjusted jigsaw method and a more traditional, individual learning approach. In the ability-adjusted jigsaw method, fourth to sixth graders $(n=550)$ worked on a cooperative design assignment in heterogeneous, mixed-ability, groups of four. Preceding this design, children gathered information on one of four topics through differentiated inquiry tasks in (abilitybased) homogeneous groups of three to six. In a control condition $(n=473)$, children worked individually on the same topics by completing tasks that lacked the cooperative, collaborative, and inquiry characteristics. Children's domain knowledge gain, inquiry knowledge gain, and attitudes toward technology and science were compared. Results showed that working in the context of the ability-adjusted jigsaw method generated equal cognitive benefits as studying the same information individually. Through working with the ability-adjusted jigsaw method, children reached the same cognitive level as through individual learning, while they were working in a context that encouraged social interaction between children of different ability levels. Future research should look into the conditions that need to be met for the ability-adjusted jigsaw method to even outperform traditional, individual learning on the cognitive outcomes.
\end{abstract}




\section{Introduction}

In Dutch elementary education, children are placed in age-based mixed-ability classrooms (Aronson et al., 1978; Bosker \& Doolaard, 2009; Mooij, 2007). Consequently, teachers have to tailor their lessons to the different needs, interests, and competencies of the children of different abilities in their classroom (Lou et al., 1996). Teachers' main focus often is on lowability and average-ability children's development so that these children are able to reach a predetermined cognitive level (Doolaard \& Oudbier, 2010). High-ability children are expected to reach a proficient performance level on their own, receiving less attention during classroom activities. Existing methods that are used to adapt to the level of highability children focus on compacting the regular curriculum for these children so that more time can be spent on additional, challenging assignments (i.e., enrichment; Doolaard \& Oudbier, 2010; Mooij, 2007). A common way of application of these methods is that children complete most assignments individually, and are pulled out of their classes when working on the assignments. The main reason that this approach is frequently deployed, is that high-ability children's cognitive performance seems to benefit from these adapted programs (Mooij, 2007). However, excluding the high-ability children from regular class activities might have negative consequences. In their book, Förrer et al. (2000) stress that separating high-ability children from their classmates might hinder development of social skills as they have little opportunity to communicate with their (other-ability) classmates, and might induce social exclusion since the other children in class might envy 'those who get to do the extra assignments'. Also, the other children's cognitive benefits are reduced when high-ability children are socially excluded as the lower ability children might profit from working together with their higher ability classmates (Förrer et al., 2000).

In an ideal situation, both cognitive and social development of children of all ability levels are attended to. In the current study, we have investigated a lesson series that allowed children to engage in social activities with children of different ability levels which seems to be a prerequisite for children's social development (Förrer et al., 2000) and social inclusion (Abdullah \& Shariff, 2008; Cohen, 1994). At the same time, we tried to ensure cognitive development for all children.

\section{Learning together}

The effects of learning together in homogeneous and heterogeneous groups have been the focus of a large number of studies (e.g., Kulik \& Kulik, 1991; Lou et al., 1996). Research into the effects of cooperative and collaborative learning on children's social development are unambiguously positive (e.g., Slavin, 1990). Already in the beginning of the $20^{\text {th }}$ century, Parkhurst (1922) and Dewey (1938) emphasized the role of cooperative and collaborative learning in children's social development in school. Their stance was that cooperation and 
collaboration prepares children for their later role in society. Cooperative and collaborative learning teaches children how to interact with others, and forces them to take into account and act upon differences between themselves and their partners. Grouping heterogeneously lets children become familiar with the different children in their class and experience the value of working together with children of different backgrounds and abilities (Castelijns \& Stevens, 1996; Förrer et al., 2000).

Regarding children's cognitive development research is less conclusive (e.g., Lou et al., 1996). Especially when attention is paid to the effects of learning in groups for children of different ability levels. For instance, high-ability and average-ability children would benefit from working together with same-ability others (Lou et al., 1996; Webb, 1991). However, there are also concerns about the benefits of homogeneous grouping for the high-ability children (Webb, 1991). In homogeneous groups, high-ability children often assume that high-ability partners do not need each other and are perfectly able to work individually on the task. Research into grouping effects for lower ability children point out that lower ability children benefit most from a heterogeneous group setting (Gillies, 2003; Lou et al., 1996; Webb, 1991). There is even a concern that low-ability children, grouped homogeneously (i.e., with other low-ability children), are denied the opportunity to learn. However, when grouped heterogeneously, low-ability children are at risk of being excluded from the group activities by their higher ability peers because they might be considered incompetent (Whicker, Bol, \& Nunnery, 1997). When high-ability, averageability, and low-ability children are placed together in a group, this might be disadvantageous for the high-ability children (Lou et al., 1996) and the average-ability children (Webb \& Palincsar, 1996). High-ability children are expected to experience a lack of intellectual challenge when working with lower ability others (Lou et al., 1996). In turn, average-ability children might be excluded from the cooperative discourse as high-ability and low-ability children might develop a teacher-student relationship in which the average-ability children do not take part (Webb \& Palincsar, 1996).

The ambiguity of these results persists when the distinction is made between cooperative and collaborative learning. When looking into the difference between these two ways of working together, a distinction could be made according to the degree of division of labor (Dillenbourg, 1999). In cooperative tasks, children divide tasks and responsibilities (i.e., vertical division of work). Subsequently, individual contributions are merged into a joint solution. In collaborative tasks children perform the same tasks 'together' (i.e., horizontal division of work), during which children could assist each other in conducting the learning tasks. 
In conclusion, it seems difficult to point out a specific group composition that could be considered uniformly superior for promoting cognitive development of all children (e.g., Lou et al., 1996; Saleh, Lazonder, \& de Jong, 2005). It might, therefore, be beneficial to look into a learning arrangement that combines different groupings within one setting.

\section{Jigsaw method}

A learning method that combines individual learning, cooperative learning, and collaborative learning, and takes into account both cognitive and social aspects of learning is the jigsaw method (Aronson et al., 1978). The jigsaw method is designed to create a learning situation in which children treat each other as resources instead of competitors. Children have to cooperate with each other in order to complete a shared learning goal, creating involvement of the different members of the group that has a positive effect on children's achievement (Abdullah \& Shariff, 2008; Cohen, 1994). Children are mutually interdependent of each other as the learning domain is cut into different topics and preceding the cooperative process, group members collaboratively gather information on the topic that was assigned to them. Subsequently, children share the content of their assigned topic in their cooperative group to complete the shared assignment.

For learning in groups to be effective for all its group members, it has to address different criteria, such as individual accountability and social interdependence (Johnson et al., 2007). Research shows that jigsaw cooperation meets these criteria. Students become more actively engaged in the content of the learning goals, take more responsibility for their own learning, and rely on their group members for information (Abdullah \& Shariff, 2008; Colosi \& Zales, 1998; Karacop \& Doymus, 2013). The jigsaw method has also proven to be effective in enhancing students' cognitive development (Doymus, 2008; Doymus et al., 2010; Karacop \& Doymus, 2013). In comparison to the traditional teaching methods, jigsaw cooperation provides children with the experience how to function successfully in a group, prepares them for future cooperation with others they do not know or who are different to them, has shown to be effective in improving communication and cooperation skills, and demonstrated to be more beneficial for students' knowledge gain than working according a traditional teaching method (Colosi \& Zales, 1998; Doymus, 2008; Karacop \& Doymus, 2013).

\section{This study: Ability-adjusted jigsaw method}

In this study, ability-related differences between children were interwoven with the different phases of the jigsaw method. Children worked together with same-ability peers in the homogeneous expert phase of the jigsaw method and worked cooperatively with otherability peers in the heterogeneous design phase of the jigsaw method (see Chapter 2). As the 
original jigsaw method has proven to be beneficial for children's learning in general, we applied and adapted this method to children of different ability levels working together. In this way, we encouraged social interaction between children of different ability levels while at the same time aiming to improve, or at least maintain, cognitive learning outcomes. The outcomes were compared with outcomes of a more traditional, individual, learning approach.

In homogeneous expert groups, children studied an assigned topic by completing diverse inquiry assignments that were adjusted to their ability level (van Dijk, Eysink, \& de Jong, 2016). In inquiry learning, children are responsible themselves for discovering new knowledge and play an active role in the process of discovering and interpreting new information, which should evoke deep learning (Alfieri, Brooks, Aldrich, \& Tenenbaum, 2011; Mayer, 2003, 2004; Minner, Levy, \& Century, 2010). Besides this, inquiry learning should contribute to children's engagement in the group process and should enhance their feelings of 'expertise' as they are responsible for their own learning (Alfieri et al., 2011; Mayer, 2003, 2004; Minner et al., 2010). By matching the assignments to ability levels, children should be enabled to grasp the content of the tasks, and, therefore, become experts on the topic assigned to them. Subsequently, in heterogeneous cooperative groups, children of different ability levels worked together on solving a socio-technical problem. To strengthen the positive effects of the jigsaw method, the shared assignment was intentionally shaped within the context of learning by design. The shared design assignment created a situation in which knowledge of various subjects that was gathered in the homogeneous groups, needed to be integrated in order to reach a shared goal. Explicating children's unique part in the group process intended to support the process of information sharing in the heterogeneous groups.

The combination of homogeneous collaboration and heterogeneous cooperation was incorporated in a seven-week lesson series, embedded in a digital learning environment (see Chapter 2). A pretest-midtest-posttest-retention test experimental design was used to investigate whether the ability-adjusted jigsaw method would lead to cognitive development of high, average, and low-ability children whilst making a comparison with children in a control condition. In the control condition, children worked individually on traditional learning tasks (i.e., tasks without features of inquiry learning, collaborative, and cooperative learning). Differences between conditions were investigated regarding children's cognitive development (i.e., domain knowledge), children's knowledge of the inquiry cycle, and children's attitudes towards science and technology. The latter two measurements were added in this study as the BE COOL! lesson series took place in the context of inquiry learning and dealt with a science domain. 
Working with the ability-adjusted jigsaw method was expected to lead to higher, or at least, equivalent learning outcomes (i.e., domain knowledge) as working within the traditional condition. This effect was expected for high-ability, average-ability, and lowability children. In the ability-adjusted jigsaw condition, children were offered differentiated inquiry assignments in the homogeneous groups that included abilityadjusted structure of the inquiry tasks. The inquiry learning aspect of the tasks would evoke deeper learning (Alfieri, Brooks, Aldrich, \& Tenenbaum, 2011; Mayer, 2003, 2004; Minner, Levy, \& Century, 2010) and the differentiated support that accompanied the inquiry assignments was expected to enhance this effect. On top of that, the explicit support of the cooperative dialogue in the heterogeneous design phase by means of a worksheet (see Chapter 4) would be able to equalize results to learning individually in the control condition.

Considering that the differentiated assignments took place in the context of inquiry learning and learning by design, inquiry knowledge of children in the ability-adjusted jigsaw condition was expected to show a higher development than that of children in the control condition. Although no instruction on the steps of the inquiry cycle was given, children in the ability-adjusted jigsaw condition were continuously exposed to the different inquiry steps, explicitly mentioned in the different inquiry tasks.

Both the children in the ability-adjusted jigsaw condition and the control condition worked on the same scientific domain. A major difference between the two conditions was the inquiry method that was used to shape the tasks in the ability-adjusted jigsaw condition. The frequency of lessons in technology has proven to be positively related to children's attitudes (Walma van der Molen, 2007). The inquiry-structured way of working was, therefore, expected to lead to more positive attitudes toward technology and science in the ability-adjusted jigsaw condition than in the control condition.

\section{Method}

\section{Participants}

We started this study from an original number of 2451 fourth, fifth, and sixth graders from 30 different elementary schools from a mid-sized city in the Netherlands. From these children, we made selections (to be described next) to be able to create the needed ability groups. Creating a subsample was based on children's ability levels. To determine children's level of ability (i.e., high-ability, average-ability, or low-ability), categorization occurred by means of the Dutch student monitoring system (CITO, 2012), and the Dutch 'Digital Measuring Protocol Giftedness' (i.e., Digitaal Handelingsprotocol Hoogbegaafdheid, DHH; van Gerwen \& Drent, 2011). A first indication was based on 
children's CITO scores, determining their relative position within their age group. CITO monitors children's performance and abilities on all elementary domains. Scores on CITO tests vary from ' $\mathrm{I}$ ' (20\% highest scoring children) to ' $\mathrm{V}$ ' (20\% lowest scoring children). In the current study, children's general ability levels were assessed by means of their scores on four subjects: technical reading skills, mathematics, spelling, and reading comprehension. Criteria were formulated to create a distribution of ability levels that should resemble the normal distribution of ability levels in heterogeneous school classes. Children were categorized as low-ability when they scored ' $\mathrm{V}$ ' on at least two of the four subjects, and as high-ability when they received a score ' $\mathrm{I}$ ' on at least three of the four subjects. To include possible underachievers, children's DHH-indications were inspected. The DHH protocol includes both teacher's and parent's impression of children's abilities as well as data on children's actual cognitive performance. Based on these data, gifted underachieving children were added to the high-ability group. Remaining children were indicated as part of the average-ability group. This led to the following distribution: 243 low-ability children (24\%), 535 average-ability children (52\%), and 245 high-ability children (24\%).

Teachers registered the children of their own class into the digital learning environment based on the categorization criteria. The learning environment assigned children to the experimental condition or the control condition. To create the subsample, children in the experimental condition that were part of an 'ideal' heterogeneous group (i.e., one highability, two average-ability, and one low-ability) were selected. Where possible, a control group-counterpart was selected within the same class. A child was considered a good match when he or she had the same level of ability, was assigned the same expertise, and was from the same grade. Children who did not complete the pretest or the posttest were left out of the sample $(N=129)$. All in all, this resulted in a final sample of 1023 children (see Table 5.1 for the descriptive statistics of children in the ability-adjusted jigsaw condition and the control condition).

Children participated in this study as part of their regular school curriculum. Prior to the study, children's parents were informed by the schools on their child's participation in the study, and gave their consent for their children's participation.

Table 5.1

Descriptive statistics of children in the ability-adjusted jigsaw and the control condition

\begin{tabular}{lrrrrrrrr}
\hline & \multicolumn{4}{c}{ Ability-adjusted jigsaw } & \multicolumn{5}{c}{ Control } \\
\cline { 2 - 9 } & Boys & Girls & Mage $_{\text {age }}$ & SD & Boys & Girls & Mage $_{\text {SD }}$ \\
\hline High-ability & 79 & 63 & 10.28 & .89 & 59 & 44 & 10.31 & .90 \\
Average-ability & 145 & 131 & 10.49 & .93 & 127 & 132 & 10.47 & .92 \\
Low-ability & 65 & 67 & 10.77 & .89 & 45 & 66 & 10.64 & .85 \\
\hline
\end{tabular}




\section{Materials}

Learning environment and lesson series. Data were collected in the context of two sevenweek lesson series: 1) a lesson series for the ability-adjusted jigsaw condition (see Chapter 2), and 2) a parallel lesson series for the control condition. Both lesson series included seven lessons of two hours and were embedded in the BE COOL! learning environment (Eysink, van Dijk, \& de Jong, 2014). See Figure 5.1 for an overview of the lesson series for both conditions.

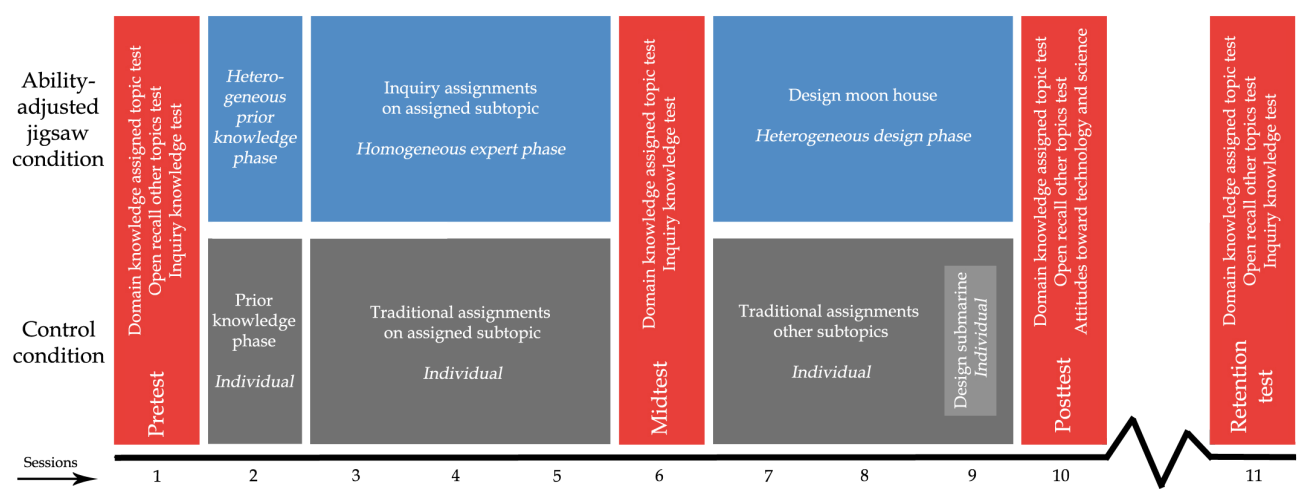

Figure 5.1. Overview of phases and tests for the ability-adjusted jigsaw condition and the control condition

In the ability-adjusted jigsaw condition, children were to design a house on the moon that could be inhabited by a family of four (two adults, two children). The learning environment showed three phases that children had to walk through consecutively. First, in the prior knowledge phase children worked in heterogeneous groups on a simulationbased task on gravity and air friction, and a cooperative task activating their prior knowledge. The task on gravity and air friction was added to the lesson series to make sure that children learned about the degree of gravity on the moon. Earlier in the process of developing the BE COOL! lesson series (see Chapter 3), it was found that children often have a number of misconceptions concerning this domain. Knowledge on this domain would help children to make correct design choices later on in the lesson series. Second, in the expert phase, children received a set of seven to nine inquiry assignments on a topic that was assigned to their ability level (see Chapter 2). High-ability children gathered information on the topic of Light $\mathcal{E}$ Heat, average-ability children studied either the topic of Oxygen or Water, and low-ability children looked into Nutrition. The assignments were differentiated with regard to their structure and degree of support (van Dijk et al., 2016). Children worked in homogeneous groups on the assignments that covered the different subdomains of their topic. In each assignment, children had to follow four inquiry steps (i.e., exploring, researching, concluding, evaluating, and broadening). To complete the 
expert phase, children concluded with an overarching core assignment that served as a summary of the topic that they studied in the three preceding weeks. In the third and final phase, children designed their moon house in their heterogeneous design groups (i.e., same groups as the first lesson). To structure their design lessons, children had to follow different steps of the design cycle. First, children shared their expert knowledge in their group by explaining the most important information from their assigned topic and created a first selection of design ideas. This process of information sharing was extensively supported by means of a worksheet that explicated children's unique part in the group process (see Chapter 4). Second, the groups created a prototype of their design, where after they checked and optimized their prototype before presenting the definitive design. The final design contained both a design of the moon house and a written report of their design choices as a group.

Children in the control condition worked on a parallel project with equal learning goals, an equal time span, and shared the same physical learning space (i.e., classroom or computer area). Similar to the experimental learning environment, the learning environment for the children in the control condition showed three phases. They started with the prior knowledge phase in which children worked individually on a task that covered gravity and air friction, and created a mindmap to activate their prior knowledge on the four topics that were central to the lesson series. The following three weeks, children worked individually on traditional assignments that covered the subtopics of their assigned topic. Control group children were, in a similar way as children in the ability-adjusted jigsaw condition, assigned to a topic that matched their ability level in terms of content. In the final three weeks, children studied the other three topics individually by means of short assignments covering all subtopics of these topics and repeated the main subtopics from their assigned topic. Children finished their lesson series with a design lesson in which they individually created a submarine. This latter assignment was added to the control group lesson series to make sure that the effective time spent on 'studying the four topics' was equal to the time spent on this by the children in the ability-adjusted jigsaw condition.

In the student section of the learning environment (see Chapter 2), the two conditions were not referred to as the ability-adjusted jigsaw condition (or the BE COOL! condition) and the control condition. They were given different, theme-related names: children who worked with the ability-adjusted jigsaw lesson series were named 'Astronauts', referring to children's main assignment to design a house on the moon, and the children in the control condition were called 'Globetrotters', referring to become real 'globetrotters' by learning all there is to know about living and surviving on the earth. These names were communicated to the children, so that they were not aware of the condition that they were part of. 
Domain knowledge assigned topic test. Domain knowledge tests were developed for all four topics (i.e., Light \& Heat, Oxygen, Water, and Nutrition). Each test consisted of eight open questions covering four different topics. Four questions measured children's conceptual knowledge on the subtopics of their expertise (e.g., 'Name a kind of energy production that is sustainable. Explain why you think that this kind is sustainable.'), and four other questions tested applied knowledge on the same subtopics (e.g., 'The moon does not have an atmosphere. Explain why it is therefore impossible to produce wind energy on the moon. And name a kind of energy that is possible to produce on the moon').

For each domain knowledge test, parallel versions of the pretests, midtests, posttests, and retention tests were developed. These parallel versions dealt with the same concepts that were part of the topics, but the way the question was asked differed slightly per version (e.g., using different metaphors to introduce a concept). The 16 different domain knowledge tests had sufficient, and a few weak, reliabilities; Cronbach's alpha's varying between .38 and .68 .

Open recall other topics test. Children's conceptual knowledge on the other three topics (those that were not the subject of their expert group) was assessed by means of an open recall test. Children were asked to write down the different concepts that they connected to the three specific topics. Three guiding questions per topic stressed the main issues of the topics (e.g., 'What do you know about the production of oxygen?'). Children could use single words or short sentences, without a set minimum or maximum. In the pretest, children were asked to write down all concepts that they could already relate to each of the topics (i.e., prior knowledge). In the posttest and retention test, they were instructed to write down the concepts that they had learned about during the final three weeks of the lesson series.

Inquiry knowledge test. To assess children's knowledge on the different steps of the inquiry cycle, an inquiry knowledge test was developed. The test contained eight multiple choice questions. Children were presented with a short case in which a specific step from the inquiry cycle applied and they had to determine which step of the inquiry cycle would follow or precede the described example. To answer the question, children had to select one of the remaining steps from the inquiry cycle (i.e., exploring, researching, concluding, evaluating, or broadening).

The inquiry knowledge test was administered three times, containing the same items presented in a different order. The inquiry knowledge tests had adequate reliabilities (KR20 ) at the pretest, midtest, and retention test, of $.67, .71$, and .70 , respectively. 
Attitudes toward technology and science questionnaire. Children's personal attitude towards technology and science were assessed by means of the validated measurement instrument developed by Walma van der Molen (2007). The questionnaire consisted of two parts, measuring attitude towards technology and science separately. Each part of the questionnaire contained 23 statements that referred to five underlying dimensions of attitude: (1) children's view on the relevance of technology or science for society (i.e., Relevance; e.g., 'Technology is important for our society'), (2) children's view on the difficulty of technological or scientific issues (i.e., Difficulty; e.g., 'Science is exclusively suitable for smart people.'), (3) children's stereotypical beliefs with regard to gender differences in the context of technology or science (i.e., Gender beliefs; e.g., 'Boys know more about technological issues than girls do.'), (4) the extent to which children enjoy engaging in technological or scientific activities (i.e., Enjoyment; e.g., 'I enjoy learning about scientific topics.'), and (5) children's intention to pursue a technological or scientific oriented education or profession in their future (i.e., Future; e.g., In my future, I would like to be educated in technology.'). Children could indicate their opinion using a four-point Likert scale, ranging from 'I totally disagree' to 'I totally agree'.

Children's attitudes were measured as part of the posttest; at the end of the lesson series. The different scales in both parts of the questionnaire reached sufficient reliabilities. The scales of the attitude towards technology questionnaire showed Cronbach's alpha's varying between .59 and .90 . The scales of the attitude towards science questionnaire reached Cronbach's alpha's varying between .48 and .86 .

\section{Procedure}

Children's participation, both in the ability-adjusted jigsaw condition and the control condition, spanned eleven sessions; seven sessions as part of the lesson series and four sessions to assess their progress by means of individual tests (see Figure 1 for an overview of the lesson series and moments of testing). In the first session, children completed the pretest containing the domain knowledge test on their assigned topic, the open recall test on the other topics, and the inquiry knowledge test. In the sixth session, after the first four weeks of the lesson series, children filled out the midtest consisting of the domain knowledge test on their assigned topic and the inquiry knowledge test. In the week following the last session of the lesson series, children completed the posttest consisting of the domain knowledge test on their assigned topic, the open recall test on the other topics, and the questionnaire measuring their attitude toward technology and science (session ten). Three months later, a retention test was administered (session eleven). The test contained the domain knowledge test on children's assigned topic, the open recall test on the other topics, and the inquiry knowledge test. Children were given one hour to complete the tests. 


\section{Data analysis}

Domain knowledge assigned topic test. The (open) questions of the domain knowledge tests were scored by means of a coding scheme. The answers were awarded zero to three points, depending on the presence of the required concept(s) and process(es) in children's answers. The maximum score for each test was 24 points. A second coder scored $31 \%$ (i.e., about 1200) of the domain knowledge tests. The inter-rater reliability coefficient (i.e., Cohen's kappa) was calculated for all sixteen tests separately. Cohen's kappa showed good inter-rater reliabilities, varying between .86 and .97 .

Domain knowledge gain was analyzed by means of three repeated measures analyses. Differences in knowledge gain could be expected for the different phases of the lesson series. In that respect, knowledge gain from pretest to midtest, from midtest to posttest, and from posttest to retention test were assessed separately. As children of different ability levels were assigned different topics, analyses were conducted for each ability level separately. The two topics for the average-ability children were taken together.

Open recall other topics test. To assess children's conceptual knowledge on the other topics of the lesson series, their open recall tests were scored by means of a coding scheme that listed the main concepts per topic. This selection was based on the major concepts of the assignments of the different topics in the expert phase. The coding process contained two steps. First, the concepts mentioned by the children on the different tests were scored. Second, the presence of new concepts in the posttest and retention test compared to the concepts in the pretest was assessed. Every new concept was awarded one point. To take into account children's prior knowledge as shown in their score on the pretest, a normalized learning gain was calculated (i.e., the number of new concepts on the posttest or retention test, respectively, divided by their potential learning possibility (i.e., maximum score on the pretest minus their actual score on the pretest)). Calculating normalized learning gain scores was a necessary measure as the openness of the assignment (e.g., 'What have you learned about the production of oxygen?') caused children to repeat already mentioned concepts in the pretest. A second coder scored 17\% (i.e., about 500) of the test-combinations. Inter-rater reliability was calculated for scoring the concepts in the tests, and detecting new concepts in the posttest or retention test. Cohen's kappa showed good inter-rater reliabilities of .82 and .84 , respectively.

Children's knowledge gain on these three other topics was analyzed by means of two univariate analyses of variance (ANOVAs) that included the normalized learning gain scores as described above. As different ability levels coincided with different assigned 
topics, the three remaining topics differed as well. Hence, analyses were conducted for each ability level separately.

Inquiry knowledge test. Children's knowledge on the different steps of the inquiry cycle was assessed by means of eight multiple questions per test. A correct answer was rewarded one point. The maximum score of each test was, therefore, 8 points.

Repeated measures analyses were conducted to assess children's inquiry knowledge gain from pretest to midtest, and from midtest to retention test. Differences between conditions were again assessed for the different ability levels separately.

Attitudes toward technology and science questionnaire. Technology and science parts of the questionnaire were both divided into five scales, based on the work of Walma van der Molen (2007): Relevance, Difficulty, Gender beliefs, Enjoyment, and Future. Mean scores on the different scales were calculated, varying from one to four points. In line with previous analyses, differences between conditions were assessed for the different ability levels separately. Six multivariate analyses of variance (MANOVAs) were conducted to examine children's attitudes toward technology and science.

Sample. The sample size and the number of different participating schools and classes could justify a multilevel analysis. However, considering that children within schools and classes were randomly divided over the ability-adjusted jigsaw condition and the control condition, multilevel analysis is not necessary to answer the research questions of the current study. For the sake of completeness, a multilevel analysis was performed. The results did not differ from the ones described in the Results-section below.

\section{Results}

\section{Domain knowledge assigned topic}

Table 5.2 shows children's mean domain knowledge scores on the pretest, midtest, posttest, and retention test on their assigned topic.

High-ability children's domain knowledge gain was first assessed from pretest to midtest. Repeated measures analysis, using Wilks' statistic, revealed a significant main effect for the within-subject factor Time $\left(\Lambda=.61, F(1,219)=140.08, p<.001, \eta_{\mathrm{p}}{ }^{2}=.39\right)$. There was no significant interaction (Time $\times$ Condition; $\Lambda=.99, F(1,219)=.50, p=.482, \eta_{\mathrm{p}}^{2}=.00$ ). Second, repeated measures analysis from midtest to posttest revealed a significant main effect for the within-subject factor Time $\left(\Lambda=.80, F(1,218)=53.36, p<.001, \eta_{\mathrm{p}}{ }^{2}=.20\right)$. There was no 
Table 5.2

Mean scores and standard deviations on the domain knowledge tests on children's assigned topics for the ability-adjusted jigsaw condition and the control condition

\begin{tabular}{|c|c|c|c|c|c|c|}
\hline & \multicolumn{2}{|c|}{$\begin{array}{c}\text { Ability- } \\
\text { adjusted } \\
\text { jigsaw }\end{array}$} & \multicolumn{2}{|c|}{ Control } & \multicolumn{2}{|c|}{ Total } \\
\hline & $\mathrm{M}$ & SD & $\mathrm{M}$ & SD & $\mathrm{M}$ & SD \\
\hline \multicolumn{7}{|l|}{ High-ability } \\
\hline Domain knowledge pretest & 5.80 & 4.55 & 5.51 & 4.57 & 5.68 & 4.55 \\
\hline Domain knowledge midtest & 9.41 & 4.96 & 8.84 & 5.02 & 9.17 & 4.98 \\
\hline Domain knowledge posttest & 11.51 & 4.62 & 11.34 & 4.66 & 11.44 & 4.63 \\
\hline Domain knowledge retention test & 9.90 & 4.93 & 9.34 & 4.42 & 9.68 & 4.73 \\
\hline \multicolumn{7}{|l|}{ Average-ability } \\
\hline Domain knowledge pretest & 5.01 & 3.64 & 4.88 & 3.34 & 4.95 & 3.49 \\
\hline Domain knowledge midtest & 5.39 & 3.63 & 6.04 & 4.12 & 5.70 & 3.88 \\
\hline Domain knowledge posttest & 8.03 & 3.87 & 8.56 & 4.06 & 8.28 & 3.97 \\
\hline Domain knowledge retention test & 8.29 & 4.69 & 8.86 & 4.53 & 8.55 & 4.62 \\
\hline \multicolumn{7}{|l|}{ Low-ability } \\
\hline Domain knowledge pretest & 4.23 & 2.67 & 4.37 & 2.86 & 4.29 & 2.75 \\
\hline Domain knowledge midtest & 6.40 & 3.30 & 6.30 & 3.00 & 6.36 & 3.16 \\
\hline Domain knowledge posttest & 8.63 & 3.69 & 8.96 & 3.57 & 8.78 & 3.63 \\
\hline Domain knowledge retention test & 6.52 & 3.67 & 6.98 & 3.68 & 6.73 & 3.67 \\
\hline
\end{tabular}

Note. Maximum score of the domain knowledge tests was 24.

interaction (Time $\times$ Condition; $\Lambda=.99, F(1,218)=.84, p=.361, \eta_{\mathrm{p}}{ }^{2}=.00$ ). A final repeated measures analysis to assess domain knowledge three months after completion of the lesson series, measured by means of the retention test, as compared to the posttest, indicated a significant main effect for Time $\left(\Lambda=.85, F(1,202)=34.61, p<.001, \eta_{\mathrm{p}}{ }^{2}=.15\right)$. No significant interaction was found (Time $x$ Condition; $\Lambda=.99, F(1,202)=.88, p=.348, \eta_{\mathrm{p}}^{2}=.00$ ).

A repeated measures analysis to indicate average-ability children's domain knowledge gain from pretest to midtest showed a significant main effect for the within-subjects factor Time $(\Lambda=.97$, $\left.F(1,484)=13,51, p<.001, \eta_{\mathrm{p}}{ }^{2}=.03\right)$. There was no interaction (Time $\mathrm{x}$ Condition; $\Lambda=.99, F(1$, $\left.484)=3.84, p=.051, \eta_{\mathrm{p}}^{2}=.01\right)$. A second repeated measures analysis, assessing domain knowledge from midtest to posttest, revealed a significant main effect for the within-subject factor Time $\left(\Lambda=.65, F(1,482)=261.89, p<.001, \eta_{p}^{2}=.35\right)$. There was no interaction (Time $\mathrm{x}$ Condition; $\left.\Lambda=1.00, F(1,482)=01, p=.931, \eta_{\mathrm{p}}^{2}=.00\right)$. A final repeated measures analysis to assess to assess domain knowledge from posttest to retention test showed no significant main effect for Time $\left.(\Lambda=.99, F(1,4) \mathrm{z} 59)=.71, p=.401, \eta_{\mathrm{p}}{ }^{2}=.00\right)$, nor was there a significant interaction (Time $x$ Condition) $\Lambda=1.00, F(1,459)=.20, p=.656, \eta_{\mathrm{p}}^{2}=.00$ ). 
Low-ability children's domain knowledge was first assessed from pretest to midtest. Repeated measures analysis, using Wilks' statistic, indicated a significant main effect for the within-subject factor Time $\left(\Lambda=.72, F(1,228)=87.75, p<.001, \eta_{\mathrm{p}}{ }^{2}=.28\right)$. There was no significant interaction (Time $\times$ Condition; $\Lambda=.99, F(1,228)=.67, p=.415, \eta_{\mathrm{p}}^{2}=.00$ ). Second, repeated measures analysis from midtest to posttest revealed a significant main effect for the within-subject factor Time $\left(\Lambda=.64, F(1,227)=128.28, p<.001, \eta_{\mathrm{p}}^{2}=.36\right)$. There was no significant interaction (Time $\times$ Condition; $\Lambda=.99, F(1,227)=2.56, p<.111, \eta_{\mathrm{p}}{ }^{2}=.01$ ). A final repeated measures analysis to assess domain knowledge from posttest to retention test revealed a significant main effect for Time $\left(\Lambda=.73, F(1,211)=78.82, p<.001, \eta_{\mathrm{p}}{ }^{2}=.27\right)$. There was no interaction (Time $\times$ Condition; $\Lambda=1.00, F(1,211)=.03, p=.870, \eta_{\mathrm{p}}^{2}=.00$ ).

The significant main effects indicate that, over the course of the study, children showed an increase in knowledge about their assigned topic. The scores on the retention test showed a small decrease in knowledge. This was the case for all three ability levels, with one exception: the average-ability children did not show differences in scores from posttest to retention test. The lack of significant interactions means that whether or not children worked within the context of the ability-adjusted jigsaw method or the control condition did not influence the results.

\section{Domain knowledge other topics}

Table 5.3 shows children's normalized learning gain on the recall tests on the three remaining topics. Normalized learning gain scores were calculated to account for children's prior knowledge as the openness of the test greatly increased recurrence of concepts.

The ANOVAs revealed no significant differences between conditions for all three ability levels. High-ability children's normalized learning gain showed no differences between conditions on the posttest $\left(F(1,242)=.00, p=.969, \eta_{\mathrm{p}}^{2}=.00\right)$, nor on the retention test $(F(1$, $\left.211)=.73, p=.394, \eta_{\mathrm{p}}^{2}=.00\right)$. Comparable results were found for the average-ability children on the posttest $\left(F(1,532)=.08, p=.778, \eta_{\mathrm{p}}^{2}=.00\right)$ and the retention test $(F(1,466)=.01, p=$ $\left..916, \eta_{\mathrm{p}}{ }^{2}=.00\right)$, as well as for the low-ability children on the posttest $(F(1,240)=1,56, p=.212$, $\left.\eta_{\mathrm{p}}{ }^{2}=.01\right)$ and the retention test $\left(F(1,211)=.53, p=.469, \eta_{\mathrm{p}}^{2}=.00\right)$.

\section{Inquiry knowledge}

Table 5.4 gives an overview of children's mean scores on the inquiry knowledge tests, administered as a pretest, midtest, and retention test.

High-ability children's inquiry knowledge was first analysed with a repeated measures analysis from pretest to midtest. Using Wilks' statistic, the analysis indicated a significant 
Table 5.3

Mean normalized learning gain scores and standard deviations on the recall tests on the other topics for the ability-adjusted jigsaw condition and the control condition

\begin{tabular}{|c|c|c|c|c|c|c|}
\hline & \multicolumn{2}{|c|}{$\begin{array}{c}\text { Ability-adjusted } \\
\text { jigsaw }\end{array}$} & \multicolumn{2}{|c|}{ Control } & \multicolumn{2}{|c|}{ Total } \\
\hline & $\mathrm{M}$ & SD & $\mathrm{M}$ & SD & $\mathrm{M}$ & $\mathrm{SD}$ \\
\hline \multicolumn{7}{|l|}{ High-ability } \\
\hline Pretest - Posttest & .18 & .14 & .18 & .15 & .18 & .14 \\
\hline Pretest - Retention test & .15 & .14 & .14 & .11 & .15 & .13 \\
\hline \multicolumn{7}{|l|}{ Average-ability } \\
\hline Pretest - Posttest & .15 & .13 & .14 & .12 & .14 & .13 \\
\hline Pretest - Retention test & .14 & .13 & .13 & .13 & .13 & .13 \\
\hline \multicolumn{7}{|l|}{ Low-ability } \\
\hline Pretest - Posttest & .11 & .10 & .13 & .12 & .12 & .11 \\
\hline Pretest - Retention test & .10 & .12 & .11 & .11 & .11 & .12 \\
\hline
\end{tabular}

main effect of the within-subject factor Time $\left(\Lambda=.83, F(1,219)=44.84, p<.001, \eta_{\mathrm{p}}{ }^{2}=\right.$ .17). There was no interaction (Time $x$ Condition; $\Lambda=.99, F(1,219)=1.83, p=.177, \eta_{\mathrm{p}}{ }^{2}=.01$ ). Second, a repeated measures analysis from midtest to retention test showed no significant main effect for the within-subject factor Time $\left(\Lambda=1.00, F(1,192)=.00, p=.983, \eta_{\mathrm{p}}{ }^{2}=.00\right)$, neither was there a significant interaction (Time $\mathrm{x}$ Condition; $\Lambda=.99, F(1,192)=.57, p=$ $\left..453, \eta_{\mathrm{p}}{ }^{2}=.00\right)$.

A repeated measures analysis concerning average-ability children's inquiry knowledge from pretest to midtest revealed a significant main effect of the within-subject factor Time $(\Lambda=$ $.86, F(1,484)=76.49, p<.001, \eta_{\mathrm{p}}^{2}=.14$ ). There was no interaction (Time $\mathrm{x}$ Condition; $\Lambda=$ 1.00, $\left.F(1,484)=.25, p=.618, \eta_{\mathrm{p}}{ }^{2}=.00\right)$. Subsequent repeated measures analysis from midtest to retention test showed no significant effects; neither for the within-subject factor Time $\left(\Lambda=.99, F(1,423)=1.48, p=.225, \eta_{p}{ }^{2}=.00\right)$, nor was there an interaction (Time $x$ Condition; $\left.\Lambda=1.00, F(1,423)=.02, p=.883, \eta_{\mathrm{p}}^{2}=.00\right)$.

For the low-ability children, repeated measures analysis from pretest to midtest revealed a significant main effect of the within-subject factor Time $(\Lambda=.95, F(1,228)=11.65, p=.001$, $\eta_{\mathrm{p}}{ }^{2}=.05$ ). There was no significant interaction (Time $\mathrm{x}$ Condition; $\Lambda=.99, F(1,228)=.96, p$ $\left.=.330, \eta_{\mathrm{p}}{ }^{2}=.00\right)$. Subsequently, repeated measures analysis from midtest to retention test showed no significant effects; neither for the within-subject factor Time $(\Lambda=1.00, F(1,199)$ $=.06, p<.807, \eta_{\mathrm{p}}{ }^{2}=.00$ ) nor was there an interaction (Time $\mathrm{x}$ Condition; $\Lambda=.99, F(1,199)=$ $\left..85, p=.359, \eta_{\mathrm{p}}^{2}=.00\right)$. 
Table 5.4

Mean scores and standard deviations on the inquiry knowledge tests for the ability-adjusted jigsaw condition and the control condition

\begin{tabular}{|c|c|c|c|c|c|c|}
\hline & \multicolumn{2}{|c|}{$\begin{array}{c}\text { Ability-adjusted } \\
\text { jigsaw }\end{array}$} & \multicolumn{2}{|c|}{ Control } & \multicolumn{2}{|c|}{ Total } \\
\hline & $\mathrm{M}$ & SD & $\mathrm{M}$ & SD & $\mathrm{M}$ & SD \\
\hline \multicolumn{7}{|l|}{ High-ability } \\
\hline Inquiry knowledge pretest & 3.28 & 2.20 & 3.29 & 2.20 & 3.29 & 2.20 \\
\hline Inquiry knowledge midtest & 4.58 & 2.20 & 4.11 & 2.50 & 4.38 & 2.33 \\
\hline Inquiry knowledge retention test & 4.48 & 2.36 & 4.30 & 2.32 & 4.41 & 2.34 \\
\hline \multicolumn{7}{|l|}{ Average-ability } \\
\hline Inquiry knowledge pretest & 1.93 & 1.82 & 1.97 & 1.72 & 1.95 & 1.77 \\
\hline Inquiry knowledge midtest & 2.87 & 2.01 & 2.85 & 2.07 & 2.86 & 2.04 \\
\hline Inquiry knowledge retention test & 2.94 & 2.04 & 3.00 & 2.08 & 2.97 & 2.05 \\
\hline \multicolumn{7}{|l|}{ Low-ability } \\
\hline Inquiry knowledge pretest & 1.46 & 1.36 & 1.53 & 1.62 & 1.49 & 1.49 \\
\hline Inquiry knowledge midtest & 1.74 & 1.53 & 2.04 & 1.56 & 1.87 & 1.55 \\
\hline Inquiry knowledge retention test & 1.91 & 1.57 & 2.08 & 1.48 & 1.99 & 1.53 \\
\hline
\end{tabular}

The significant main effects from pretest to posttest show that children of all three ability levels increased in knowledge about the inquiry cycle during the lesson series. There was no follow-up effect from midtest to retention test. The absence of interactions showed that results were not dependent of the condition the children worked in.

\section{Attitudes toward technology and science}

Table 5.5 shows children's mean scores on the different scales of the attitude toward technology and science questionnaire.

Attitude toward technology. Three MANOVAs assessed high-ability, average-ability, and low-ability children's attitudes toward technology. Using Wilks' statistic, the analysis revealed no significant differences between conditions for high-ability children $(\Lambda=.98, F(5$, $\left.157)=.50, p=.777, \eta_{\mathrm{p}}{ }^{2}=.02\right)$, average-ability children $\left(\Lambda=.99, F(5,318)=.61, p=.692, \eta_{\mathrm{p}}{ }^{2}=\right.$ $.01)$, and low-ability children $\left(\Lambda=.96, F(5,141)=1.23, p=.300, \eta_{\mathrm{p}}^{2}=.04\right)$.

Attitudes toward science. Three similar MANOVAs assessed children's attitudes toward science. Using Wilks' statistic, the analyses indicated no significant differences between conditions for high-ability children $\left(\Lambda=.94, F(5,159)=1.99, p=.083, \eta_{\mathrm{p}}{ }^{2}=.06\right)$, average-ability 
children $\left(\Lambda=.99, F(5,327)=.43, p=.827, \eta_{\mathrm{p}}^{2}=.01\right)$, and low-ability children $(\Lambda=.96, F(5,127)$

$\left.=1.15, p=.340, \eta_{\mathrm{p}}^{2}=.04\right)$.

Table 5.5

Mean attitude scores and standard deviations toward technology and science for the ability-adjusted jigsaw and the control condition

\begin{tabular}{|c|c|c|c|c|c|c|c|c|c|c|c|c|}
\hline & \multicolumn{6}{|c|}{ Attitudes toward technology } & \multicolumn{6}{|c|}{ Attitudes toward science } \\
\hline & \multicolumn{2}{|c|}{$\begin{array}{c}\text { Ability- } \\
\text { adjusted } \\
\text { jigsaw }\end{array}$} & \multicolumn{2}{|c|}{ Control } & \multicolumn{2}{|c|}{ Total } & \multicolumn{2}{|c|}{$\begin{array}{l}\text { Ability- } \\
\text { adjusted } \\
\text { jigsaw }\end{array}$} & \multicolumn{2}{|c|}{ Control } & \multicolumn{2}{|c|}{ Total } \\
\hline & $\mathrm{M}$ & SD & $\mathrm{M}$ & SD & $\mathrm{M}$ & SD & $\mathrm{M}$ & SD & $\mathrm{M}$ & SD & $\mathrm{M}$ & SD \\
\hline High-ability & & & & & & & & & & & & \\
\hline Relevance & 2.74 & .56 & 2.77 & .59 & 2.75 & .57 & 3.01 & .63 & 2.89 & .57 & 2.96 & .61 \\
\hline Difficulty & 1.81 & .52 & 1.79 & .53 & 1.80 & .53 & 2.54 & .66 & 2.50 & .66 & 2.53 & 66 \\
\hline Gender beliefs & 2.20 & .93 & 2.17 & 1.03 & 2.19 & .97 & 1.89 & .93 & 1.80 & .96 & 1.85 & .94 \\
\hline Enjoyment & 3.21 & .60 & 3.13 & .60 & 3.17 & 60 & 3.16 & .63 & 3.04 & .71 & 3.11 & .66 \\
\hline Future & 2.23 & .96 & 2.14 & .93 & 2.19 & .95 & 2.19 & .84 & 1.99 & .82 & 2.11 & .83 \\
\hline Average-ability & & & & & & & & & & & & \\
\hline Relevance & 2.74 & .57 & 2.71 & .51 & 2.73 & .54 & 2.92 & .55 & 2.88 & .54 & 2.90 & .54 \\
\hline Difficulty & 1.87 & .59 & 1.94 & .65 & 1.90 & .62 & 2.60 & .74 & 2.66 & .73 & 2.63 & .74 \\
\hline Gender beliefs & 2.46 & 1.00 & 2.44 & 1.01 & 2.45 & 1.01 & 2.03 & .99 & 2.02 & .99 & 2.03 & .99 \\
\hline Enjoyment & 3.10 & .60 & 3.04 & .64 & 3.07 & .62 & 2.95 & .70 & 2.91 & .71 & 2.93 & .70 \\
\hline Future & 1.98 & .87 & 2.02 & .91 & 2.00 & .89 & 1.82 & .75 & 1.86 & .77 & 1.84 & .76 \\
\hline Low-ability & & & & & & & & & & & & \\
\hline Relevance & 2.78 & .52 & 2.70 & .56 & 2.75 & .54 & 2.83 & .57 & 2.86 & .60 & 2.85 & .58 \\
\hline Difficulty & 1.98 & .60 & 2.08 & .70 & 2.03 & .65 & 2.48 & .79 & 2.61 & .68 & 2.53 & .75 \\
\hline Gender beliefs & 2.32 & .96 & 2.18 & .96 & 2.26 & .96 & 1.88 & .86 & 1.95 & .92 & 1.91 & .88 \\
\hline Enjoyment & 3.02 & .62 & 3.11 & .57 & 3.07 & .60 & 2.79 & .79 & 2.89 & .73 & 2.83 & .75 \\
\hline Future & 1.96 & .87 & 2.05 & .98 & 2.00 & .92 & 1.82 & .83 & 1.79 & .71 & 1.81 & .78 \\
\hline
\end{tabular}

\section{Discussion}

In this study, an ability-adjusted version of the jigsaw method that combined differentiated learning in homogeneous groups with explicit support for heterogeneous cooperation was created and investigated. This ability-adjusted jigsaw method intended to improve, or at least maintain, cognitive development as compared to more traditional, individual learning within the social context of the mixed-ability classroom. Assuming that children benefit a great deal on a social level from working together with the same-ability and other-ability classmates (e.g., Abdullah \& Shariff, 2008; Cohen, 1994; Förrer et al., 2000), the focus of this study was to determine the effect of the ability-adjusted jigsaw method on children's cognitive development. 
The results of this study showed that children profited equally from the ability-adjusted jigsaw method and the more traditional method in which children individually studied similar topics. Children in both conditions showed an increase in domain knowledge and knowledge of the inquiry cycle after having completed the lesson series but there were no differences between conditions. These results were found for all three ability levels and indicate that learning according to the ability-adjusted jigsaw method could be considered just as cognitively beneficial for children as individual learning. We will now evaluate the results of this study further and look for possibilities to increase the effectiveness of the ability-adjusted jigsaw method.

In the homogeneous groups that were part of the ability-adjusted jigsaw condition, children worked on inquiry tasks with structure and support that were matched to their ability level (van Dijk et al., 2016). Ability-related differences between children and difficulties that (younger) children experience with inquiry assignments were taken into account (Wang et al., 2010; Zimmerman, 2007). Differentiating learning tasks that match children's potential have proven to be effective in enhancing their learning outcomes (e.g., Tomlinson, 2000). The inquiry tasks in the current study resulted in equivalent cognitive learning outcomes (i.e., domain knowledge and inquiry knowledge) as the more traditional, individual tasks. These results are promising, but it is interesting to investigate how to further improve learning in the homogeneous expert phase. An important issue to look at is children's familiarity with the inquiry learning method. We deliberately chose active processing of knowledge by inquiry learning as a learning method to enhance children's feeling of 'expertise' and engagement in the group process (Alfieri et al., 2011; Mayer, 2003, 2004; Minner et al., 2010). However, inquiry learning was relatively new for children. To further accommodate the children during the homogeneous expert phase, assignments were offered in a specific order and sub-sets were made for the different weeks. However, future research could be done to gain more insight into what children need to be able to learn when engaging in inquiry learning activities. Within this context, it seems interesting to look into the effects of providing children with more time to spend on these tasks or offer children time to practice their inquiry learning skills by, for example, making inquiry tasks more prominent earlier in their curriculum.

In the heterogeneous design phase of the ability-adjusted jigsaw condition, children shared the knowledge on their assigned topic in heterogeneous cooperative groups to co-create their design of a moon house. Even though knowledge gains were small, the results of this study showed that children were able to expand their knowledge base on their assigned topic during this phase and that there were no differences with the knowledge gain of the children in the control condition that studied the information individually. Future research should look into the possibilities to further enhance children's cognitive development 
while working in heterogeneous cooperative groups. A promising result is that, even though children in the ability-adjusted jigsaw method were personally responsible for sharing knowledge on their assigned topic, they were able to further develop this knowledge. The worksheet that structured the information-sharing lesson of the heterogeneous design phase (see Chapter 4) intended to make children aware that the information they gathered during the homogeneous expert phase was important for the success of the cooperative process in the next phase of the jigsaw learning process. However, children's knowledge gain on their assigned topic might be further enhanced when they receive support that might help them identify important and relevant information during the knowledge-gathering activities in the homogeneous expert phase. In the current lesson series, the assignments covering the different subtopics and the core assignment that outlined these most important subtopics offered this support in an implicit way. However, since the identification of relevant information is considered difficult for children (Zimmerman, 2007), it is interesting to investigate the effects of more explicit forms of support that guide this process.

Looking at children's domain knowledge on the other topics, the finding that there were no differences between conditions could be caused by the fact that children in the abilityadjusted jigsaw condition were dependent on each other for information to be able to learn about their group members' topics (Slavin, 2015). In the control condition, children were given the opportunity to study these topics themselves. This finding might suggest that the set-up of the ability-adjusted jigsaw condition, that included specific support for the information sharing process in the heterogeneous design phase, has yielded some benefits. With the support offered in this study's lesson series, children were able to provide their group members with as much information on the topic that they represented as the information that children gathered by studying the topics themselves in the control condition. However, future research should investigate what is needed to further improve learning about group members' topics in the jigsaw-context.

The absence of differences between conditions on knowledge of the inquiry cycle and children's attitudes toward technology and science were unforeseen. The assignments in the control condition were not based on the inquiry cycle whereas the inquiry cycle appeared frequently in the assignments of the ability-adjusted jigsaw condition. Apparently, the fact that both lesson series concerned the same scientific learning goals led to equal possibilities to develop inquiry knowledge and attituces towards technology and science. Furthermore, the inquiry knowledge tests may have implicitly triggered children's inquiry knowledge in the control condition and children might have picked up the logic by practicing with the test (i.e, testing effect). 
In the current study, the ability-adjusted jigsaw method was designed on the assumption that a combination of heterogeneous cooperation and homogeneous collaboration would meet the requirements for social development and social inclusion of children of different ability levels (Abdullah \& Shariff, 2008; Aronson et al., 1978; Förrer et al., 2000; Slavin, 1990). Now that the results of this study have demonstrated that there are no cognitive disadvantages of learning together in a combination of homogeneous and heterogeneous groups compared to individually studying the same learning goals, it might be interesting to further investigate the notion that the ability-adjusted jigsaw method would indeed have a positive effect on children's social development. Future studies might look into the strength of the effect of the ability-adjusted jigsaw method on social cohesion by means of sociogram or network analysis and on children's development of social skills. Besides, given that the current intervention was a short one (i.e., seven lessons) and children worked together with a small delegation of their classmates, it would be recommended to look at the effects of the jigsaw method on long term so that children could get used to this method of learning and have had the opportunity to collaborate and cooperate with various, other classmates in their mixed-ability classrooms.

\section{Conclusions}

The results of this study indicate that working together by means of the ability-adjusted jigsaw method could be considered a suitable alternative for individual learning when attending to cognitive development of children of different ability levels. There were no differences in cognitive benefits from either learning within the context of the abilityadjusted jigsaw method or learning individually with more traditional assignments in the control condition. Taking into account that children's social development might benefit from working according the ability-adjusted jigsaw method, one might advocate adding this method to the elementary school curriculum. 

Chapter 6

General discussion 



\section{Introduction}

This dissertation is written in a time when Dutch professionals in elementary education are challenged to renew and improve their education. Children's cognitive development is considered the most important measure to pass judgment on the success of elementary educational practice (Berends \& Wolthuis, 2014; Doolaard \& Oudbier, 2010). At the same time, teachers are expected to differentiate between ability levels (Dekker, 2014; Tomlinson, 2000) and children's social skills development (in the context of 21st century skills) is put forward as in important prerequisite to prepare children for their future role in society (Geisinger, 2016; Thijs et al., 2014; Trilling \& Fadel, 2009).

Teachers often struggle how to implement these different demands in their daily practice. This is mainly caused by the contradictions that teachers feel that exist between the different demands. Regarding the development of social skills, teachers wonder how to make sure that (mixed-ability) cooperative or collaborative learning is not at the expense of children's cognitive development. When paying more attention to children's different levels of ability (i.e., differentiation), teachers ask themselves how to find a balance in paying attention to children who perform below average and children who already show sufficient levels of performance but do not reach their potential. And an ever-recurring overarching factor in this regard is that teachers struggle with the questions: how to find time in their overcrowded time schedule to implement these new demands in daily practice. To address these issues, a lesson series was developed that intended to combine the different demands without adding additional pressure on teachers' work schedule.

This final chapter intends to create an overview of the research reported in this dissertation. The next sections review the results of the different studies conducted in the context of this dissertation and issues that could have influenced these results. First, the main aims of the four-year design-project, resulting in the BE COOL! lesson series, will be addressed. Then, the practical implications, limitations, and ideas for future research in the context of this dissertations' research will be considered. Finally, the implementation process of a large-scale intervention like the one in this dissertation will be reflected upon.

\section{BE COOL! lesson series}

The learning method that laid the foundation for the BE COOL! lesson series is the jigsaw method (Aronson et al., 1978). In a four-year design-project that was described in the current dissertation, the jigsaw method was adapted so that elementary school teachers could provide their children with a lesson series that incorporated differentiated support to children's level of ability, and the opportunity for children to collaborate and cooperate with their classmates that vary in ability level. The ability-adjusted jigsaw method should 
assist teachers in complying the demands concerning both cognitive and social development.

Assuming that working in the context of the ability-adjusted jigsaw method would enhance children's social development, the research focus of this dissertation was on children's cognitive development. When it could be shown that children of different ability levels are able to profit cognitively from working together in different group compositions, as is proposed in the ability-adjusted jigsaw lesson series, teachers might be more prone to use this way of 'working together' in their daily practice.

Building up to the large-scale evaluation study, two experimental studies were performed that, combined with three pilot studies, provided input for the development of the lesson series (see Figure 2.11 for an overview). To this end, children were put to work with different parts of the lesson series. The results of these studies eventually led to the final version of the lesson series that included differentiated support for the inquiry assignments in the homogeneous expert phase (see Chapter 3) and a worksheet that supported the transition from homogeneous expert groups to heterogeneous design groups in which children's main task was to share their knowledge with their group members (see Chapter 4).

In the large-scale evaluation study, described in Chapter 5, the ability-adjusted jigsaw method was compared to more traditional, individual, learning. Results of this study indicated that a combination of differentiated homogeneous collaboration and supported heterogeneous cooperation in a context of inquiry learning and learning by design leads to equivalent cognitive benefits for children as working individually on the same learning goals. Differences between children who worked within the ability-adjusted jigsaw condition and children who worked with a control condition were not found. This positive result was present for children of all three ability levels.

\section{Evaluating the lesson series}

The ability-adjusted jigsaw method was structured and supported on the basis of multiple studies that provided input for the concrete design of the lesson series. The intervention can be regarded a success in the sense that children (of all ability levels) reached the same cognitive level as children in the control condition while children of different ability levels were encouraged to socially interact with each other.

The lesson series should be considered as a 'package as a whole'. Nevertheless, it is interesting to shed some light on the findings and content of the different phases of the 
ability-adjusted jigsaw method to gain insight in concrete features that offer room for improvement and to provide implications for research and practice.

\section{Homogeneous expert phase}

One of the main features of this dissertation's ability-adjusted jigsaw method was the way of learning: a combination of learning by design and inquiry learning. Concerning the latter learning method, the inquiry cycle was deliberately chosen to shape the assignments that were part of the homogeneous expert phase. The most important reason for this was that inquiry learning, if designed and supported thoroughly, has been proven to lead to better results than learning by direct instruction (e.g., Eysink \& de Jong, 2012; Furtak, Seidel, Iverson, \& Briggs, 2012; Mayer, 2004; Smetana \& Bell, 2012). Inquiry learning forces students to play an active role in collecting and processing information, and in constructing new knowledge (Alfieri et al., 2011; Mayer, 2003, 2004; Minner, Levy, \& Century, 2010). Consequently, the active role that children have in gathering their knowledge in the homogeneous expert phase should increase their feelings of responsibility and mastery over the to-be-shared knowledge in the heterogeneous design phase. However, both the content of the tasks as the way of working with the tasks (i.e., inquiry learning) were relatively new for most children. Children showed low prior knowledge on the topics that were central in the inquiry assignments in the homogeneous expert phase and inquiry learning might be less effective when children possess little prior knowledge on the to-belearned domain (Frey, Fisher, \& Hattie, 2017; Hattie \& Donoghue, 2016; Lazonder et al., 2008). Considering this, future research could look into the additional value of adding specific domain-related information to the inquiry assignments for children's learning outcomes in the homogeneous expert phase. Starting with a higher prior knowledge base, children should be able to engage in more fruitful inquiry activities which increases children's potential for learning from these activities (Frey et al., 2017). Furthermore, inquiry learning as a process was also new to the children whereas the more traditional working method that shaped the assignments in the control condition was very familiar for the children. This might have influenced the results. An improvement might be that children learn in repeated sequences of the ability-adjusted jigsaw lesson series. To realize this, the ability-adjusted jigsaw method needs to be developed within different domains or maybe even different subjects, like mathematics. It might be a logical next step to upscale the lesson series and future research should point out whether different, consecutive versions of the ability-adjusted jigsaw method would yield the same, or possible improving, effects.

The studies described in this dissertation have contributed to a lesson series that included differentiated inquiry assignments that intended to account for children's needs for 
structure to complete the assignments as part of the homogeneous expert phase. Results that indicated that most children experienced difficulties with completing the entire set of assignments on time, led to the further structuring of the sets of assignments that were central to this phase. These structural features catered mainly to children's ability to plan and complete the assignments within the given time. However, in the large-scale evaluation study (Chapter 5) teachers reported that children still experienced difficulties with completing the set of tasks accurately and precisely. This could have had a negative effect on the outcomes of the evaluation study. An explanation could be sought in the demands that were placed on both children's macro-level self-regulation skills (such as planning) and micro-level self-regulation skills (such as monitoring progress within a task). These demands, when working on the inquiry assignments in the homogeneous expert phase, might be considered high. Children might have spent too much time on planning and monitoring their next steps both within and between inquiry assignments, which might have caused them to have little time left to spend on the tasks at hand. Adding selfregulation support to the lesson series might increase children's capability to complete the assignments in time and, therefore, fully benefit from the way of learning that was offered. Previous research has shown that children indeed need sufficient self-regulation skills for inquiry learning to be effective (Kuhn, Black, Keselman, \& Kaplan, 2000; Manlove, Lazonder, \& de Jong, 2007). However, determining when children's self-regulation skills are 'sufficient' is, however, not unambiguous and more research could shed light on the necessary level of self-regulation. In this context, it might be interesting to investigate whether a similar distinction between ability levels, as was distinguished in this dissertation, could be made to tailor support for self-regulation.

\section{Heterogeneous design phase}

While previous research has expressed specific concerns for the higher ability children when working in heterogeneous groups (Gillies, 2003; Kulik \& Kulik, 1982), this dissertation showed that also high-ability children functioned well in the ability-adjusted jigsaw approach. The ability-adjusted jigsaw method seems to create a situation in which children see and approach each other as resources and allies instead of competitors or deadweight (Aronson et al, 1978). This was also visible in the results of the research described in Chapter 4: all children, regardless of ability level, took part in the cooperative dialogue regarding the shared design of the moon house. The worksheet that was offered to structure the cooperative process seemed to have positively influenced the equality of children's participation in the group dialogue and created a dialogue that showed a larger proportion of domain-related contributions. Information sharing, more specifically providing and receiving information, has been appointed more often as a major prerequisite for learning (Webb, 1982a, 1982b, 1984). In this dissertation, we seem to have 
found a way to support the heterogeneous cooperative dialogue in such a way that children of all ability levels could profit from engaging in this cooperative dialogue. However, as the results of the large-scale evaluation study (Chapter 5) show, improvements could still be made to create a learning situation in which working together outperforms studying the materials individually.

One specific way to further improve children's learning possibilities within the heterogeneous cooperative processes is to pay specific attention to children's social skills. The fifth element specified by Johnson et al. (2007), appropriate use of social skills, was not addressed in the worksheet used to support the first lesson of the heterogeneous design phase. Johnson et al. (2007) stated, however, that the appropriate use of social skills during a cooperative process is an important prerequisite for the success of the cooperative process. Deciding whether support on social skills were to be part of the worksheet was based on the consideration that social skills are considered to be complex skills and require intensive training (cf., Saab et al., 2007), especially for younger children (Gijlers, Weinberger, van Dijk, Bollen, \& van Joolingen, 2013; van Dijk, Gijlers, \& Weinberger, 2014). Such training has proven to be most effective when offered prior to the cooperative process (Saab et al., 2007). In the end, such a training was not part of the support offered in this dissertation, as it would require more extensive preparation of teacher's lessons, and would therefore not apply as a support tool that could be offered 'just-in-time'. An important aim of the lesson series developed in this dissertation was to create a lesson series that did not put additional pressure on teachers. Future research should be done to gain insight in the additional value of adding a training in social skill development to the lesson series. When proven successful for children's learning possibilities within the heterogeneous cooperative process, consideration could be given to the costs and benefits of such a training for the current context.

Of course, there are many factors, besides heterogeneity, that might influence the success of a cooperative process. As Lou et al. (1996) stated in their review, it is not possible to designate one type of group composition that fits the needs of children of different ability levels best. This is stated from a cognitive perspective. A number of other characteristics (e.g., demographic characteristics such as gender or SES, classroom-specific characteristics such as the day of the week that a lesson was conducted, or characteristics of the children such as their personal preferences) could influence the cooperative process too. To provide a clear overview of the influence of these characteristics and their consequences for grouping practice, additional research should be conducted. This could then create practical guidelines for teachers on how to assemble groups in their classroom, ruling out all possibilities of disturbing factors within a group. In any case, the studies in this dissertation showed that teachers who, till this day, tend to avoid heterogeneous group 
settings as they are not sure of possible consequences for the high-ability children in the group, now have a way to realize mixed-ability level cooperation.

\section{Ability-adjusted jigsaw method}

Even though the grouping method that was used in the research described in this dissertation, that divided the children into high-ability, average-ability, and low-ability children, was based on conventional performance measures and was in line with teachers' intuitive division of abilities in their classes, grouping of children remains a re-occurring topic of debate. Also, for this dissertation additional questions could be asked. First of all, a categorization like the one used in this dissertation could suggest 'teach down' practices. However, in this dissertation, a reverse situation is actually the case: children are offered assignments that match their ability level, so that they are challenged at their own level. Second, the categorization method that was used did not pay specific attention to children with learning problems, such as dyslexia. However, in Dutch educational practice the tripartite division as used here is a commonly used distinction method. Adding the Dutch 'Digital Measuring Protocol Giftedness' (i.e., Digitaal Handelingsprotocol Hoogbegaafdheid, DHH; van Gerwen \& Drent, 2011) increased the accuracy of the categorization procedure regarding signaling high-ability children who perform below their potential. Future studies could take learning problems into account when grouping children or gain more insight into the effect of these learning problems on children's inquiry learning activities. Third, it has been stated that heterogeneous cooperation is most efficient when grouping children with 'extreme differences in ability levels' (e.g., lowability and high-ability children in one group; Lou et al., 1996; Wang et al., 2010) is avoided. However, one of the main goals of this dissertation's lesson series was to make sure that the learning method that was used would also have a positive influence on social inclusion of children within the mixed-ability classroom. In Dutch education, children are grouped in age-based classes with ability-related differences between children. Social inclusion deals with all children in the classroom, regardless of their level of ability. Children could benefit from working together with other-ability others as it lets children become familiar with the different children in their class and experience the value of working together with children of different backgrounds and abilities (Castelijns \& Stevens, 1996; Förrer et al., 2000).

\section{Implementation of the lesson series}

An important factor that might have affected the results of the research described in this dissertation is the way teachers implemented the BE COOL! lesson series. The implementation of a large-scale evidence-based intervention is known to be a complicated process (Forman, Olin, Hoagwood, Crowe, \& Saka, 2009). Before implementing evidence- 
based programs into school settings, consideration must be given to a number of paradoxes regarding school organization, training of teachers, and project-specific characteristics.

The lesson series that was central in this dissertation had many complex features, like the allocation of ability-related topics, differentiated assignments, and different grouping composition. Leaving the orchestration of the different facets of the lesson series to the teacher would place additional and unnecessary pressure on the teachers. Therefore, the lesson series was implemented in a digital learning environment and developed in such a way that it could 'run on its own'. Teachers should be able to carry out the lesson series in their daily practice, there would be no additional pressure on teachers' lesson preparations, and interference from researchers and developers should be kept to a minimum. Logging into the learning environment, children would be automatically redirected to their personalized learning environment that took into account children's ability level and group composition. The lesson series' complex and ever-changing features (created by a certain freedom of choice for the children) were easily applicable in the digital learning environment, so that teachers did not have to engage in orchestrating the lesson series in itself. The idea behind this set up was that teachers could now focus on providing contentspecific attention and feedback to individual children or groups that needed this attention, and should be able to spend time on monitoring and assisting the groups in their cooperative or collaborative processes. However, a prerequisite for this situation to occur is that enough computers, laptops, or tablets are available at the schools, and that the schools' internet facilities are sufficient. Although, the intention was to assist schools in creating such workable conditions, in many participating schools, this was not the case. Teachers, therefore, had to spend much time on orchestrating possibilities for children to complete the assignments by, for example, making paper copies of the assignments or setting up computer time schedules. A first paradox that could be derived from this, is how to find a balance between implementing innovative ways of learning and actual workable conditions in schools for these innovative ways of learning to succeed?

Additionally, teachers often lacked experiences with the working methods (i.e., jigsaw method, inquiry learning, and learning by design). Forman et al. (2009) stated that it is important to train and consult teachers that participate in a project to prepare them for the upcoming demands that are placed on their teaching skills. Even though teachers attended a workshop in which the entire BE COOL! lesson series was reviewed and explained and they could request and use regular consultation with the main researcher, teachers still experienced difficulties during the intervention. The element that caused most difficulties was the design of the large-scale evaluation study (Chapter 5), in which children within classrooms were randomly assigned to either the experimental condition or the control condition. This meant that teachers had to implement both conditions at the same time. 
Teachers reported that they found it difficult to support these parallel groups at the same time, which might also have affected the results of this study. However, to guard the quality of the research and to exclude school or class-related variables, performing both conditions in each class was considered the 'golden standard'. A second paradox arises: What is preferred, meeting the needs and wishes of teachers or performing the golden standard?

A third important prerequisite for the implementation of a project like the BE COOL! lesson series to be successful, is developing support from school administrators and teachers that are supposed to conduct the project (Forman et al., 2009). A project is most likely to succeed when teachers are enthusiastic about the project, as they are the ones to implement it. These teachers, of course, need the backing of their school boards to implement the project in their class. In the BE COOL! project, schools were approached in the opposite way. Prior to the BE COOL! project, a partnership with 33 elementary schools from a mid-sized city in the Netherlands was drawn up. Despite that the original initiative for the BE COOL! project came from the different overarching school boards in the particular city, the implementation of the project and associated studies evoked resistance from participating schools and teachers. This again emphasizes the importance of developing support from those who actually participate in the intervention. However, when involving many schools in a singular large-scale project, it is practically not feasible to approach enthusiastic, supportive teachers individually. This would have as an additional disadvantage that results would be exclusively generalizable to similar enthusiastic teachers. Moreover, it is not always the case that teachers, that might be enthusiastic about participating in the project, stay active throughout the project at the same school. In order to generate a varied and large-scale sample, it is, therefore, almost a prerequisite to enter through the top of the organization (i.e., overarching school boards). A third paradox is raised: How should schools and teachers be approached for participating in a large-scale intervention like the BE COOL! project: top-down or bottom-up?

When schools have agreed to participate in the project, it is important to keep the lines of communication short. One way to shape this communication is to hire intermediate coordinators that act as intermediary contacts between researchers and schools. In the BE COOL! project, two educational professionals (and also teachers at two participating schools) were hired by means of an application procedure. However, professionals who applied for this position could be considered as 'more enthusiastic' about the project than the average participating teachers, which also led to a communication gap between these mediators and the other teachers. Additional to the previous paradox, the following question can be raised: How should the communication with participating schools and teachers be shaped so that schools and teachers stay supportive of the project? 
A fifth element that enhances the success of implementation is the way the method of working fits the profile of the participating schools (Forman et al., 2009). Quality of the developed intervention does not determine whether or not the content of the project fits the aims, goals, and philosophy of a school. When performing large-scale interventions with many different schools, like the studies that are described in this dissertation, development of one set of materials with a clear view on learning might create a situation in which some of these schools do not see the added value of the lesson series. The one school particularly appreciated the focus on cooperative and collaborative learning in the lesson series whereas another already paid close attention to cooperation and collaboration and therefore did not see the added value. This issue caused the following paradox to arise: What should be the determining factor: creating generalizability by implementing the large-scale intervention in many different schools or should implementation of a large-scale intervention be limited to schools that match the approach at hand? In addition to matching the aims, goals, and philosophy of schools, it is also important to take into account school's annual schedule. An intervention of seven weeks, like the seven-week BE COOL! lesson series, might be too extensive to easily fit in the school's schedule. Between various holidays, test weeks, project weeks, and school festivities it is hard to fit in a large intervention. However, shorter interventions might result in a lack of effects. A paradox that could be derived from this, is: Should be given preference to a large-scale intervention that might be difficult to fit in the regular school curriculum or to a shorter intervention that reduces the probability of significant effects.

Sixth, the visible impact of the intervention is another important prerequisite for an implementation process to succeed (Forman et al., 2009). However, a design-based research project, like the BE COOL! project, within which the materials have to be developed and tested, takes much time (i.e., in the context of BE COOL!: three years to develop and pilot the lesson series and another year to evaluate the lesson series). Expectations from schools who wanted to get started as soon as possible with the to-be-designed materials and the time it takes to develop such (innovative) materials was not synchronized. The paradox here is about how to find a costs-efficiency ratio that satisfies both schools and researchers.

\section{Conclusion}

In educational practice, teachers struggle with the demands to give enough attention to both children's cognitive and social development. They want to ensure children are able to learn at their own level and, at the same time, that they are able to develop their social skills and are socially included in their mixed-ability classroom. The work presented in this dissertation aimed to develop an ability-adjusted jigsaw lesson series that should comply with both demands, and investigated whether this lesson series would lead to cognitively equivalent, or potentially better, learning outcomes than more traditional, individual 
learning. The results showed that the ability-adjusted jigsaw method, that encourages social interaction between children of different ability levels, led to equally good learning outcomes. These results might carefully be considered promising as the results of this dissertation could be used to advocate a learning approach like the ability-adjusted jigsaw method. The cognitive learning outcomes are not inferior to individual learning, but on a social level the ability-adjusted jigsaw method has many advantages that are lacking in individual learning methods. Future research should reveal to what extent an abilityadjusted jigsaw method could lead to better cognitive learning outcomes than individual learning, and what is needed to reach this goal. 


References 

Abdullah, S., \& Shariff, A. (2008). The effects of inquiry-based computer simulation with cooperative learning on scientific thinking and conceptual understanding of gas laws. Eurasia Journal of Mathematics, Science \& Technology Education, 4, 387-398. Retrieved from: http://www.ejmste.com/v4n4/EURASIA_v4n4_Abdullah.pdf

Alexander, J. M., \& Schwanenflugel, P. J. (1996). Development of metacognitive concepts about thinking in gifted and nongifted children: Recent research. Learning and Individual Differences, 8, 305-325. doi:10.1016/S1041-6080(96)90021-7

Alfieri, L., Brooks, P. J., Aldrich, N. J., \& Tenenbaum, H. R. (2011). Does discovery-based instruction enhance learning? Journal of Educational Psychology, 103, 1-18. doi:10.1037/a0021017

Arnold, J. C., Kremer, K., \& Mayer, J. (2014). Understanding students' experiments: What kind of support do they need in inquiry tasks? International Journal of Science Education, 36, 2719-2749. doi:10.1080/09500693.2014.930209

Aronson, E., Blaney, N., Stephan, C., Sikes, J., \& Snapp, M. (1978). The jigsaw classroom. Beverly Hills, CA: Sage.

Aronson, E., \& Patnoe, S. (2011). Cooperation in the classroom: The jigsaw method (3rd ed.). London: Pinter \& Martin, Ltd.

Baker, M., \& Lund, K. (1997). Promoting reflective interactions in a CSCL environment. Journal of Computer Assisted Learning, 13, 175-193. doi:10.1046/j.1365-2729.1997.00019.x

Berends, R., \& Wolthuis, H. (2014). Focus op Dalton [Focus on Dalton]. Lierderholthuis: Saxion Dalton University Press.

Berkowitz, M. W. (1980a). The role of transactive discussion in moral development. The history of a six-year program of research - part I. Moral Education Forum, 5, 13-26. Retrieved from: http:// files.eric.ed.gov/fulltext/ED196750.pdf

Berkowitz, M. W. (1980b). The role of transactive discussion in moral development. The history of a six-year program of research - part II. Moral Education Forum, 5, 15-27. Retrieved from: http://files.eric.ed.gov/fulltext/ED196750.pdf

Berry, D. C., \& Broadbent, D. E. (1987). Explanation and verbalization in a computer-assisted search task. The Quarterly Journal of Experimenal Psychology, 39A, 585-609. doi:10.1080/14640748708401804

Bosker, R., \& Doolaard, S. (2009). De pedagogische kwaliteit van differentiatie in het onderwijs [Pedagogical quality of differentiation in education]. In A. Minnaert, H. Lutje-Spelberg \& H. Amsing (Eds.), Het Pedagogisch Quotiënt [The Pedagogical Quotient] (pp. 151-168). Houten: Bohn Stafleu van Loghum.

Castelijns, J., \& Stevens, L. M. (1996). Responsieve instructie in de onderbouw [Responsive instruction in lower elementary school]. Hoevelaken, The Netherlands: CPS Uitgeverij.

Chaiken, S., \& Maheswaran, D. (1994). Heuristic processing can bias systematic processing: Effects of source credibility, argument ambiguity, and task importance on attitude judgment. Journal of Personality and Social Psychology, 66, 460-473. doi:10.1037/00223514.66.3.460 
CITO. (2012). Toetsscore, vaardigheidsscore... en dan? [Test score, proficiency score... and then?]. Retrieved from http://www.cito.nl/ /media/cito_nl/Files/Primair en speciaal onderwijs/cito_toetsscore_vaardigheidsscore_en_dan.ashx

Cohen, E. G. (1994). Restructuring the classroom: Conditions for productive small groups. Review of Educational Research, 64, 1-35. doi:10.3102/00346543064001001

Cohen, E. G., \& Lotan, R. A. (1995). Producing equal-status interaction in the heterogeneous classroom. American Educational Research Journal, 32, 99-120. doi:10.2307/1163215

Colosi, J. C., \& Zales, C. R. (1998). Jigsaw cooperative learning improves biology lab courses. BioScience, 48, 118-124. doi: 10.2307/1313137

Cronbach, L. J., \& Snow, R. E. (1977). Aptitudes and instructional methods : A handbook for research on interactions. New York, NY: Irvington Publishers.

Damon, W., \& Phelps, E. (1989). Critical distinctions among three approaches to peer education. International Journal of Educational Research, 13, 9-19. doi:10.1016/0883-0355(89)90013-X

d'Angelo, C., Rutstein, D., Harris, C., Bernard, R., Borokhovski, E., \& Haertel, G. (2014). Simulations for STEM learning: Systematic review and meta-analysis. Menlo Park, CA: SRI International.

Davis, E. A., \& Linn, M. C. (2000). Scaffolding students' knowledge integration: Prompts for reflection in KIE. International Journal of Science Education, 22, 819-837. doi:10.1080/095006900412293

de Bruin, A. B. H., \& van Gog, T. (2012). Improving self-monitoring and self-regulation: From cognitive psychology to the classroom. Learning and Instruction, 22, 245-252. doi:10.1016/j.learninstruc.2012.01.003

Dede, C. (2010). Comparing frameworks for 21st century skills. In J. B. R. Brandt (Ed.), 21st Century Skills (pp. 51-76). Bloomington, IN: Solution Tree Press.

de Jong, T. (2006). Technological advances in inquiry learning. Science, 312, 532-533. doi:10.1126/science. 1127750

de Jong, T., \& Ferguson-Hessler, M. G. M. (1996). Types and qualities of knowledge. Educational Psychologist, 31, 105-113. doi:10.1207/s15326985ep3102_2

de Jong, T., \& van Joolingen, W. R. (1998). Scientific discovery learning with computer simulations of conceptual domains. Review of Educational Research, 68, 179-201. doi:10.3102/00346543068002179

de Jong, T., van Joolingen, W. R., Giemza, A., Girault, I., Hoppe, U., Kindermann, J., . . van der Zanden, M. (2010). Learning by creating and exchanging objects: The SCY experience. British Journal of Educational Technology, 41, 909-921. doi:10.1111/j.14678535.2010.01121.x

Dekker, S. (2014). Plan van aanpak toptalenten 2014-2018: Brief aan de kamer [Action plan hightalented 2014-2018: Letter to parliament]. Den Haag: Ministerie van Onderwijs, Cultuur en Wetenschap [Ministry of Education, Culture, and Science]. Retrieved from: http:// www.rijksoverheid.nl/documenten/kamerstukken/2014/03/10/plan-vanaanpak-toptalenten-2014-2018

Dewey, J. (1938). Experience and education. New York/London: D. Appleton Century Company. 
Diezmann, C. M., \& Watters, J. J. (1997). Bright but bored: Optimising the environment for gifted children. Australian Journal of Early Childhood, 22, 17-21. Retrieved from: https:/ / eprints.qut.edu.au/2696/1/2696.pdf

Dillenbourg, P. (1999). What do you mean by collaborative learning? In P. Dillenbourg (Ed.), Collaborative leaning: Cognitive and computational approaches (pp. 1-19). Oxford, England: Elsevier.

Doolaard, S., \& Oudbier, M. (2010). Onderwijsaanbod aan (hoog)begaafde leerlingen in het basisonderwijs [Education for (highly) gifted students in elementary education]. Utrecht, The Netherlands: Inspectie van het Onderwijs.

Doymus, K. (2008). Teaching chemical bonding through jigsaw cooperative learning. Research in Science \& Technology Education, 26, 47-57. doi:10.1080/02635140701847470

Doymus, K., Karacop, A., \& Simsek, U. (2010). Effects of jigsaw and animation techniques on students' understanding of concepts and subjects in electrochemistry. Educational Technology Research and Development, 58, 671-691. doi:10.1007/s11423-010-9157-2

ELAN Multimedia Annotation Tool. (2013). Retrieved from http://tla.mpi.nl/tools/tlatools/elan/

Eysink, T. H. S., \& de Jong, T. (2012). Does instructional approach matter? How elaboration plays a crucial role in multimedia learning. The Journal of the Learning Sciences, 21, 583625. doi:10.1080/10508406.2011.611776

Eysink, T. H. S., Gersen, L., \& Gijlers, H. (2015). Inquiry learning for gifted children. High Ability Studies, 26, 63-74. doi:10.1080/13598139.2015.1038379

Eysink, T. H. S., van Dijk, A. M., \& de Jong, T. (2014). BE COOL!: A digital learning environment to challenge and socially include gifted learners. Paper presented at the ECHA conference, Ljubljana, Slovenia.

Ferguson-Hessler, M. G. M., \& de Jong, T. (1990). Studying physics text: Differences in study processes between good and poor performers. Cognition and Instruction, 7, 41-54. doi:10.1207/s1532690xci0701_2

Forman, S. G., Olin, S. S., Hoagwood, K. E., Crowe, M., \& Saka, N. (2009). Evidence-based interventions in schools: Developers' views of implementation barriers and facilitators. School Mental Health, 1, 26-36. doi:10.1007/s12310-008-9002-5

Förrer, M., Kenter, B., \& Veenman, S. (2000). Coöperatief leren in het basisonderwijs [Cooperative learning in primary education]. Amersfoort: CPS, onderwijsontwikkeling en advies.

Frey, N., Fisher, D., \& Hattie, J. (2017). Surface, deep, and transfer? Considering the role of content literacy instructional strategies. Journal of Adolescent $\mathcal{E}$ Adult Literacy, 60, 567575. doi:10.1002/jaal.576

Furtak, E. M., Seidel, T., Iverson, H., \& Briggs, D. C. (2012). Experimental and quasiexperimental studies of inquiry-based science teaching. Review of Educational Research, 82, 300-329. doi:10.3102/0034654312457206

Geisinger, K. F. (2016). 21st century skills: What are they and how do we assess them? Applied Measurement in Education, 29, 245-249. doi:10.1080/08957347.2016.1209207 
Gijlers, H., \& de Jong, T. (2009). Sharing and confronting propositions in collaborative inquiry learning. Cognition and Instruction, 27, 239-268. doi:10.1080/07370000903014352

Gijlers, H., Weinberger, A., van Dijk, A. M., Bollen, L., \& van Joolingen, W. R. (2013). Collaborative drawing on a shared digital canvas in elementary science education: The effects of script and task awareness support. International Journal of Computer-Supported Collaborative Learning, 8, 427-453. doi:10.1007/s11412-013-9180-5

Gillies, R. M. (2003). Structuring co-operative learning experiences in primary school. In R. M. Gillies \& A. F. Ashman (Eds.), Co-operative learning (pp. 36-53). London: RoutledgeFalmer.

Green, J. A., \& Azevedo, R. (2009). A macro-level analysis of SRL processes and their relations to the acquisition of a sophisticated mental model of a complex system. Contemporarry Educational Psychology, 34, 18-29. doi:10.1016/j.cedpsych.2008.05.006

Hattie, J. A. C., \& Donoghue, G. M. (2016). Learning strategies: A synthesis and conceptual model. NPJ Science of Learning, 1, 16013. doi:10.1038/npjscilearn.2016.13

Hulshof, C., \& de Jong, T. (2006). Using just-in-time information to support scientific discovery learning about geometrical optics in a computer-based simulation. Interactive Learning Environments, 14, 79-94. doi:10.1080/10494820600769171

Johnson, D. W., Johnson, R. T., \& Smith, K. (2007). The state of cooperative learning in postsecondary and professional settings. Educational Psychology Review, 19, 15-29. doi:10.1007/s10648-006-9038-8

Kalyuga, S. (2007). Expertise reversal effect and its implications for learner-tailored instruction. Educational Psychology Review, 19, 509-539. doi:10.1007/s10648-007-9054-3

Kalyuga, S., Ayres, P., Chandler, P., \& Sweller, J. (2003). The expertise reversal effect. Educational Psychologist, 38, 23-31. doi:10.1207/S15326985EP3801_4

Karacop, A., \& Doymus, K. (2013). Effects of jigsaw cooperative learning and animation techniques on students' understanding of chemical bonding and their conceptions of the particulate nature of matter. Journal of Science Education and Technology, 22, 186-203. doi:10.1007/s10956-012-9385-9

King, A. (1998). Transactive peer tutoring: Distributing cognition and metacognition. Educational Psychology Review, 10, 57-74. doi:10.1023/A:1022858115001

Klahr, D., \& Dunbar, F. K. (1988). Dual space search during scientific reasoning. Cognitive Science, 12, 1-48. doi:10.1207/s15516709cog1201_1

Klahr, D., \& Dunbar, F. K. (1993). Heuristics for scientific experimentation: A developmental study. Cognitive Psychology, 25, 111-146. doi:10.1006/cogp.1993.1003

Kolodner, J. L., Camp, P. J., Crismond, D., Fasse, B., Gray, J., Holbrook, J., . . Ryan, M. (2003). Problem-based learning meets case-based reasoning in the middle-school science classroom: Putting learning by design into practice. Journal of the Learning Sciences, 12, 495-547. doi:10.1207/S15327809JLS1204_2

Kuhn, D., Black, J., Keselman, A., \& Kaplan, D. (2000). The development of cognitive skills to support inquiry learning. Cognition and Instruction, 18, 495-523. doi:10.1207/S1532690XCI1804_3 
Kulik, C. C., \& Kulik, J. A. (1982). Effects of ability grouping on secondary school students: A meta-analysis of evaluation findings. American Educational Research Journal, 19, 415-428. doi:10.3102/00028312019003415

Lazonder, A. W., \& Harmsen, R. (2016). Meta-analysis of inquiry-based learning: Effects of guidance. Review of Educational Research, 86, 681-718. doi:10.3102/0034654315627366

Lazonder, A. W., Wilhelm, P., \& Hagemans, M. G. (2008). The influence of domain knowledge on strategy use during simulation-based inquiry learning. Learning and Instruction, 18, 580-592. doi:10.1016/j.learninstruc.2007.12.001

Lens, W., \& Rand, P. (2000). Motivation and cognition: Their role in the development of giftedness. In K. A. Heller, F. J. Mönks, R. J. Sternberg, \& R. F. Subotnik (Eds.), International handbook of giftedness and talent, 2nd edition (pp. 193-202). Kidlington, Oxford: Elsevier Science Ltd.

Lou, Y., Abrami, P.C., \& Spence, J.C. (2000). Effects of within-class grouping on student achievement: An exploratory model. The Journal of Educational Research, 94, 101-112. doi:10.1080/00220670009598748

Lou, Y., Abrami, P. C., Spence, J. C., Poulsen, C., Chambers, B., \& d'Apollonia, S. (1996). Withinclass grouping: A meta-analysis. Review of Educational Research, 66, 423-458. doi:10.3102/00346543066004423

Manlove, S., Lazonder, A. W., \& de Jong, T. (2006). Regulative support for collaborative scientific inquiry learning. Journal of Computer Assisted Learning, 22, 87-98. doi:10.1111/j.1365-2729.2006.00162.x

Manlove, S., Lazonder, A. W., \& de Jong, T. (2007). Software scaffolds to promote regulation during scientific inquiry learning. Metacognition $\mathcal{E}$ Learning, 2, 141-155. doi:10.1007/s11409-007-9012-y

Margolis, H., \& McCabe, P. P. (2003). Self-efficacy: A key to improving the motivation of struggling learners. Preventing School Failure: Alternative Education for Children and Youth, 47, 162-169. doi:10.1080/10459880309603362

Mayer, R. E. (2003). Learning and instruction. Upper Saddle River, NJ: Prentice Hall.

Mayer, R. E. (2004). Should there be a three-strikes rule against pure discovery learning? American Psychologist, 59, 14-19. doi:10.1037/0003-066X.59.1.14

Mercer, N. (1996). The quality of talk in children's collaborative activity in the classroom. Learning and Instruction, 6, 359-377. doi:10.1016/S0959-4752(96)00021-7

Mercer, N., Dawes, L., Wegerif, R., \& Sams, C. (2004). Reasoning as a scientist: Ways of helping children to use language to learn science. British Educational Research Journal, 30, 359377. doi:10.1080/01411920410001689689

Mercer, N., Wegerif, R., \& Dawes, L. (1999). Children's talk and the development of reasoning in the classroom. British Educational Research Journal, 25, 95-111. doi:10.1080/0141192990250107

Minner, D. D., Levy, A. J., \& Century, J. (2010). Inquiry-based science instruction: What is it and does it matter? Results from a research synthesis years 1984 to 2002. Journal of Reseach in Science Teaching, 47, 474-496. doi:10.1002/tea.20347 
Mooij, T., Hoogeveen, L., Driessen, G., van Hell, J., \& Verhoeven, L. (2007). Succescondities voor onderwijs aan hoogbegaafde leerlingen: Samenvattend eindverslag van drie deelonderzoeken. [Success conditions for education for gifted students: Summarizing final report of three substudies]. Nijmegen: Radboud Universiteit, ITS/CBO.

Mugny, G., \& Doise, W. (1978). Socio-cognitive conflict and structure of individual and collective performances. European Journal of Social Psychology, 8, 181-192. doi:10.1002/ejsp.2420080204

Njoo, M., \& de Jong, T. (1993). Exploratory learning with a computer simulation for control theory: Learning processes and instructional support. Journal of Research in Science Teaching, 30, 821-844. doi:10.1002/ tea.3660300803

OECD. (2004). 21st century learning: Research, innovation, and policy directions from recent OECD analyses. Paris: OECD.

Parkhurst, H. (1922). Education on the dalton plan. New York (NY): E.P.Dutton \& Company.

Pedaste, M., Mäeots, M., Siiman, L. A., de Jong, T., van Riesen, S. A. N., Kamp, E. T., . . . Tsourlidaki, E. (2015). Phases of inquiry-based learning: Definitions and the inquiry cycle. Educational Research Review, 14, 47-61. doi:10.1016/j.edurev.2015.02.003

Phillips, N., \& Lindsay, G. (2006). Motivation in gifted students. High Ability Studies, 17, 57-73. doi:10.1080/13598130600947119

Platform Onderwijs2032. (2016). Ons onderwijs2032: Eindadvies. [Our education2032: Final report]. Den Haag: Bureau Platform Onderwijs2032.

Reed, S. K. (1999). Abstracting solutions. Word problems: Research and curriculum reform (pp. 101115). Mahway, NJ: Lawrence Erlbaum Associates, Inc.

Reis, S. M., \& Renzulli, J. S. (2010). Is there still a need for gifted education? An examination of current research. Learning and Individual Differences, 20, 308-317. doi:10.1016/j.lindif.2009.10.012

Roll, I., Briseno, A., Yee, N., \& Welsh, A. (2014). Not a magic bullet: The effect of scaffolding on knowledge and attitudes in online simulations. Paper presented at the ICLS 2014, Boulder, Colorado.

Rutten, N., van Joolingen, W. R., \& van der Veen, J. T. (2012). The learning effects of computer simulations in science education. Computers and Education, 58, 136-153. doi:10.1016/j.compedu.2011.07.017

Saab, N., van Joolingen, W. R., \& van Hout-Wolters, B. H. A. M. (2007). Supporting communication in a collaborative discovery learning environment: The effect of instruction. Instructional Science, 35, 73-98. doi:10.1007/s11251-006-9003-4

Saleh, M., Lazonder, A.W., \& de Jong, T. (2005). Effects of within-class ability grouping on social interaction, achievement, and motivation. Instructional Science, 33, 105-119. doi:10.1007/s11251-004-6406-z

Segal, E. (2004). Incubation in insight problem solving. Creativity Research Journal, 16, 141-148. doi:10.1207/s15326934crj1601_13

Shepperd, J. A. (1993). Productivity loss in performance groups: A motivation analysis. Psychological Bulletin, 113, 67-81. doi:10.1037/0033-2909.113.1.67 
Sio, U. N., \& Ormerod, T. C. (2015). Incubation and cueing effects in problem solving: Set aside the difficult problems but focus on the easy ones. Thinking \& Reasoning, 21, 113-129. doi:10.1080/13546783.2014.886626

Slavin, R. E. (1990). Cooperative learning: Theory, research, and practice. Englewood Cliffs, NJ: Prentice-Hall.

Slavin, R. E. (2015). Cooperative learning in elementary schools. Education 3-13: International Journal of Primary, Elementary and Early Years Education, 43, 5-14. doi:10.1080/03004279.2015.963370

Sloetjes, H., \& Wittenburg, P. (2008). Annotation by category-ELAN and ISO DCR. Proceedings of the 6th International Conference on Language Resources and Evaluation (LREC 2008). Marrakech, Marroco.

Smetana, L. K., \& Bell, R. L. (2012). Computer simulations to support science instruction and learning: A critical review of the literature. International Journal of Science Education, 34, 1337-1370. doi:10.1080/09500693.2011.605182

Teasley, S. D. (1997). Talking about reasoning: How important is the peer in peer collaboration? Paper presented at the NATO Advanced Research Workshop on Discourse, Tools, and Reasoning: Situated Cognition and Technologically Supported Environments, Luca, Italy.

Thijs, A., Fisser, P., \& van der Hoeven, M. (2014). 21e eeuwse vaardigheden in het curriculum van het funderend onderwijs [21st century skills in the curriculum of fouding education]. Enschede, the Netherlands: SLO Nationaal Expertisecentrum Leerplanontwikkeling) [National Expertise Centre Curriculum Development].

Tomlinson, C. A. (2000). Differentiation of instruction in the elementary grades. Champaign, IL: ERIC Clearinghouse on Elementary and Early Childhood Education.

Trilling, B., \& Fadel, C. (2009). 21st century skills. San Francisco: Jossey-Bass.

van Dijk, A. M., Eysink, T. H. S., \& de Jong, T. (2016). Ability-related differences in performance of an inquiry task: The added values of prompts. Learning and Individual Differences, 47, 145-155. doi:10.1016/j.lindif.2016.01.008

van Dijk, A. M., Gijlers, H., \& Weinberger, A. (2014). Scripted collaborative learning in elementary science education. Instructional Science, 42, 353-372. doi:10.1007/s11251-0139286-1

van Gerwen, E., \& Drent, S. (2011). Digitaal handelingsprotocol hoogbegaafdheid [Digital action protocol giftedness]. Retrieved from: http://www.dhh-po.nl/

VanTassel-Baska, J. (2003). What matters in curriculum for gifted learners: Reflections on theory, research, and practice. In N. Colangelo \& G. A. Davis (Eds.), Handbook of gifted education, 2nd edition (pp. 174-183). Boston: Pearson Education, Inc.

Vollmeyer, R., \& Rheinberg, F. (2000). Does motivation affect performance via persistence? Learning and Instruction, 10, 293-309. doi:10.1016/S0959-4752(99)00031-6

Vygotsky, L. S. (1986). Thought and language. Cambridge, MA: The MIT Press. 
Walker, I., \& Crogan, M. (1998). Academic performance, prejudice, and the jigsaw classroom: New pieces to the puzzle. Journal of Community \& Applied Social Psychology, 8, 381-393. doi:10.1002/(SICI)1099-1298(199811

Walma van der Molen, J. H. (2007). Eindrapportage VTB Attitude Monitor. De ontwikkeling van een attitude-instrument op het gebied van wetenschap en techniek voor leerlingen in het basisonderwijs [Final Report VTB Attitude Monitor. The development of an attitude measurement instrument in the field of science and technology for elementary school children]. Den Haag, The Netherlands: Platform Bèta Techniek.

Wang, F., Kinzie, M. B., McGuire, P., \& Pan, E. (2010). Applying technology to inquiry-based learning in early childhood education. Early Childhood Education Journal, 37, 381-389. doi:10.1007/s10643-009-0364-6

Webb, N. M. (1982a). Group composition, group interaction, and achievement in cooperative small groups. Journal of Educational Psychology, 74, 475-484. doi:10.1037/00220663.74.4.475

Webb, N. M. (1982b). Peer interaction and learning in cooperative small groups. Journal of Educational Psychology, 74, 642-655. doi:10.1037/0022-0663.74.5.642

Webb, N. M. (1984). Stability of small group interaction and achievement over time. Journal of Educational Psychology, 76, 211-224. doi:10.1037/0022-0663.76.2.211

Webb, N. M. (1991). Task-related verbal interaction and mathematics learning in small groups. Journal for Research in Mathematics Education, 22, 366-389. doi:10.2307/749186

Webb, N. M. (1995). Group collaboration in assessment: Multiple objectives, processes, and outcomes. Educational Evaluation and Policy Analysis, 17, 239-261. doi:10.3102/01623737017002239

Webb, N. M., Nemer, K. M., Chizhik, A. W., \& Sugrue, B. (1998). Equity issues in collaborative group assessment: Group composition and performance. American Educational Research Journal, 35, 607-651. doi:10.3102/00028312035004607

Webb, N. M., Nemer, K. M., \& Zuniga, S. (2002). Short circuits of superconductors? Effects of group composition on high-achieving students' science assessment performance. American Educational Research Journal, 39, 943-989. doi:10.3102/00028312039004943

Webb, N. M., \& Palincsar, A. S. (1996). Group processes in the classroom. In D. C. Berliner. \& R. C. Calfee (Eds.), Handbook of educational psychology. New York, NY: Macmillan Library Reference USA.

Weinberger, A., \& Fischer, F. (2006). A framework to analyze argumentative knowledge construction in computer-supported collaborative learning. Computers and Education, 46, 71-95. doi:10.1016/j.compedu.2005.04.003

Weinert, F. E., \& Helmke, A. (1998). The neglected role of individual differences in theoretical models of cognitive development. Learning and Instruction, 8, 309-323. doi:10.1016/S0959-4752(97)00024-8

Whicker, K. M., Bol, L., \& Nunnery, J. A. (1997). Cooperative learning in the secondary mathematics classroom. The Journal of Educational Research, 91, 42-48. doi:10.1080/00220679709597519 
Wiley, J. (1998). Expertise as mental set: The effects of domain knowledge in creative problem solving. Memory \& Cognition, 26, 716-730. doi:10.4758/bf03211392

Wood, D., Bruner, J. S., \& Ross, G. (1976). The role of tutoring in problem solving. Journal of Child Psychology and Psychiatry, 17, 89-100. doi:10.1111/j.1469-7610.1976.tb00381.x

Zacharia, Z. C., Manoli, C., Xenofontos, N., de Jong, T., Pedaste, M., van Riesen, S. A. N., ... Tsourlidaki, E. T. (2015). Identifying potential types of guidance for supporting student inquiry when using virtual and remote labs in science: A literature review. Educational Technology Research and Development, 63, 257-302. doi:10.1007/s11423-015-9370-0

Zimmerman, C. (2007). The development of scientific thinking skills in elementary and middle school. Developmental Review, 27, 172-223. doi:10.1016/j.dr.2006.12.001 

English Summary 



\section{Introduction}

In elementary education, an everlasting topic of debate revolves around the question what skills are important to teach our children. Basically, the success of Dutch elementary education is generally determined by children's cognitive performance levels. Teachers are urged to construct a learning environment in which all children can achieve minimum levels of cognitive performance. As a consequence, teachers have little time and experience little need to attend to children who could excel at a higher performance level or pay attention to the development of social skills. However, at the same time, teachers are encouraged to stimulate the development of children's cooperative and communicative skills, as part of the trend in 21st century skills, and to pay attention to children's learning needs on different levels of ability (i.e., differentiation). Teachers struggle how to implement these different, and often considered contradictory, demands.

This dissertation focused on finding a balanced approach between demands regarding cognitive development for children of different ability levels and children's development on the social level. A lesson series, based on the jigsaw method, was developed that incorporated same-ability collaboration and mixed-ability cooperation in a context of inquiry learning and learning by design. The main research focus was to investigate whether it is possible to encourage social interaction between children of different ability levels, while improving - or at least maintaining - cognitive learning outcomes for children of different ability levels.

The development of the lesson series and associated research described in this dissertation were conducted in the context of the BE COOL! project. The consecutive (pilot) studies reported in this dissertation intended to gain input for the design of the lesson series and an accompanying digital learning environment. The final study, a large-scale evaluation study, sought to establish the effect of the lesson series compared to more traditional, individual learning.

\section{BE COOL!}

BE COOL! is the Dutch acronym of a four-year project that aimed to develop and test a seven-week lesson series in which children of different ability levels would learn together in homogeneous collaborative groups and heterogeneous cooperative groups (see Chapter 2 for a description of the lesson series). Children were to design a moon house that could accommodate a family of four. In the context of the jigsaw method, children completed three phases. They created their design in mixed-ability groups of four, as part of the heterogeneous design phase. Previously to the heterogeneous design phase, that lasted three weeks, children gathered information on one of four different topics during the 
homogeneous expert phase that also lasted three weeks. The to-be-studied topics in the homogeneous expert phase were pre-assigned to children of different ability levels: highability children studied the topic of 'Light \& Heat', average-ability children studied either 'Oxygen' or 'Water', and the low-ability children worked on assignments that covered the topic 'Nutrition'. For each topic, a set of differentiated inquiry assignments were provided that covered the main elements within the topics. As a start to the complete lesson series, children were provided with an introduction to the lesson series, the working method, and completed an assignment to trigger their prior knowledge (i.e., heterogeneous prior knowledge phase). See Figure 1 for an overview of the phases of the seven-week lesson series.

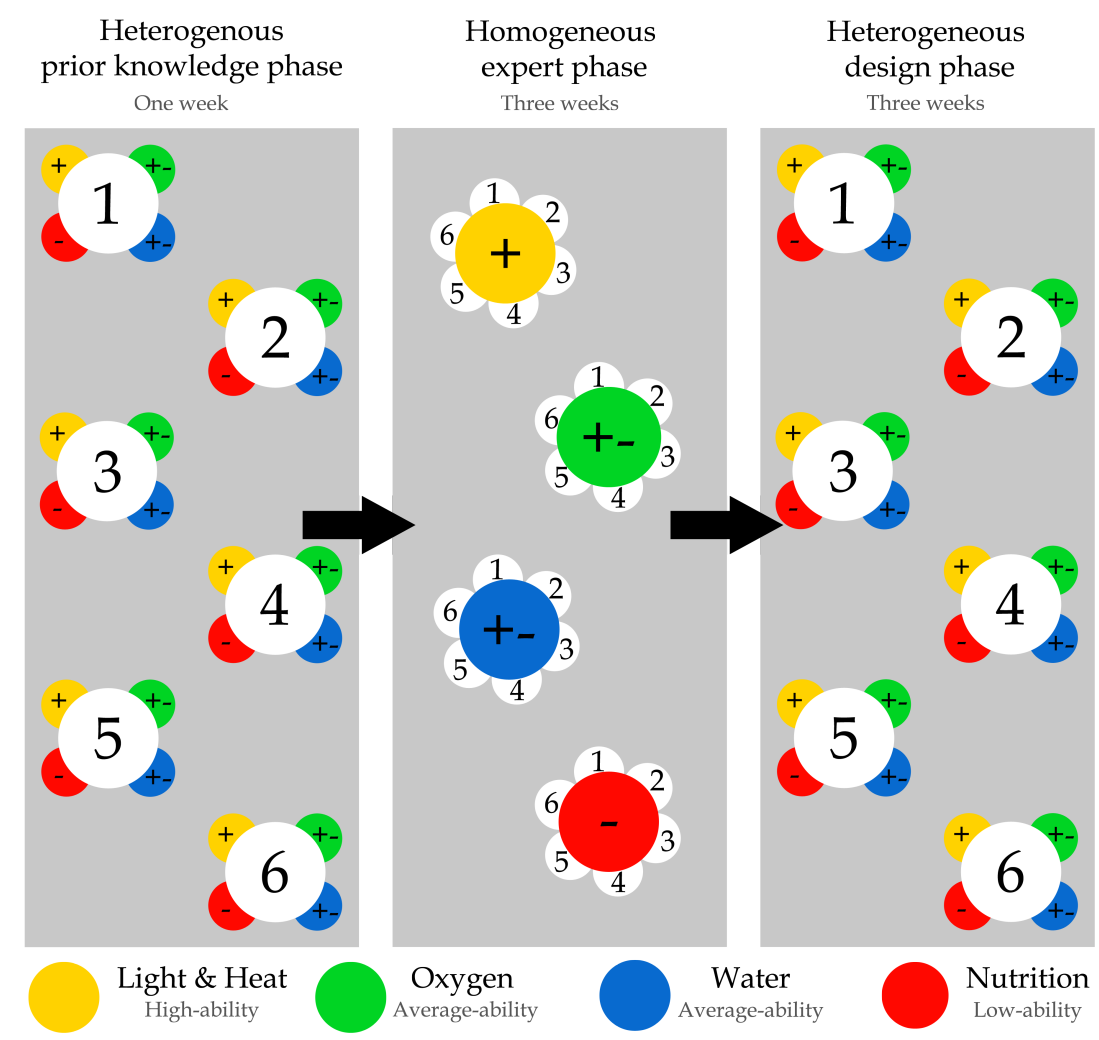

Figure 1. Overview of the phases as implemented in the BE COOL! jigsaw lesson series. The four colors represent the four topics assigned to children of different ability levels. The plus signs and minus signs represent the ability levels of the children (i.e., $+=$ high-ability, $+-=$ average-ability, and - = low-ability). The numbers identify the heterogeneous design groups to which the children belong.

The BE COOL! lesson series was implemented in a digital learning environment. The learning environment consisted of two sections: 1) a student section that presented children 
with the assignments and showed children their group members in both the homogeneous expert group and the heterogeneous design group, and 2) a teacher section that enabled teachers to set-up the lesson series for their children, provided teachers with an overview of children's progress, and created the opportunity for providing feedback on assignments that were handed in by the children.

\section{Empirical studies and design process}

In the BE COOL! project, research and development alternated to shape the lesson series and the digital learning environment. Results from the different (pilot) studies were used to design and develop materials for the consecutive studies and for the final version of the lesson series.

\section{Pilot study: Needs analysis and usability analysis}

To gain input for the inquiry assignments in the homogeneous expert phase of the lesson series, a pilot study was conducted that consisted of two parts: 1) a needs analysis among teachers $(n=13)$ to explicate their needs and expectations regarding the development of the lesson series and accompanying learning environment, and 2) a usability study to gain insight in elementary school children's $(n=36)$ experience with inquiry assignments, both digitally and non-digitally.

The main issues that came up in the needs analysis were: a) the domain of the lesson series should be easy to integrate into the curriculum, b) topics should be challenging but feasible for children of different ability levels, c) the learning environment should contain resources so that children could work independently, d) heterogeneous cooperation should be supported, and e) teachers should be able to monitor and evaluate children's progress. These issues were taken into consideration while designing and developing the specific features of the lesson series and digital learning environment.

The most important results from the usability study were: a) all children, regardless of ability level, needed contextualizing information for them to be able to work within the context of the inquiry cycle, b) high-ability children needed less support to work with the inquiry assignments than lower-ability children, and c) when children requested support or information, high-ability children were satisfied with more abstract instructions whereas lower-ability children preferred and needed more concrete instructions to be able to complete the inquiry activities at hand. These results determined the design and development of the first inquiry assignment and support for this assignment that was investigated in the upcoming study. 


\section{Differentiation in the homogeneous expert phase}

After it was established that children of different ability levels all needed start-up information to kick-start their inquiry process and differed in their need for follow-up support, an exploratory study was conducted that looked into the application of differentiation within inquiry learning activities. The goal of this study was to explore whether and how children of different ability levels varied in the way they approached an inquiry task, whether and how support played an additional role in their inquiry process, whether this affected learning outcomes, and if children's motivation was influenced by the presence of support.

Children were to investigate the effects of gravity, air resistance, and shape on the speed of falling objects by working with a simulation-based inquiry task. Taking into account differences between children regarding need for support in this context, prompts were designed and implemented. The prompts intended to steer children in the right direction regarding identifying the variables they should include in their experiments. The prompts offered information that progressed from merely trying to activate prior knowledge and promote recognition and understanding of the topics to suggesting informative simulation runs to answer the research questions at hand. Children could activate the prompts when needed, and had to view all five prompts before proceeding to the next task.

The exploratory study followed an experimental pretest-posttest-retention test design. Two conditions were compared: a prompted condition and a control condition. Children in the prompted condition received a set of five prompts per task to help them answer the research questions at hand. Children in the control condition did not receive any prompts. A total of 478 fifth and sixth graders of three different ability levels participated in this study (mean age 11.30 years). Domain knowledge, effectivity of the inquiry process (logfile data), and children's motivation were assessed.

Results indicated that prompted children showed a more active and effective inquiry process than children who did not receive the prompts. However, children of different ability levels differed in their use of the prompts. High-ability children used the prompts frequently. Average-ability and low-ability children rarely used the prompts. Consequently, high-ability children engaged in more active and effective inquiry than children of lower ability. When lower-ability children did use the prompts, this appeared to affect their inquiry process as well.

High-ability children's more effective inquiry process was mainly visible in the learning outcomes reflected in the inquiry tasks. They outperformed the others on responding correctly to the research questions accompanying the simulation-based inquiry tasks. Even 
though knowledge gains were small, results showed that high-ability children also showed a higher learning gain on the knowledge tests than average-ability and low-ability children. High and average-ability children gained knowledge from pretest to posttest but not from posttest to retention test; low-ability children only gained knowledge from posttest to retention test. The results of this study point to a need to find effective ways to support low-ability and average-ability children during the inquiry process.

Based on these results, the assignments and the accompanying structure and support within the topics in the homogeneous expert phase were matched to ability level. Highability children received start-up information for the different activities, where after they were able to shape their inquiry process themselves. Average-ability and low-ability children were provided with more information on the different steps of the inquiry cycle, how to complete these steps, and the connection between these steps. Low-ability children were given more extensive information than the average-ability children.

\section{Pilot study: First check of the BE COOL! lesson series}

After a new set of assignments was developed by using the results of the previous studies, a large-scale pilot study with 155 fourth, fifth, and sixth graders from six different schools was performed to evaluate and get feedback on the assignments developed so far.

Observations and evaluations from researcher and teachers showed that children did not have enough time to finish all assignments of the homogeneous expert phase within the set time of three two-hour lessons. Furthermore, teachers reported that the average-ability and low-ability children needed more structure in the assignments, especially concerning when and how to use the resources. These findings resulted in a reduction of the number of assignments in the homogeneous expert phase, and a creation of subsets of the assignments for the three weeks. Furthermore, the different inquiry activities were made more prominent within the assignments for the average-ability and low-ability children, and these children were provided with more explanations about the next steps in the procedure.

Also, a first set of assignments was created and piloted that shaped the heterogeneous design phase. To structure the first lesson of this phase, in which children were to share the (most important) information on their topics with their group members, a worksheet was designed. The researcher was present during this first lesson of the heterogeneous design phase to observe children's cooperative processes and the use of the worksheet within these processes. One of the steps of the worksheet appeared not self-evident. Children 
needed additional explanation about the purpose of this step. Therefore, the worksheet was updated by including new and more extensive explanation about this step.

Children also completed a first version of the pretest and posttest on their knowledge of their topic and the topics of the others in their group. The analysis revealed that some questions contained difficult terms and sentences. These questions were adjusted to better match children's level of understanding.

\section{Support for the heterogeneous design phase}

Based on the results of the previous pilot study and the changes that were consequently applied to the worksheet, we conducted a study to examine the effects of the worksheet on the heterogeneous cooperative process. Specific focus was on the first lesson of the heterogeneous design phase: the information-sharing lesson. Starting the heterogeneous design phase, children were to share information on their assigned topic that they gathered during the previous three weeks of the homogeneous expert phase. In the heterogeneous design phase, children's main task was to combine and integrate information from these four different topics to create a substantiated design of a moon house. The worksheet that was designed to support this process was based on four of the elements of the Social Interdependence Theory of Johnson, Johnson, and Smith (2007): individual accountability, social interdependence, promotive interaction, and group evaluation.

The study followed an experimental pretest-posttest design. In total, 136 fourth to sixth graders worked cooperatively in heterogeneous groups of four (mean age 10.95 years). A comparison was made between groups that worked with the worksheet $(n=19)$ and groups that worked without the worksheet $(n=15)$. Children's cooperative processes and their domain knowledge on both the assigned topic and the topics of others were assessed.

Results indicated that the group dialogues benefited from working with the worksheet. Groups supported by the worksheet showed a more equally distributed domain-related participation by the group members, a larger proportion of the dialogue was task-oriented, and supported groups spent more of their dialogue on exchanging domain-related explanations than groups that did not receive the worksheet. However, the results of this study did not indicate a significant domain knowledge gain, neither for the children in the supported groups nor for the children in the unsupported groups. Future research should explore the possibilities to further structure the cooperative process so that children's learning outcomes could benefit more from the information shared in the heterogeneous group dialogue. 
This study was conducted in the context of the entire BE COOL! lesson series. This gave the opportunity to also gain insight into the suitability of the adjusted assignments in the homogeneous expert phase. According to teachers' observations, children were now able to finish the set of assignments that were part of their assigned topic, and were better able to work with the structure of the assignments.

On the basis of the results of this study small changes were made regarding the explication of the purpose of the assignments, formulation of assignments, and bugs in the learning environment. Before starting the final and large-scale evaluation study, time was spent on addressing these issues.

\section{Study: Large-scale evaluation study}

In this study, the final version of the lesson series (i.e., 'ability-adjusted jigsaw lesson series') was investigated. The ability-adjusted jigsaw lesson series was developed to encourage social interaction between children of different ability levels without impeding their cognitive development. This study investigated whether the learning benefits from the ability-adjusted jigsaw method were higher than, or at least equal to, children engaged in more traditional, individual learning.

The study followed an experimental pretest-midtest-posttest-retention test design. A comparison was made between the ability-adjusted jigsaw method and a more traditional, individual learning approach. A total of 1023 children participated in the study (mean age 10.49 years). Domain knowledge on both the assigned topic and the topics of others, inquiry knowledge, and attitudes toward technology and science were assessed.

Results revealed that children in the ability-adjusted jigsaw method showed equal cognitive learning outcomes as children who studied the same information individually, in a more traditional way. There were also no differences between children concerning their attitudes toward technology and science. Future research should look into the conditions that need to be met for the ability-adjusted jigsaw method to even outperform traditional, individual learning on the cognitive outcomes.

\section{Conclusion}

Based on the results of the above-mentioned studies, we can conclude that the abilityadjusted jigsaw method, that encourages social interaction between children of different ability levels, led to equally good learning outcomes as more traditional, individual learning. These results might carefully be considered promising as the cognitive learning 
outcomes are not inferior to individual learning, but on a social level the ability-adjusted jigsaw method has many advantages that are lacking in individual learning methods. 


Nederlandse samenvatting 



\section{Inleiding}

Een steeds terugkerend onderwerp van discussie in het basisonderwijs betreft de vraag welke vaardigheden kinderen zich tijdens hun basisschoolperiode eigen moeten maken. Over het algemeen wordt de mate van succes van het Nederlandse basisonderwijs gebaseerd op de cognitieve prestaties van kinderen. In dit kader wordt van leerkrachten gevraagd een leeromgeving te creëren waarin kinderen in staat moeten zijn aan minimale eisen te voldoen. Het gevolg is dat leerkrachten weinig tijd hebben en niet altijd de noodzaak voelen om aandacht te besteden aan kinderen die op een hoger niveau kunnen presteren of om de ontwikkeling van sociale vaardigheden te stimuleren. Dit staat in contrast tot een huidige tendens waarin leerkrachten worden aangemoedigd om de ontwikkeling van coöperatieve en communicatieve vaardigheden van leerlingen te stimuleren, als onderdeel van de 21e eeuwse vaardigheden, en om aandacht te besteden aan de verschillende competentieniveaus van leerlingen (i.e., differentiatie). Leerkrachten worstelen met de implementatie van deze verschillende en gevoelsmatig tegenstrijdige vragen.

In dit proefschrift is gezocht naar een gebalanceerde aanpak die recht doet aan zowel de eisen die gesteld worden aan de cognitieve ontwikkeling van kinderen met verschillende competentieniveaus als de eisen met betrekking tot ontwikkeling op sociaal gebied. In dit kader is een lessenserie ontwikkeld, gebaseerd op de jigsaw methode, waarin leerlingen in een homogene samenstelling collaboratief samenwerken en in heterogene groepen coöperatief samenwerken in een context van onderzoekend en ontwerpend leren. In deze context is de onderzoeksfocus van dit proefschrift: in hoeverre is het mogelijk om gelijktijdig de sociale interactie tussen kinderen van verschillende competentieniveaus aan te moedigen terwijl de cognitieve leeropbrengsten voor deze kinderen verbeteren, of op zijn minst op hetzelfde niveau blijven.

De ontwikkeling van de lessenserie en de bijbehorende onderzoeken die in dit proefschrift beschreven zijn, zijn uitgevoerd in de context van het BE COOL! project. De opeenvolgende (pilot)studies die worden beschreven in dit proefschrift hadden als doel om input te leveren voor het ontwerp van de lessenserie en een bijbehorende digitale leeromgeving. Een derde studie, een grootschalige effectiviteitsevaluatie, richtte zich op het in kaart brengen van de effecten van de lessenserie vergeleken met meer traditioneel, individueel leren.

\section{BE COOL!}

BE COOL! is een acroniem dat staat voor het Bevorderen van Excellentie door Coöperatief Onderzoekend en Ontwerpend Leren. Dit vier jaar durende project richtte zich op het 
ontwikkelen en testen van een zeven weken durende lessenserie waarin kinderen van verschillende competentieniveaus samen leren in homogene en heterogene groepssamenstellingen (zie hoofdstuk 2 voor een beschrijving van de lessenserie). Kinderen kregen de opdracht om een maanhuis te ontwerpen waarin een gezin van vier kan leven en overleven. Om dit ontwerp te creëren, doorliepen de kinderen drie fases in de context van de jigsaw methode. In de heterogene ontwerpfase, creëerden de kinderen een eigen ontwerp in een heterogene groep bestaande uit vier leden (i.e., één bovengemiddeld kind, twee gemiddelde kinderen en één ondergemiddeld kind). Voorafgaand aan de heterogene ontwerpfase, die drie weken duurde, verzamelden de kinderen informatie over één van vier verschillende onderwerpen in de homogene expertfase, die eveneens drie weken duurde. De onderwerpen in de homogene expertfase zijn vooraf toegewezen aan de kinderen op basis van hun competentieniveau: bovengemiddelde kinderen bestudeerden het onderwerp 'Licht en Warmte', gemiddelde kinderen bestudeerden 'Zuurstof' of 'Water' en de ondergemiddelde kinderen werkten aan opdrachten over het onderwerp 'Voedsel'. Voor elk onderwerp was een set van onderzoekend leren-opdrachten ontwikkeld waarin zij werden voorzien van structuur en ondersteuning op maat (i.e., passend bij het competentieniveau van het kind). De opdrachten behandelden, gezamenlijk, de belangrijkste elementen van het onderwerp. In de week voordat de kinderen van start gingen met de homogene expertfase, werd de kinderen een introductieles aangeboden. Kinderen kregen een introductie over de lessenserie, de manier van leren (i.e., onderzoekend, ontwerpend en samenwerkend leren) en ze volbrachten een opdracht voor het activeren van domein-specifieke voorkennis (i.e., de heterogene voorkennisfase). Zie Figuur 1 voor een overzicht van de drie fases van de zeven weken durende lessenserie.

De BE COOL! lessenserie is geïmplementeerd in een digitale leeromgeving. Deze leeromgeving bestond uit twee secties: 1) een studentensectie waarin de opdrachten en de groepssamenstellingen voor zowel de homogene expertgroep als de heterogene ontwerpgroep werden getoond, en 2) een leerkrachtensectie waarin de leerkrachten de lessenserie voor de kinderen konden voorbereiden, beschikking hadden over een overzicht waarin de voortgang van leerlingen werd getoond en de mogelijkheid hadden om leerlingen te voorzien van feedback op ingeleverde opdrachten.

\section{Beschrijvende studies en ontwerpproces}

Voor het ontwikkelen van de lessenserie en de digitale leeromgeving zijn resultaten van verschillende (pilot)studies als input gebruikt. Onderzoek en ontwikkeling wisselden elkaar gedurende de looptijd van het BE COOL! project af. De laatste studie heeft de complete versie van de lessenserie geëvalueerd. 


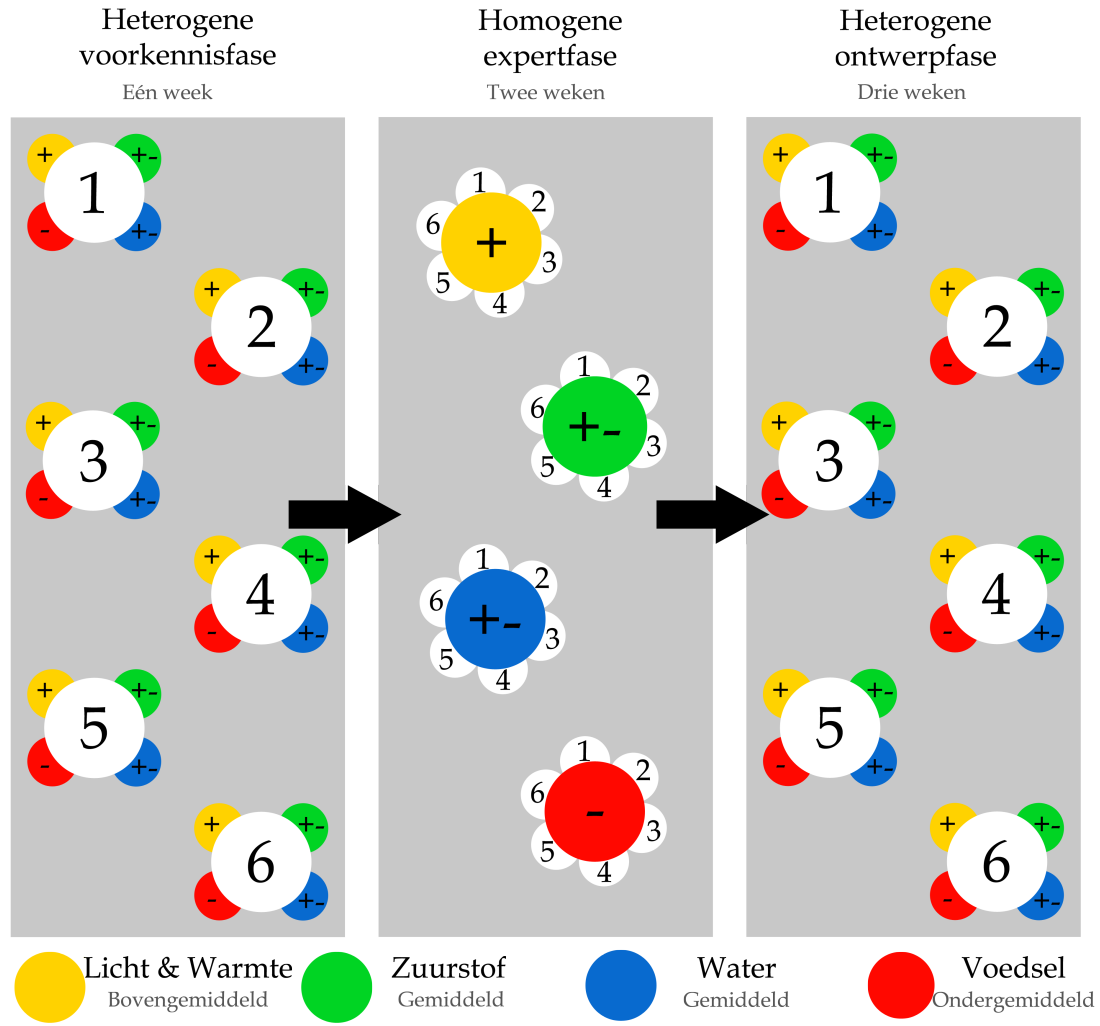

Figuur 1. Overzicht van de fases zoals geïmplementeerd in de BE COOL! lessenserie. De vier kleuren staan symbool voor de vier onderwerpen die zijn toegewezen aan de kinderen van verschillende competentieniveaus. De plus- en mintekens staan voor de competentieniveaus van de kinderen $\left(_{+}=\right.$bovengemiddeld, $+-=$gemiddeld en $-=$ ondergemiddeld). De cijfers identificeren de heterogene ontwerpgroepen waar de kinderen toe behoren.

\section{Pilotstudie: Behoefte- en bruikbaarheidsanalyse}

Om input te krijgen voor de ontwikkeling van de onderzoekend leren-opdrachten in de homogene expertfase van de lessenserie is een pilotstudie uitgevoerd die uit twee delen bestond: 1) een behoefteanalyse bij leerkrachten $(n=13)$ om hun behoeftes en verwachtingen met betrekking tot de ontwikkeling van de lessenserie en bijbehorende digitale leeromgeving in kaart te brengen, en 2) een bruikbaarheidsstudie voor het vergaren van data over de ervaringen van basisschoolleerlingen $(n=36)$ met onderzoekend leren-opdrachten, zowel digitaal als niet-digitaal.

Uit de behoefteanalyse bij leerkrachten kwam naar voren dat: a) het domein van de lessenserie eenvoudig te integreren moet zijn in het curriculum, b) de onderwerpen 
uitdagend maar ook uitvoerbaar moeten zijn voor kinderen van verschillende competentieniveaus, c) de leeromgeving informatiebronnen moet bevatten zodat kinderen zelfstandig kunnen werken, d) heterogene samenwerking ondersteund moet worden, en e) leerkrachten de voortgang van de kinderen moeten kunnen monitoren en evalueren. Deze resultaten zijn meegenomen tijdens het ontwerpen en ontwikkelen van de lessenserie en de digitale leeromgeving.

De belangrijkste resultaten van de bruikbaarheidstudie waren: a) alle kinderen, ongeacht competentieniveau, hebben contextuele informatie nodig om met onderzoekend lerenopdrachten uit de voeten te kunnen, b) bovengemiddelde kinderen hebben voor de onderzoekend leren-opdrachten minder ondersteuning nodig dan de ondergemiddelde kinderen, en c) wanneer kinderen om ondersteuning of informatie vroegen, waren de bovengemiddelde kinderen tevreden met abstracte instructie terwijl de ondergemiddelde kinderen de voorkeur gaven en behoefte hadden aan meer concrete instructie om de onderzoeksactiviteiten te kunnen volbrengen. Deze resultaten bepaalden het ontwerp en de ontwikkeling van de eerste onderzoekend leren-opdrachten en de ondersteuning die centraal stond in de volgende studie.

\section{Differentiatie in de homogene expertfase}

Op basis van het voorgaande pilotonderzoek is vastgesteld dat kinderen van verschillende competentieniveaus allen baat hebben bij contextualiserende informatie die het onderzoekend leren-proces op gang kan brengen, maar dat ze verschilden in de behoefte aan ondersteuning tijdens het onderzoekend leren-proces zelf. Hierop is een exploratieve studie uitgevoerd waarin is onderzocht in hoeverre en op welke manier kinderen van verschillende competentieniveaus verschilden in de manier waarop zij een onderzoekend leren-opdracht benaderden, in hoeverre en op welke manier ondersteuning een rol speelde in hun onderzoekend leren-proces, in hoeverre dit effect had op hun leeruitkomsten, en of de motivatie van kinderen werd beïnvloed door de ondersteuning. Op deze manier kon inzichtelijk worden gemaakt hoe invulling kon worden gegeven aan een gedifferentieerde aanpak binnen de onderzoekend-leren-activiteiten in de homogene expertfase.

Kinderen werkten aan drie taken binnen een simulatieopdracht, waarin ze de effecten van zwaartekracht, luchtweerstand en de invloed van de vorm van objecten op de valsnelheid moesten onderzoeken. Hints zijn ontworpen voor de drie taken in de simulatieopdracht, waarbij rekening werd gehouden met eventuele verschillen in competentie tussen kinderen met betrekking tot hun behoefte aan ondersteuning. De hints hadden als doel om kinderen te helpen de juiste variabelen te selecteren die nodig waren om de experimenten uit te kunnen voeren. Per taak werden vijf hints werden gepresenteerd in een oplopende 
volgorde, waarbij de eerste hint enkel de voorkennis van de kinderen probeerde te activeren en (daarmee) de opdracht van context probeerde te voorzien, en de vijfde hint concrete experimenten opperde waarmee de kinderen de onderzoeksvragen konden beantwoorden. Kinderen konden de hints opvragen wanneer ze dachten deze nodig te hebben tijdens hun onderzoekend leren-proces. Uiteindelijk moesten kinderen alle vijf de hints hebben geopend voordat ze door konden gaan naar de volgende taak.

De exploratieve studie kende een experimenteel voortoets-natoets-retentietoets onderzoeksdesign. Twee condities werden met elkaar vergeleken: een hint-conditie waarin kinderen de vijf hints tot hun beschikking hadden en een controle conditie waarin kinderen de vijf hints niet konden raadplegen. In totaal namen 478 kinderen van drie verschillende competentieniveaus uit groep 7 en groep 8 deel aan het onderzoek (gemiddelde leeftijd 11,30 jaar). In het onderzoek werden de domeinkennis, de effectiviteit van het onderzoekend leren-proces en de motivatie van kinderen gemeten.

De resultaten lieten zien dat de kinderen die beschikking hadden over de hints een actiever en effectiever onderzoekend leren-proces hebben doorlopen dan kinderen die de hints niet tot hun beschikking hadden. Kinderen met verschillende competentieniveaus verschilden van elkaar in het gebruik van de hints. Bovengemiddelde kinderen gebruikten de hints vaker wanneer zij deze tot hun beschikking hadden. Zij lieten tevens een actiever en effectiever onderzoekend leren-proces zien dan de gemiddelde en ondergemiddelde kinderen. Gemiddelde en ondergemiddelde kinderen gebruikten de hints weinig. Echter, wanneer deze kinderen de hints wel gebruikten, leek dit een positieve invloed te hebben op hun onderzoekend leren-proces.

Het effectievere onderzoekend leren-proces van de bovengemiddelde kinderen is met name zichtbaar in de leeruitkomsten binnen de onderzoekend leren-opdracht. Bovengemiddelde kinderen beantwoordden de onderzoeksvragen beter dan de gemiddelde en ondergemiddelde kinderen. Hoewel de kennisopbrengst klein was, lieten de resultaten tevens zien dat de bovengemiddelde kinderen een hogere leeropbrengst hadden op de kennistoetsen dan de gemiddelde en ondergemiddelde kinderen. Bovengemiddelde en gemiddelde kinderen lieten wel een toename in kennis zien tussen de voormeting en de nameting maar niet tussen de nameting en de retentietoets. Ondergemiddelde kinderen lieten alleen een kennistoename zien tussen de nameting en de retentietoets. De resultaten van deze studie maken duidelijk dat gezocht moet worden naar alternatieve, effectieve manieren om ondergemiddelde en gemiddelde kinderen te ondersteunen tijdens het onderzoekend leren-proces. 
Gebaseerd op bovenstaande resultaten zijn de opdrachten in de homogene expertfase voorzien van structuur en ondersteuning op maat (i.e., gebaseerd op het competentieniveau van de kinderen). Bovengemiddelde kinderen ontvingen inleidende, contextuele informatie voor de verschillende onderzoekend leren-activiteiten, waarna zij in staat werden geacht om hun eigen onderzoekend leren-proces vorm te geven. Gemiddelde en ondergemiddelde kinderen werden voorzien van meer informatie over de verschillende stappen van de onderzoekend leren-cyclus, hoe deze stappen uitgevoerd moesten worden en hoe de stappen zich tot elkaar verhielden. Ondergemiddelde kinderen kregen omvangrijkere informatie dan de gemiddelde kinderen.

\section{Pilotstudie: Eerste check van de BE COOL! lessenserie}

Nadat een nieuwe set opdrachten is ontwikkeld op basis van de resultaten van de voorgaande studies, is een grootschalige pilotstudie met 155 leerlingen uit de groepen 6, 7 en 8 van zes verschillende scholen uitgevoerd met als doel om de opdrachten die tot dan toe waren ontwikkeld, te evalueren.

Observaties en evaluaties van de onderzoeker en leerkrachten lieten zien dat de kinderen niet in staat waren om alle opdrachten uit de homogene expertfase te voltooien binnen de gestelde tijd (d.w.z. drie lessen van twee uur). Deze bevinding resulteerde in een vermindering van het aantal opdrachten in de homogene expertfase en een clustering van opdrachten voor de drie verschillende weken die de homogene expertfase telde. Daarnaast gaven de leerkrachten aan dat de gemiddelde en de ondergemiddelde kinderen meer behoefte hadden aan structuur binnen de opdrachten. Met name informatie over wanneer en hoe de informatiebronnen gebruikt konden worden zou van toegevoegde waarde zijn voor deze kinderen. Hierop werden de verschillende onderzoeksactiviteiten prominenter weergegeven binnen de opdrachten voor de gemiddelde en ondergemiddelde kinderen, en werden deze kinderen voorzien van meer uitleg over de volgende stap in de procedure.

In deze studie werd tevens een eerste set van opdrachten getest die de heterogene ontwerpfase vormgaven. Voor het structureren van de eerste les van deze fase, waarin kinderen de (meest belangrijke) informatie over hun toegewezen onderwerp moesten delen met hun groepsgenoten, is een werkblad ontworpen. De onderzoeker was aanwezig tijdens de eerste les van de heterogene ontwerpfase om de coöperatieve processen van de groepjes en de bruikbaarheid van het werkblad binnen dit proces te observeren. Bij één van de stappen van het werkblad bleken de kinderen niet direct te begrijpen hoe deze stap binnen het totaal paste en wat precies van hen verwacht werd. Kinderen hadden aanvullende uitleg nodig over het doel van deze stap. Hierop werd het werkblad aangepast door nieuwe, meer expliciete uitleg over deze stap toe te voegen. 
Kinderen voltooiden daarnaast eerste versies van de voortoetsen en de natoetsen over de kennis over hun eigen onderwerp en over de onderwerpen van hun groepsgenoten. Analyse van deze toetsen liet zien dat sommige vragen ingewikkelde termen en zinnen bevatten. Deze vragen werden aangepast zodat het beter aansloot op het begripsniveau van de kinderen.

\section{Ondersteuning van de heterogene ontwerpfase}

Voortbouwend op de resultaten van de voorgaande pilotstudie en de veranderingen die desgevolg zijn doorgevoerd in het werkblad, is een studie uitgevoerd waarin het effect van het werkblad op de heterogene samenwerkingsprocessen is onderzocht. In de eerste les van de heterogene ontwerpfase moesten de kinderen informatie over hun onderwerp, die ze hadden verzameld tijdens de daaraan voorafgaande drie weken in de homogene expertfase, delen met hun groepsgenoten in de heterogene ontwerpgroep. De belangrijkste opdracht in de heterogene ontwerpfase was het combineren en integreren van informatie over de vier verschillende onderwerpen en dit terug te laten komen in hun maanhuisontwerp. Het werkblad was ontworpen om dit proces te ondersteunen en was gebaseerd op vier elementen uit de Sociale Interdependentie Theorie van Johnson, Johnson en Smith (2007): individuele verantwoordelijkheid, positieve wederzijdse afhankelijkheid interdependentie, directe interactie en evaluatie van het groepsproces.

De studie kende een experimenteel voortoets-natoets onderzoeksdesign. In totaal werkten 136 kinderen uit groep 6 tot en met groep 8 samen in heterogene groepjes van vier kinderen (gemiddelde leeftijd 10,95 jaar). De studie maakte een vergelijking tussen groepjes die werden ondersteund door het werkblad $(n=19)$ en groepjes die werkten zonder ondersteuning van het werkblad $(n=15)$. In het onderzoek werden metingen verricht die inzicht gaven in de coöperatieve groepsdialogen en in de individuele domeinkennis van kinderen over het eigen onderwerp en over de onderwerpen van groepsgenoten.

De resultaten lieten zien dat het werkblad een positief effect had op de groepsdialogen. Groepjes die ondersteund werden door het werkblad kenmerkten zich door een gelijkwaardigere deelname van de groepsgenoten aan de domeingerelateerde dialoog, en de dialogen bestonden bovendien voor een groter deel uit taakgerichte en domeingerelateerde uitleg dan de groepsdialogen van groepjes die werkten zonder het werkblad. Echter, de resultaten van de huidige studie lieten geen significante groei in de domeinkennis van leerlingen zien. Dit gold voor zowel de kinderen in de ondersteunde groepjes als voor de kinderen in de niet-ondersteunde groepjes. Toekomstig onderzoek zou moeten uitzoeken hoe het coöperatieve proces van additionele structuur kan worden voorzien zodat kinderen meer kunnen leren van deelname in de heterogene groepsdialoog. 
De studie werd uitgevoerd in de context van de gehele BE COOL! lessenserie. Dit bood de mogelijkheid om inzichtelijk te maken in hoeverre de aanpassingen binnen de homogene expertfase leidden tot een betere uitvoerbaarheid van de opdrachten. Leerkrachtobservaties gaven aan dat kinderen met de nieuwe opdrachtensets beter in staat waren om de opdrachten af te ronden binnen de daarvoor gestelde tijd en dat kinderen beter uit de voeten konden met de structuur van de opdrachten.

Echter, op basis van de resultaten van deze studie zijn wel een aantal verbeteringen aangebracht. De uitleg van het doel van sommige opdrachten werd aangescherpt, formuleringen binnen opdrachten werden verbeterd en kleine bugs in de digitale leeromgeving werden geïdentificeerd en hersteld.

\section{Grootschalige evaluatiestudie}

In deze studie stond de uiteindelijke versie van de BE COOL! Lessenserie centraal. De BE COOL! Lessenserie, gebaseerd op de jigsaw methode, was ontwikkeld om sociale interacties tussen kinderen met verschillende competentieniveaus te faciliteren, zonder dit ten koste te laten gaan van de cognitieve leerprestaties van deze kinderen. In de studie is onderzocht in hoeverre werken in de context van de competentieniveau-integrerende jigsaw methode zou leiden tot hogere, of tenminste gelijke, cognitieve leeruitkomsten wanneer een vergelijking werd gemaakt met meer traditioneel, individueel leren.

De studie kende een experimenteel voortoets-middentoets-natoets-retentietoets onderzoeksdesign. Een vergelijking werd gemaakt tussen de competentieniveauintegrerende jigsaw methode en een meer traditionele, individuele manier van leren. In totaal namen 1023 kinderen deel aan de studie (gemiddelde leeftijd 10,49 jaar). In het onderzoek werd de domeinkennis van kinderen over het eigen onderwerp en over de onderwerpen van anderen, de kennis van kinderen over de onderzoekend leren-cyclus, en de attitudes van kinderen ten opzichte van technologie en wetenschap gemeten.

De resultaten lieten zien dat kinderen die werken in de context van de BE COOL! lessenserie gelijke cognitieve prestaties behaalden als kinderen die dezelfde leerstof op een individuele, meer traditionele wijze bestudeerden. Tevens waren geen verschillen tussen condities zichtbaar wat betreft de attitudes van kinderen ten opzichte van technologie en wetenschap. Toekomstig onderzoek zou moeten uitwijzen aan welke voorwaarden moet worden voldaan zodat de competentieniveau-integrerende jigsaw methode leidt tot betere cognitieve leeruitkomsten dan traditioneel, individueel leren. 


\section{Conclusie}

Op basis van de resultaten van het in dit proefschrift beschreven onderzoek kunnen we concluderen dat de BE COOL! lessenserie, die sociale interactie tussen kinderen van verschillende competentieniveaus faciliteert, heeft geleid tot even goede cognitieve leeruitkomsten als meer traditioneel, individueel leren. Deze resultaten kunnen als veelbelovend worden beschouwd, aangezien de cognitieve leeruitkomsten niet onderdeden voor individueel leren en deze manier van leren op sociaal gebied juist veel voordelen kent ten opzichte van individuele leermethoden. 
